\title{
A review on deformation-induced electromagnetic radiation detection: history and current status of the technique
}

\author{
Sumeet Kumar Sharma ${ }^{1}$ (D), Vishal S. Chauhan ${ }^{1}$, and Michael Sinapius ${ }^{2, *}$ (1) \\ ${ }^{1}$ School of Engineering, Indian Institute of Technology, Mandi 175075, India \\ ${ }^{2}$ Institute of Adaptronics and Functional Integration, Technische Universität Braunschweig, Langer Kamp 6, 38106 Braunschweig, \\ Germany
}

Received: 29 May 2020

Accepted: 3 November 2020

Published online:

19 November 2020

(C) The Author(s) 2020

\begin{abstract}
Development of the deformation monitoring techniques for the infrastructures so as to avoid catastrophic failure and resulting economic/human loss has remained a key interest of scientists and engineers. Among various deformation monitoring techniques utilized and explored by groups of researchers, electromagnetic radiation detection is one of the intriguing techniques which has remained popular in researchers' community till today. Almost every type of material is being explored and studied by researchers for the electromagnetic emissions when subjected to external loading and/or failure. Experimental and theoretical investigations are demonstrating these emissions to be a suitable candidate for the deformation monitoring, as a failure predictor and to know about the complex phenomenon of fracture. This article presents extensive literature review and a rigorous discussion on the work done in the past several decades regarding the exploration of electromagnetic emissions from a wide variety of materials and the underlying physical mechanisms. Thus, this review is an attempt to highlight main findings, proposed physical mechanisms, prospective applications, future scope and challenges of the electromagnetic emission detection technique.
\end{abstract}

\section{Introduction}

Material-oriented advancement in science and technology plays an important role as a driving force for innovation in various aspects of the civilization.
Materials in today's era are not only expected to possess high reliability, but should also incorporate additional functions such as damage restrains, selfdiagnosis, self-repair and notification of residual life. There have been advances in instrumentation to detect effects associated with microcrack formation,

Handling Editor: P. Nash.

Address correspondence to E-mail: m.sinapius@tu-braunschweig.de 
their propagation and fracture. The irreversible process of plastic deformation in a long period of time forces the material to fail at lower stress levels. Generally, materials contain different types of defects that may be inherent or may be introduced during manufacturing processes. These inclusions, impurities and defects lead to formation of cracks and their propagation when there is increase in stress. Hence it is presumed that an engineering component can fail sometimes suddenly without any prior warning as a consequence of these pre-existent defects which can be tedious to detect sometimes. Thus the possible preventive measure is to determine location, size and severity of the deformation. Plastic deformation and crack propagation are almost interrelated through molecular dynamics and also depend upon physical, mechanical and metallurgical properties of the materials [1]. It is well known that subjecting a material to high magnitude of stresses leading to crack formation and propagation leads to different types of emissions including thermal, acoustic, fractoemissions [2-5]. Some of these emissions have been reported as a possible tool regarding the inspection and monitoring of various aspects of materials [6-8].

Structural health monitoring (SHM) being a sensitive issue as described in the report published in nature photonics 2008 [9] is a deformation monitoring technique which can help to identify, locate the deformation regime in order to prevent the infrastructure from further failure and in some cases can be used to predict the remaining life of the structure. There are several tools used for the SHM, viz. tap test, guided wave test, acoustic emissions monitoring, electrical signals monitoring [10-12]. Among these, deformation-induced electromagnetic emission (EME) detection has evolved as an intriguing research area from the last one century [13]. Here the term electromagnetic emission (EME) is used to represent different effects such as electromagnetic radiation (EMR) emitted during and after local mechanical processes, such as crack propagation, fracture, plastic deformation or friction as well as the emission of charged particles such as electrons, ions, neutral species and photons (which is commonly known as fractoemissions) [14]. EME and EMR are used interchangeably in the present work with respect to the best suitability of use while both reflecting the same phenomenon. Although a wide variety of materials have been extensively studied for their electromagnetic responses, still there lacks a proper understanding of these emissions both from experimental and theoretical point of view which restricts this technique from being used on a large scale with respect to deformation monitoring perspective. For using this technique to serve humanity on a large scale a broad knowledge base for these electromagnetic emissions is necessary and needs further exploration. Electrical signals (change in ionic conductivity) were first observed from ionic crystals in late 1920s by Joffee et al. [15] and were further explored by numerous researchers [16-22]. Later electrical emissions from materials were further studied to use this phenomenon in crack propagation monitoring [23, 24], earthquake prognosis [25, 26], snow avalanche prediction [27, 28], stress-state monitoring of coal mines [29], predicting rock burst [30, 31] and last but not the least for developing an efficient structural health monitoring technique [32]. Monitoring systems are very important nowadays owing to complex machineries and big infrastructures. A good monitoring system will help to determine the damage in a particular component in terms of its location and severity. These techniques are very helpful in preventing the failure from turning out to be a fatal one and will also help in saving the time of the people working with the system.

As per the author's knowledge no review has been published till date describing the state of the art and the significance of the electromagnetic emissions (EMEs) from different classes of materials and their possible and futuristic applications in failure prediction as well as in monitoring. Thus the present paper is an attempt to showcase the detailed review of work done in the last ten decades in this field to better understand the mechanisms of EMEs obtained from various materials under different stimulus and their proposed applications. Various materials investigated, experimental methods used, results obtained along with their proposed genesis will be discussed in detail in the consequent sections.

\section{Brief overview of electromagnetic emission (EME) detection}

Before moving on towards the discussion on EME observed from different materials firstly it is important to have a general overview of electromagnetic radiation (EMR) which are an integral part of this 
emission detection phenomenon which will be talked about in whole of the paper. Electromagnetic radiations are transverse waves which have electrical and magnetic field components propagating perpendicular to each other as well as perpendicular to the propagation direction. A variety of materials are being investigated for the accompanying electromagnetic emissions as shown with the help of a schematic diagram in Fig. 1. Fracture phenomenon occurs due to the crack propagation which in turn electrifies the generated cracked surfaces because of the electrical charges released from the breakage of atomic bonds. The spatial movement of these electrical charges leads to the electromagnetic radiation which are detectable by using particular types of sensors. In most of the studies electrical part of these emissions is being measured and analysed (termed as electromagnetic radiation signal or electromagnetic emission) which will be discussed throughout the paper. Generally capacitive sensors/antennas are used to measure electric part of the electromagnetic field and can provide good response over a wide range of frequencies. However, some other antennas like wire antenna, coil antenna and dipole antenna have also been used by the investigators.
Electromagnetic radiations in the direction of propagation involve different regions known as near-field, transition zone and far-field region depicted in Fig. 2. For detecting deformation-induced EME signals the antenna is generally placed in the near-field region. As mentioned earlier in case of plastic deformation EME signal generation is due to the electrical charges developed on the newly generated crack surfaces due to the crack propagation. However, the EMR signals have also been detected in the elastic deformation regime of the materials. Thus, it is inferred that there is still no established unified theory, capable of explaining the mechanical and electrical dynamics of the charge movement resulting into the electromagnetic emissions. All related parameters of the EME emission and its scope will be discussed in the following sections which firstly covers the EME observed in different classes of materials along with their experimental techniques involved, then the proposed mechanisms of these observed emissions and insights into future perspective.
Figure 1 Overview of electromagnetic radiation (EMR) emission detection technique.

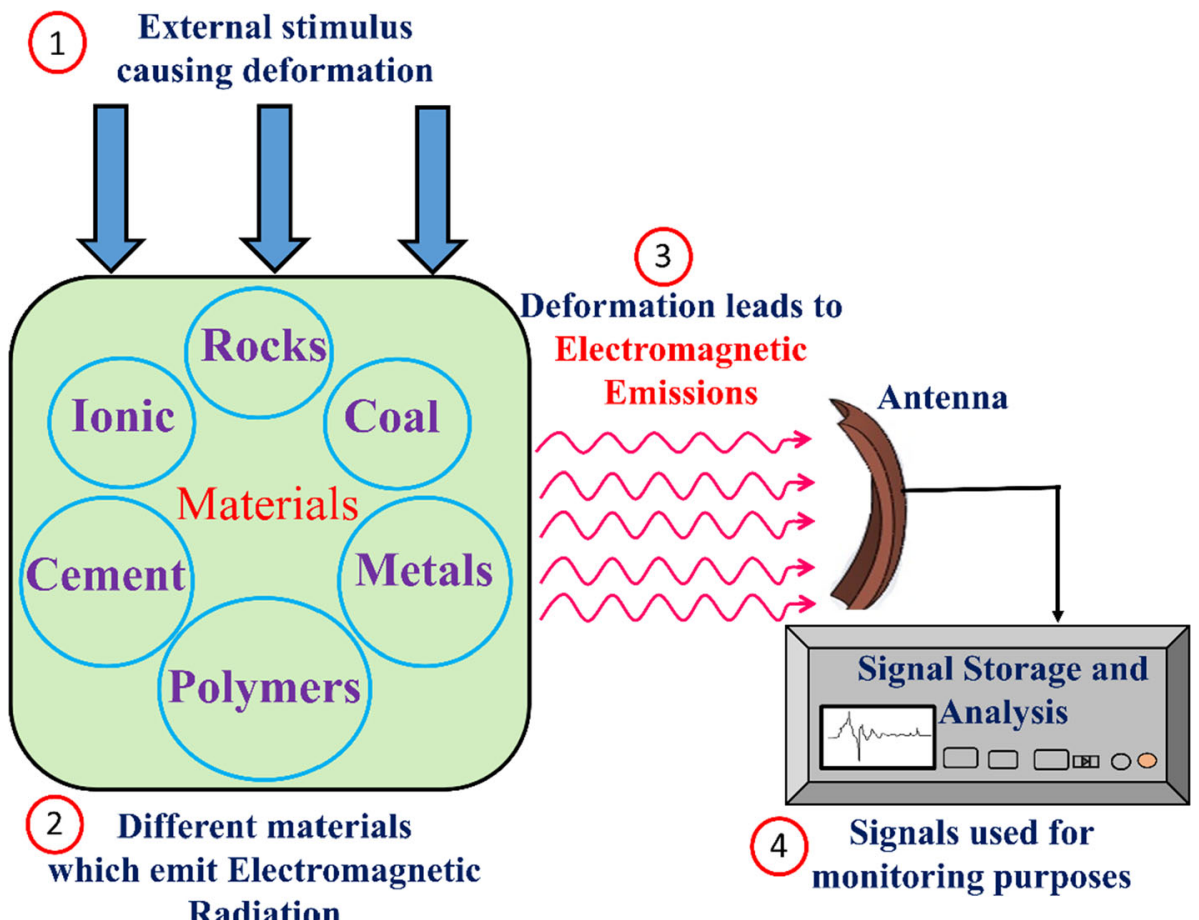




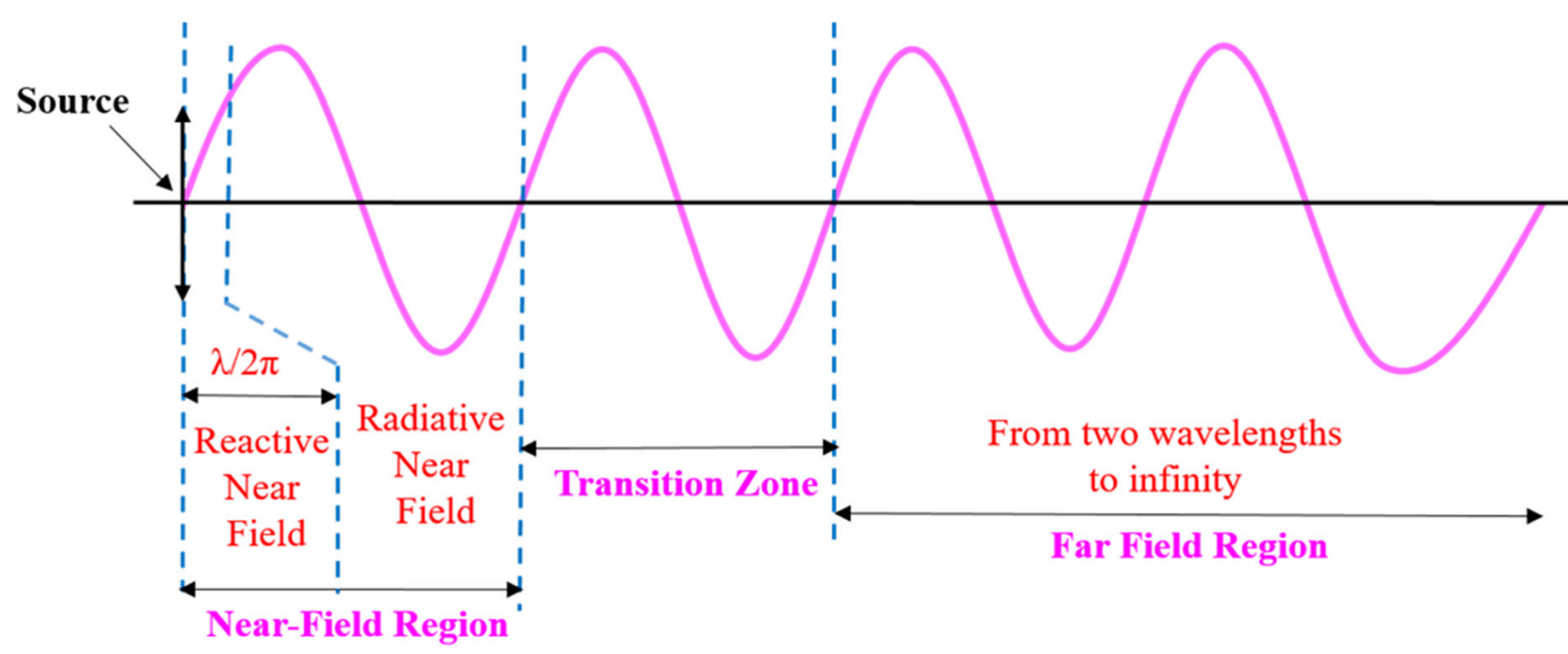

Figure 2 Electromagnetic radiation (EMR) regions.

\section{Electromagnetic effects observed in different classes of materials}

\section{Electrical and electromagnetic effects in ionic crystals/materials}

\section{Alkali halide crystals}

In the early twentieth century studying the electrical phenomenon linked with the plastic deformation of ionic crystals lacking the piezoelectric effect had gained sudden impulse when $\mathrm{NaCl}$ was reported for the increase in ionic conductivity with increase in plastic deformation [33]. Later in 1928 this phenomenon of increase in ionic conductivity with plastic deformation has been named as Gyulai and Hartly effect after its discoverers [17]. During experiments $\mathrm{NaCl}$ was subjected to compression and change in the ionic conductivity has been recorded with the electrodes placed on the opposite vertical sides of the $\mathrm{NaCl}$ [17]. Stepanow in 1930s used this effect (change in ionic conductivity) to know about the mechanism of plastic deformation in the ionic crystals [16]. Later this phenomenon was also investigated by researchers viz. Quittner et al. and Johnston et al. [18, 19, 18-19]. Various ionic crystals such as $\mathrm{AgBr}, \mathrm{KCl}, \mathrm{KI}, \mathrm{KBr}$ have been explored extensively for the change in ionic conductivity associated with the plastic deformation [20, 36].

An interesting phenomenon (other than the piezoelectric effect) which shows the charges developed on the surface of the $\mathrm{NaCl}$ crystal in the absence of any external electric field was observed by
Stepanow in 1933. Following this Stepanow investigated various factors (for the temperature range from 30 to $170{ }^{\circ} \mathrm{C}$ ) which can affect the charge developed on the surface of the $\mathrm{NaCl}$ crystal [16]. He stated that friction in the internal layers of the crystals, presence of impurities and formation of microcracks contribute to the surface charge development which is also dependent on the dimension of the $\mathrm{NaCl}$ crystal. Later Fischbach and Nowick in 1955 and 1958 performed the experimental study for relating the appearance of the electrical charge through the motion of the dislocations [37, 38] and was also explored by Caffyn and Goodfellow [20]. Further exploration of the dislocation effect leading to the surface charge was done by subjecting the crystal to external electrical field with the assumption that the charge on dislocations should also have interaction with the external electric field, and this could be a useful method to calculate the electrical charge density appearing on the dislocations [39-42]. Rigorous studies have been presented by numerous researchers by including the following mentioned parameters in the study:

(i) Response of different types of deformations on the surface charge collection [21, 38, 42-45].

(ii) Role of impurities on the charge collection due to deformation [22, 46, 47].

(iii) Temperature effect on the charged dislocations [20,48].

(iv) Influence of external electric field on the appearance of charges on the dislocations [49]. 
(v) Method for determining the charge density of a crystal during deformation.

The well-known Stepanow effect in case of ionic crystals concludes that (i) charges developed on ionic crystals vanish under constant load and after load removal, (ii) the charges developed correspond only to the edge dislocations bearing the charge, (iii) dislocations acquire charge by the elimination of vacancies in the crystal, (iv) electrical charge type and size vary with the temperature, (v) a particular sign of electrical charge shows the dominance of dislocations having that particular charge [50]. The generation of these time-varying surface charges during different types of mechanical loadings has motivated researchers to look for electromagnetic radiation emission from the ionic crystals.

Potirakis and Mastrogiannis also detected the electromagnetic emissions (EMEs) and acoustic emissions (AE) from $\mathrm{LiF}$ crystals under uniaxial compression for examining the critical behaviour of the fracture process. Hand-operated loading machine and faraday cage were used to avoid any interference from external electromagnetic noise [51]. The schematic diagram of the experimental setup is shown in Fig. 3. Dislocations in ionic crystals have been studied experimentally and theoretically by Eshellby et al. [52]. R.W Whitworth in 1974 has extensively reviewed charged dislocations in case of alkali halide by taking into account the effects of mechanical properties and internal friction and has also discussed the electrical effects associated with the movement of charged dislocations [53]. Poletaev and Shmurak in 1984 reported emission of electrons caused by the motion of dislocations in $\mathrm{KCl}, \mathrm{NaCl}$ and $\mathrm{KBr}$ and LiF crystals [54]. Thus, these electromagnetic emissions have been examined to study in detail the cracking and fracture phenomenon in case of ionic materials which otherwise is intricate.

Ice

Isothermal growth of ice from vapour phase has been observed by Lars et al. in 1978, and the resulting condensation potentials as well as electrical currents have been measured [55]. Through field experiments researchers noticed that during failure large masses
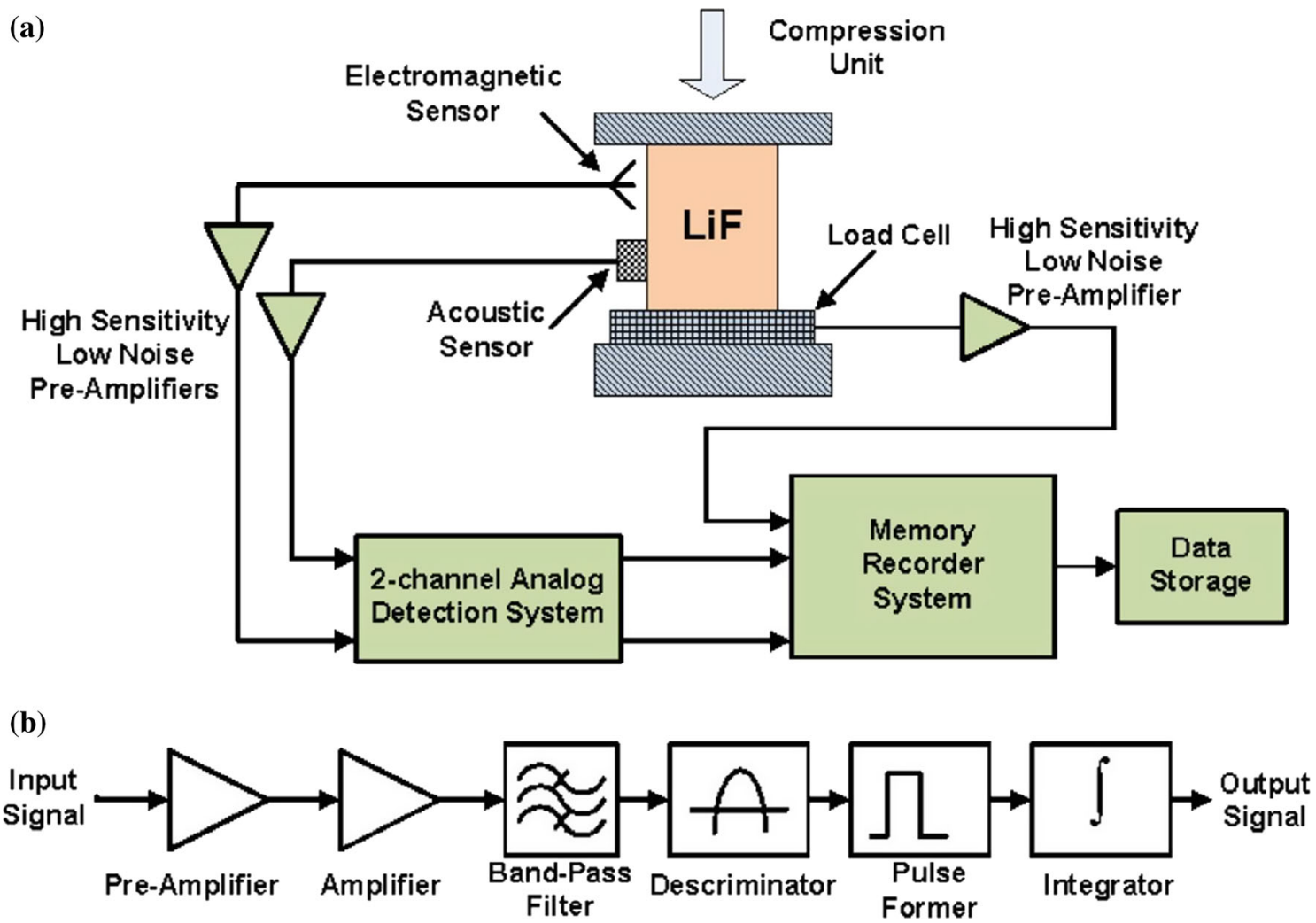

Figure 3 a Schematic diagram of experimental setup and (b) block diagram of analogue detection system (used with permission from Elsevier) [51]. 
of snow and ice also emit electromagnetic radiation. During this period this phenomenon has also been observed in snow avalanches, mountain glaciers and sea ice sheets by a number of researchers [27, 56-58]. Following the discovery of above-mentioned aspects as well as the known phenomenon of edge dislocations in the ionic crystals Petrenko and Whitworth in 1983 jointly explored the electrical currents associated with the motion of the dislocations contained in the ice [59]. Fifolt et al. in 1992 tested ice samples (freshwater ice, polycrystalline ice having small grain size and deionized polycrystalline ice with large grain size) in compression and electromagnetic emissions were detected. Ice was first cut into rectangular samples and then was compressed uniaxially using servo hydraulic MTS system placed in a cold room. Petrenko placed two aluminium electrodes near the two opposite faces of rectangular ice plates. Electromagnetic radiations have been detected using the principle of simple flat-plate capacitor (explained in "Rocks, granite, coal and other brittle materials" section), with ice placed in between the electrodes acting as a dielectric medium. During crack propagation motion of charged dislocations as well as that of charged point defects has been described as the possible source of observed emissions [60]. However, Petrenko and Colbeck in 1995 performed laboratory and field experiments where ice was subjected to friction and the resulting electrical signals were measured. Field experiments were performed using ice skates. From experiments they observed that the appearance of electrical charges on the ice surface is due to the ordering of the dipole moments of water present in the upper monolayer. It was also observed that the amplitude of current was proportional to the sliding velocity. Although the ordering of the electric dipoles of water was first described by the Weyl [61] which was also used by Fletcher [62] for describing the surface structure of ice [28], plastic deformation observed during friction is not comparable to that obtained under uniaxial compression and dislocation movement is generally appreciated during plastic deformation; thus, the ordering of the electric dipoles considered by Petrenko and Colbeck and the dislocation motion by Petrenko hold reasonably true as per their observations. Keefe and Thiel in 1996 have prepared ice samples using water and sodium chloride with varying concentration and detected radiations during fracture of ice samples. As per their observation EME signals were found to be conductivity dependent, and they have proposed that charge generation during crack propagation can be the possible cause of these emissions [63]. Ninos and Tombras in 2004 detected acoustic and electromagnetic emission during the uniaxial compression and before the catastrophic failure of dielectric crystalline materials and have proposed that the generated electrical signals are due to the newly created microcracked surfaces [64]. Thus, investigation of ice for its accompanied electromagnetic signals detection to know about the dislocation movement and internal processes occurring during crack propagation has been done. EMEs from ice have not been very actively investigated and were studied only by a limited group of researchers; thus, they can be explored further for their its futuristic application in avalanche prediction and to know about the dynamics of fracture in ice.

\section{Ceramics}

Ceramics are also a popular class of materials having comprising of a huge potential. Ceramics are oxides of non-metallic materials generally formed with ionic and covalent bonds and have found a large number of applications in a variety of fields in the present era. Ferroelectrics/piezoelectrics is a popular class of ceramics, and numerous reports are available which explore the properties of these materials when subjected to external electrical and/or mechanical loadings [65-68]. Piezoelectric materials have been explored in terms of their well-known direct and indirect effects for their usage in smart structures involving sensing and actuation [69-72]. Crack propagation and electrical/mechanical fatigue effects have been extensively studied by various authors with the increase in the use of piezoelectrics in actuation and sensing units [73-75]. Other than these observations the phenomenon of electromagnetic emissions has been explored by researchers, and a few reports are also published. Dickinson and Jensen in 1985 fractured PZT samples in vacuum when subjected to three-point bending with a tip advancement of $0.1 \mathrm{~mm} / \mathrm{s}$. During fracture fractoemissions (emission of electron, ions and photons) were observed which is due to the microdischarge from the charge separation occurring due to the crack propagation. It was observed that the samples were fractured into two pieces along a direction parallel to the horizontal supports. The fractoemissions were 
observed to be strongly dependent on the direction and magnitude of polarization which is further dependent on the direction of fracture. The most intense emissions were observed when the fracture surfaces and the direction of polarization were perpendicular to each other [76].

Asmontas et al. detected electromagnetic pulses (50 Hz-850 MHz) using indoor television antenna on cylindrical $\mathrm{Pb}\left(\mathrm{Zr}_{0.52} \mathrm{Ti}_{0.48}\right) \mathrm{O}_{3}$ polycrystalline samples stressed under uniaxial compression. Polarization and repolarization processes have been discussed as the sources for the electrical pulses obtained. They have proposed that electrical parameters and quality of ferroelectric crystals can be investigated with the help of these emissions and these can also be used as sensors where mechanical energy is transformed into the electromagnetic one [77, 78], whereas Langford et al. investigated the photon and electron emissions from $\mathrm{MgO}$ crystal in three-point bending test. It was proposed that the resulting emissions can be used to know the complex processes occurring during fracture at atomic scale. Movement of dislocations and consequent generation and excitation of point defects has been discussed as the reason behind these emissions [79]. Yoo et al. have also detected electrical emissions accompanying the fracture of $\mathrm{MgF}_{2}$ single crystals loaded in three-point bending. In their experiments the specimen $\left(\mathrm{MgF}_{2}\right.$ crystal) orientation has been changed relative to the direction of loading. Different crystal orientations produce the fracture surfaces in different directions and have different yields of electrical emissions which is due to the varying densities of defects produced during fracture [80]. Electromagnetic radiation combined along with the fractographic methods has been used by Bahat et al. to know about the crack nucleation and propagation in glass-ceramics [81]. During the detection of fractoemissions in soda-lime-silica glass no electron, ion, or photon signals were detected until crack velocities reached approximately $10^{-2} \mathrm{~m} / \mathrm{s}$, although the more intense fractoemissions observed during fast fracture are due to dissipation of the excess energy associated with unstable crack growth and were more significant in glass [82].

Enomoto and Chaudhari in 1993 performed an experimental study on the fractoemissions by fracturing engineering ceramics, such as $\mathrm{Al}_{2} \mathrm{O}_{3}, \mathrm{ZrO}_{2}$, $\mathrm{Al}_{2} \mathrm{O}_{3} / \mathrm{ZrO}_{2}$ and $\mathrm{Si}_{3} \mathrm{~N}_{4}$ using the indenter mounted on Charpy impact machine. The total charge collected varied in the range of $10^{-11}$ to $10^{-9} \mathrm{C}$, which was found to be dependent on the load, mode of fracture and the environment in which test is being performed. It was observed that during facture the specimens' surface reached a potential of a few hundred volts [83].

Recently there have been reportings on EMR emission from piezoelectric ceramics during elastic deformation when subjected to electrical and mechanical loadings. Sharma et al. have investigated EMR emission from ferroelectric materials and proposed its application for non-contact sensing applications. Sharma et al. have tested a set of lead-free ferroelectric compositions in the vicinity of the morphotropic phase boundary (MPB) when subjected to ac field [32]. Electrical part of the EMR signal has been recorded by placing a circular loop antenna made up of copper around the samples as shown in Fig. 4. Signals were recorded using Rohde \& Schwarz (Hameg) HMO 2524, $250 \mathrm{MHz} / 2.5 \mathrm{GSa} / 4 \mathrm{MB}$ Digital Storage Oscilloscope (DSO). Generated surface charges on the cylindrical loop antenna due to the EMR emission have been converted into measureable electric potential. Figure 5 shows continuous EMR signal obtained for all compositions with varying amplitude. According to the experimental results polarization in the sample is found to increase proportionally with the observed EMR signal at the respective applied electric field which suggests its use for monitoring the polarization state of the ceramics [32]. Same group has reported EMR emissions from widely used piezoelectric materials, viz. PZT SP-5A and PZT SP-4, when subjected to impact loading causing deformation with in elastic limit. The schematic of experimental setup used for impact loading is shown in Fig. 6. EMR has been observed to increase as the height of impact increases [84]. For the electromagnetic radiation (EMR) detection from the soft PZT (SP-5A) at low temperatures, the same setup was placed inside the environmental chamber and the weight was dropped from the varying height (Fig. 6). The lowest temperature attained in the experiments was $203 \mathrm{~K}$. EMR signal is found to decrease with the decrease in temperature, whereas the Young's modulus shows an increasing pattern [85]. Signal shape obtained from PZT in case of impact loading is shown in Fig. 7. Ferroelectric ceramics can be used to make low-cost impact loading sensors. Literature reveals that electromagnetic emission detection from piezoelectric materials has scarcity in the literature and has good scope to be 


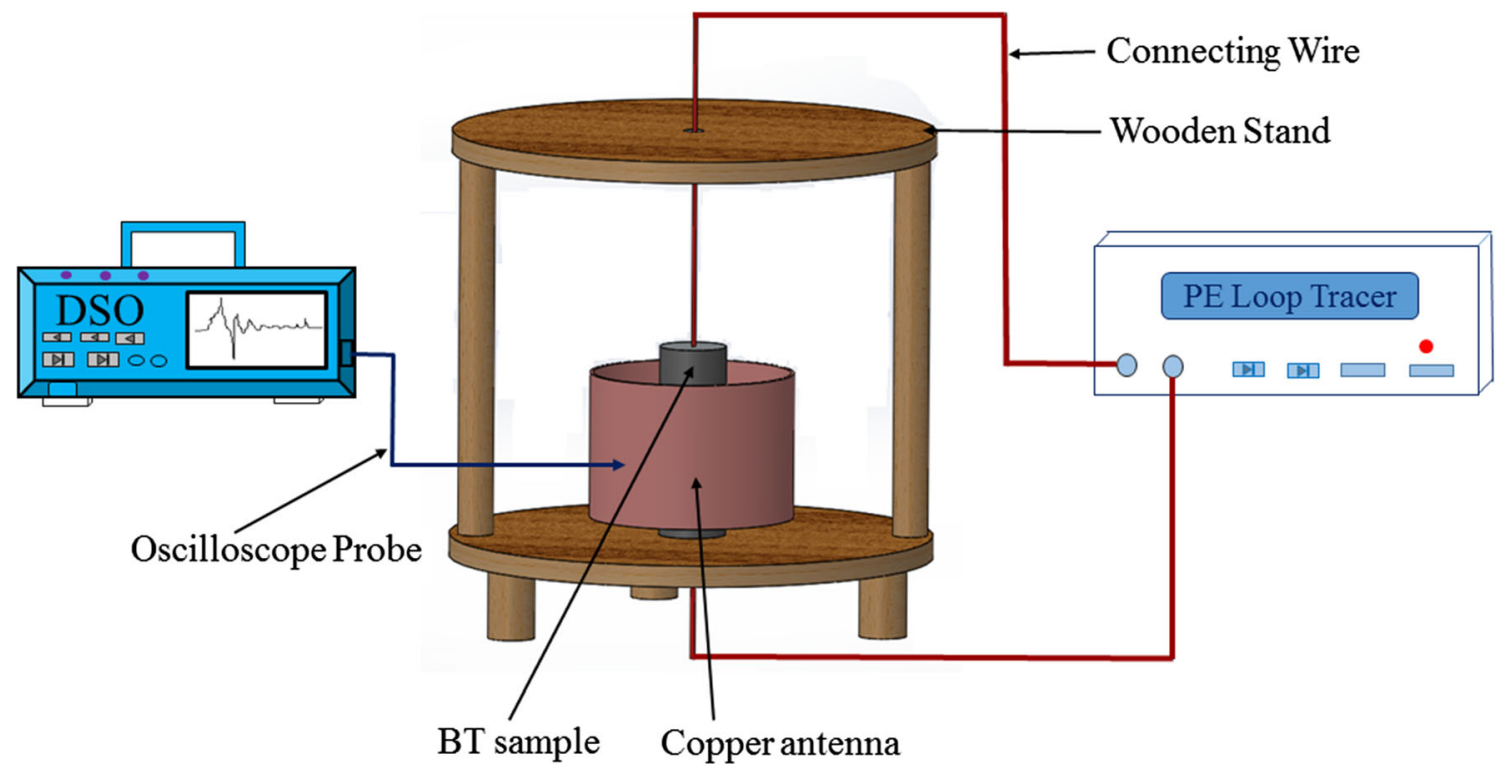

Figure 4 Schematic diagram of experimental setup used for EMR detection from ferroelectrics when subjected to alternating electric field (used with permission from Elsevier) [289].

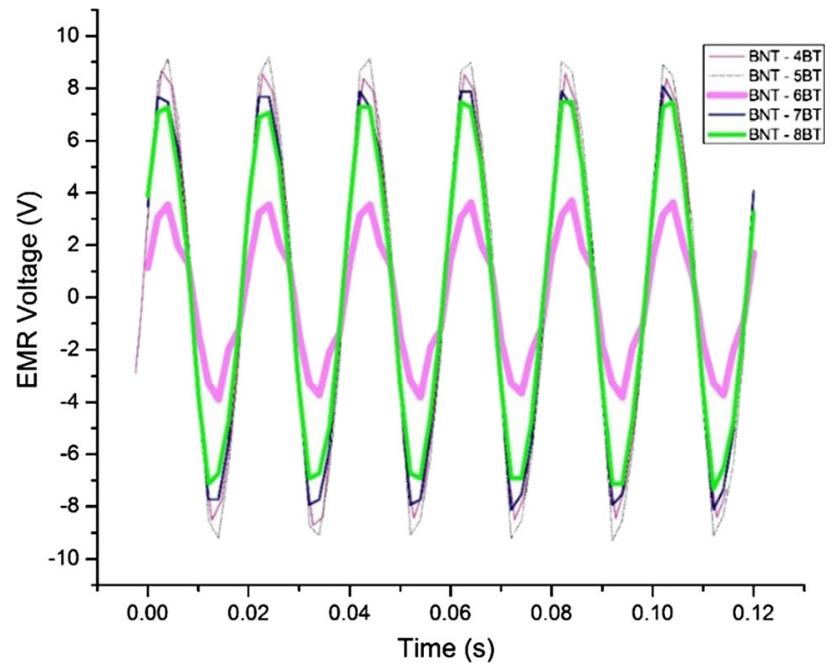

Figure 5 Typical sample plot of EMR signal obtained from ferroelectrics when subjected to alternating electric field (used with permission from Elsevier) [32].

looked upon. Figure 8 shows an overview from the author's perspective that how ferroelectric ceramics can be used for non-contact sensing. Though less number of reports are available in the literature, thorough experimental and theoretical analysis of electromagnetic signal emission from piezoelectric materials and wireless detection of these electromagnetic signals can transform the way current sensing techniques work [32].

\section{Electrical and electromagnetic effects in rocks, coal and other brittle materials \\ Rocks and brittle materials}

Electrification and charging of rocks in the earth's crust are of great importance. The main electrification processes involved in the geological strata are: electrical phenomena due to passage of ions through an energy barrier, contact phenomena, voltaic electrification, electrification of dielectric liquids or brittle fracture of dielectrics, electrification by friction, etc. In 1977 Nitsan has reported electromagnetic emissions (EMEs) during fracture of rocks. Nitsan reported EM emissions in radiofrequency range by using quartz bearing rocks and other hard piezoelectric materials [86]. Egorov et al. in 1978 reported the space-charge formation in rocks under mechanical loads [87]. However, during the same era observation of anomalous electromagnetic waves observed one to several hours before seismic activities motivated the scientists/researchers to look for the possibility of these radiations as possible precursors to earthquakes. Earthquake is a natural disaster which marks several causalities due to the severe infrastructures failure.

Earthquake is a natural disaster causing devastation due to the severe infrastructural damage. Earthquake prediction is very complex phenomenon which requires series of efforts in this direction. To 


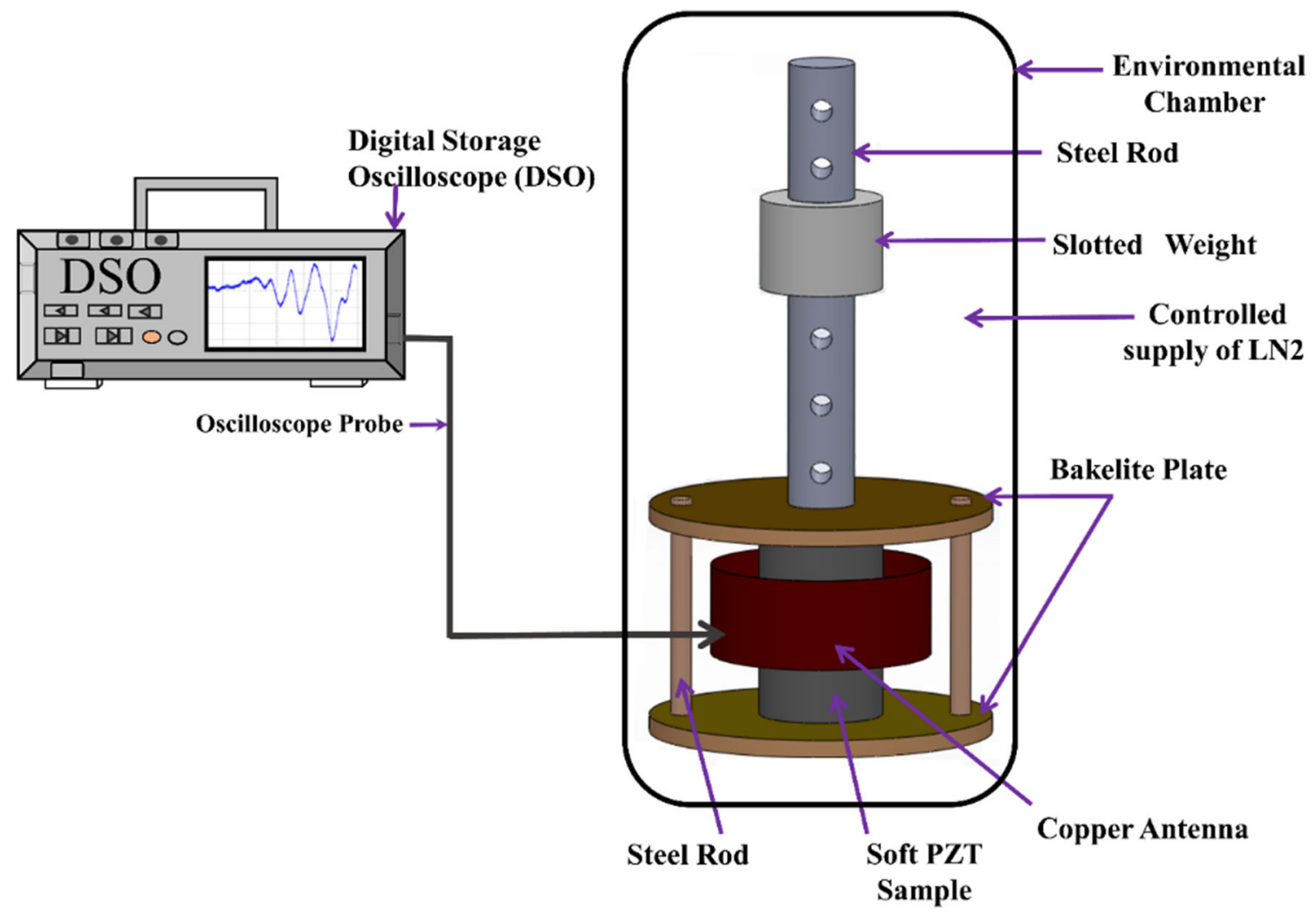

Figure 6 Schematic diagram of experimental setup used for EMR detection from ferroelectrics when subjected to impact loading (used with permission from Springer) [85].

Figure 7 EMR signals obtained from soft PZT during face reversal when subjected to impact loading (used with permission from Springer) [85].

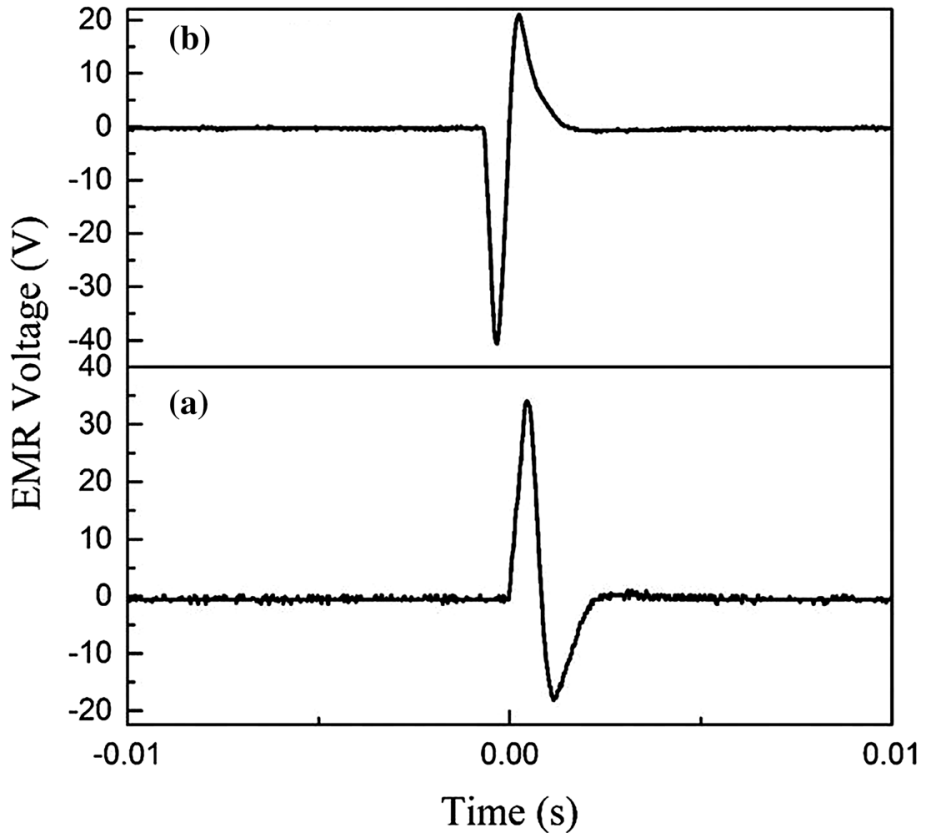

develop a sound tool for the early prediction of the earthquake several studies around the globe are being carried out. Out of the various tools available electromagnetic emissions have turned out to be promising because of its positive results obtained during the laboratory investigations due to which 


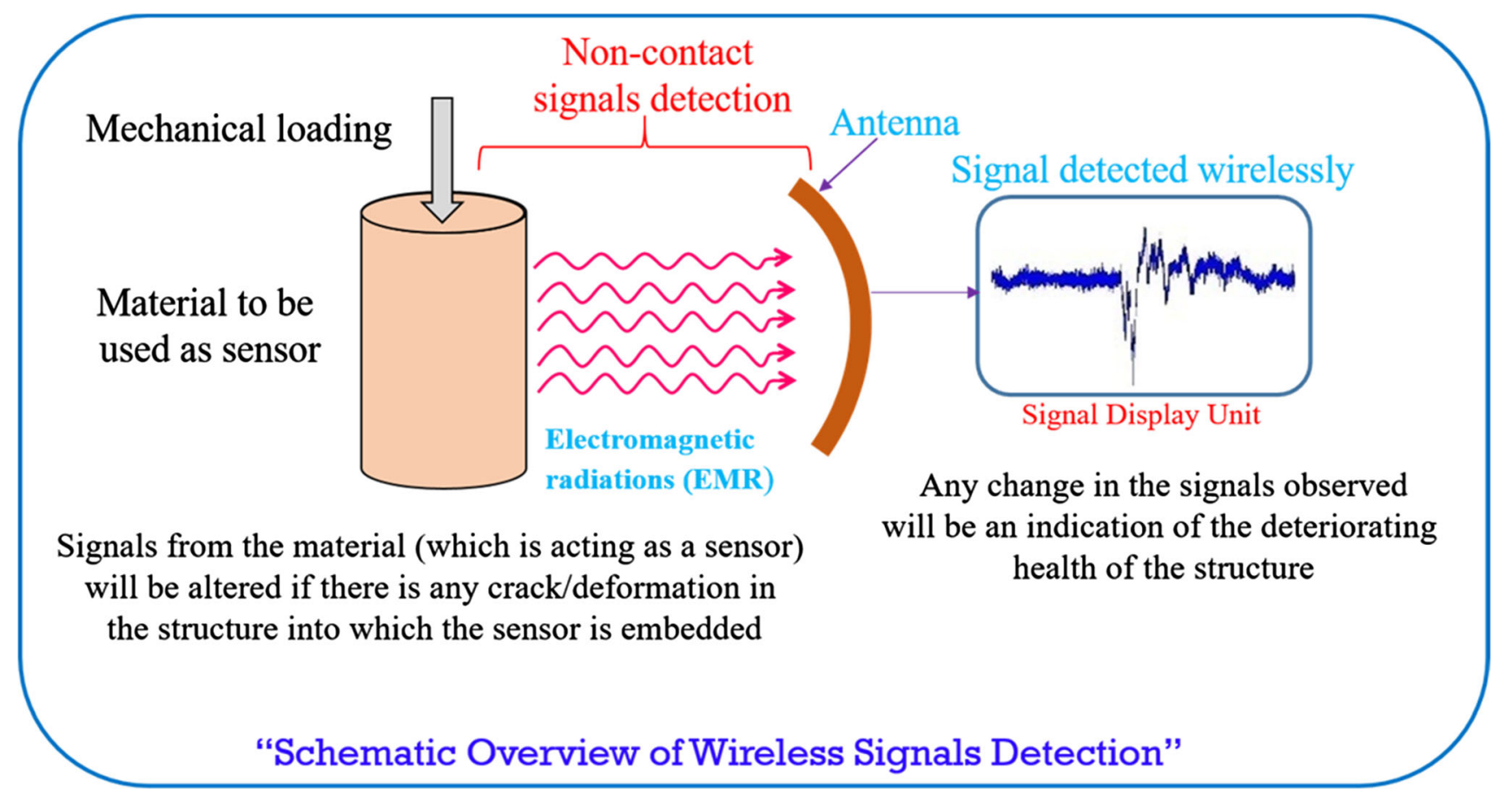

Figure 8 Proposed technique of wireless signals detection for deformation monitoring.

researchers are still working enthusiastically on using EMR detection technique for earthquake prediction and have not fully concluded in terms of its field applications. Gokhberg et al. observed anomalous electromagnetic waves/noises having frequency in $\mathrm{KHz}$ range before earthquake in Iran and Japan, respectively. In Iran the magnitude of the earthquake was 7.4, while in case of Japan it varied from 5.0, 5.3 and $7[25,88]$. Similar phenomenon has also been reported by Warick et al. where radio emissions of $18 \mathrm{MHz}$ had been detected through astronomical receivers and after six days of this event Chilean earthquake (May 22, 1960) had taken place [89]. Thus, electromagnetic emission detection from seismic activities is a fascinating phenomenon and researchers are working on it to develop a sophisticated technique for the early prediction of the seismic events. Johnston has published a comprehensive discussion involving review of electrical and magnetic effects accompanied with the seismic events [90].

Ogawa et al. tested rock samples under shock loading and during fracture by conducting different set of experiments. They observed these electromagnetic emissions when the samples (i) were struck together or hit by hammer, (ii) struck by small brass sphere having diameter of $1.5 \mathrm{~cm}$ and (iii) were tested in bending. Strain signals and electrical signals were detected simultaneously using strain gauges and the ball antennas. Ball antennas were used to detect electromagnetic emissions. Electromagnetic signals in the frequency range of $10 \mathrm{~Hz}$ to $100 \mathrm{kHz}$ were detected during the experiments [91, 92]. Cress et al. have also performed laboratory experiments on fracture of rocks, and electrical signals in the range from $900 \mathrm{~Hz}$ to $5 \mathrm{kHz}$ were detected. They have tested quartz-bearing rocks as well as quartz-free basalt rocks for EME phenomenon. Observation of equally intense high- and low-frequency electrical signals from quartz-free and quartz-bearing rocks showed that the piezoelectric effect of quartz is not the major contributor to the observed electrical signals [93]. It can be inferred from the literature that electromagnetic emission detection from rock and coal samples has remained a popular technique in terms of the laboratory as well as field experiments and is being studied by wide number of researchers which is discussed as follows.

In the late 1990s Rabinovitch et al. conducted a set of experiments to detect electromagnetic radiation during fracture of chalk, rocks, glass, ceramics and granite and have tried to correlate these experimental observations with the earthquake events. Previously published reports of observation of EMR signals from 
rocks and brittle materials during crack propagation, motivated Frid et al. to correlate the EMR signals with the crack dimensions for understanding the atomic scale phenomenon [94]. Bahat et al. have also reported electromagnetic radiation from friction process as well as from carbonate rocks under compression, drilling and blasting [95, 96]. The same group has also proposed an electromagnetic radiation (EMR) method based on detection of electromagnetic emission during rock fracture to study water infusion in rock burst-prone coal strata [97]. They have investigated the EMR activity during borehole drilling. It was observed that when the hole face approaches the stress peak due to the stress concentration, then it results in a sharp increase in the EMR signal [97].

Mavromatou et al. have also performed experiments on rock samples as well as ionic crystals when subjected to uniaxial compression. Their experimental setup consisted of uniaxial compression system, a small broadband antenna for electrical signals detection, a mechanoelectric transducer for acoustic signals detection and a load cell. They have correlated the processes occurring at the microscopic scale inside the materials with the observed EMR emissions and have also concluded that there is no necessity of having the piezoelectric origin for these emissions and each microfracture in the material acts as an elementary emission source for these emissions [98].

Hadjicontis et al. have detected polarization currents and electromagnetic emissions from rocks and ionic materials during their deformation [99]. The group has performed experiments in which firstly polarization currents and then electromagnetic emissions were detected from rocks and ionic crystals. These experiments have proved to be useful in order to answer the intriguing scientific question of electrical signal emissions preceding earthquakes. Polarization currents can be attributed to the piezoelectric effect for the material having piezoelectric properties, otherwise to the movement of charged dislocations. The polarization currents can be detected at distances quite larger than the source dimensions provided there is the presence of electromagnetic coupling medium. This phenomenon can be developed further for applications to the large masses of rocks present deep inside the earth crust. Kasahara has suggested that during the earthquake preparation process polarization currents start initially which are further followed by electromagnetic emissions due to the process of microfracturing [100].

Mastrogiannis et al. have developed the correlation between the acoustic and electromagnetic emissions from polycrystalline natural rocks when tested under uniaxial compression. They suggested that microcracking is the main source of the plastic deformation in case of brittle rocks which develops acoustic waves in it, whereas the polarization current exhibited due to the piezoelectric properties of the sample acts as the source of electromagnetic radiations. They have also provided the mathematical description of this electroacoustical phenomenon. Figure 9 shows the typical signal shapes obtained during the experiments [101]. Dexing et al. (2018) have tested coal, rock and PMMA samples under compression, and
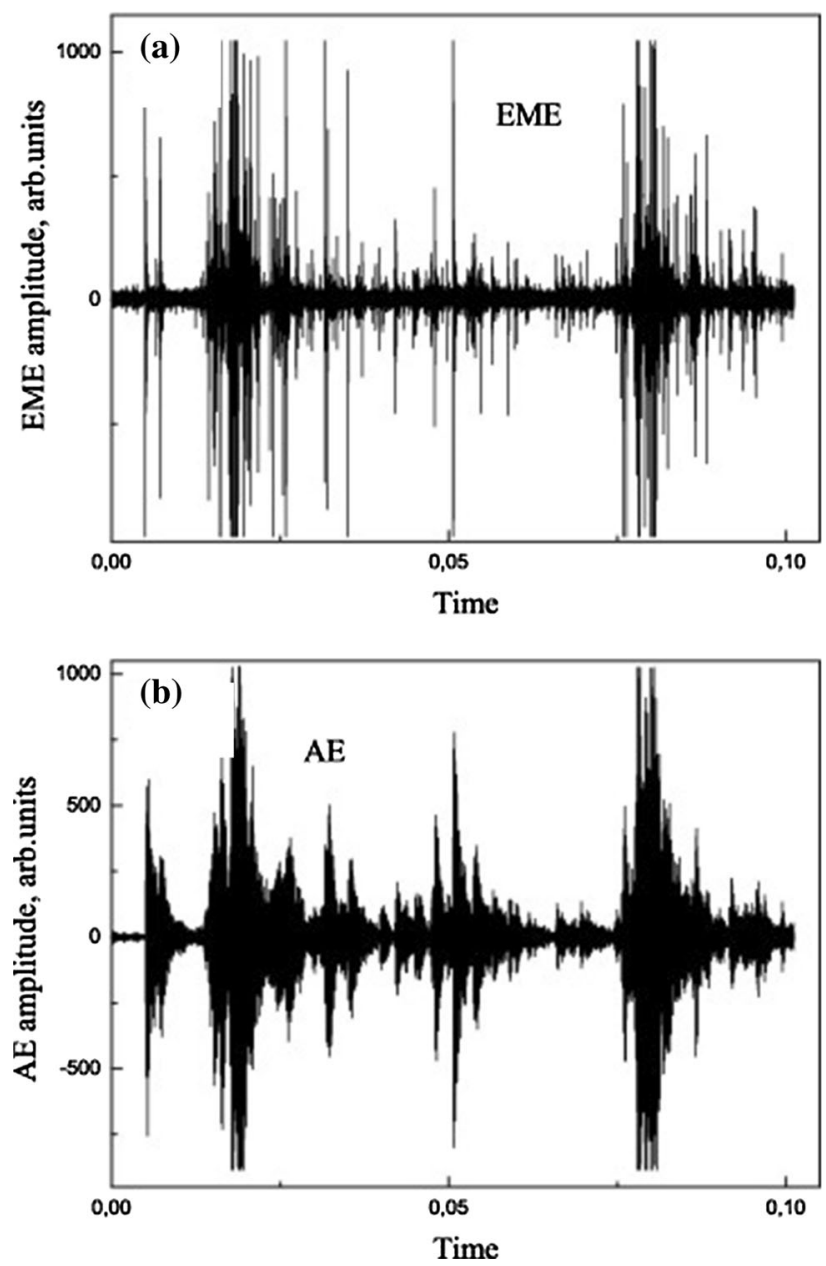

Figure 9 a Electromagnetic and (b) acoustic emissions obtained from a granite sample under compressive loading (used with permission from Elsevier) [101]. 
resulting acoustic and electromagnetic emissions were detected, and theoretical analysis was also considered. For the materials under study coal and rock samples exhibited piezoelectric effect up to some extent, while PMMA was non-piezoelectric material. The main conclusions showed that stress drop results in electromagnetic signals which are due to the charge separation and the surface charge density of the cracked surface [102]. Fukui et al. tested seven different rock samples under uniaxial compression and have found that the rock type and the testing conditions affect the EMR signals [103]. Nardi and Caputo (2009) detected EMR signals during explosions in a quarry, and during rock fracturing by a press in the laboratory, the schematic diagram of laboratory experimental setup for reference is shown in Fig. 10 [104]. Han et al. detected EMR during fracture of rocks and have established a relationship between the electric dipole moment, stress change at the crack tip and crack propagation characteristics [105]. Observation of EMR during fracturing (in laboratory experiments) has been proposed to be used for monitoring the stress conditions in rocks. Thermal stability of rocks is also important, and it can sometimes lead to the failure. Considering this Kong et al. have investigated the EMR signals from rock when subjected to continuous heat source. They have related the resulting EMR signals with the temperature [106]. Similarly, some other research groups have studied EMR detection from rocks having prefabricated cracks [107] and from rocks failing at different loading rates [108]. Liu and Wang have tested rock samples extracted from a copper mine. These samples have been tested under varied variation in loading conditions viz. uniaxial compression, tension and cyclic loading in order to relate it with the prediction of the rockburst in the copper mine [109]. Li et al. have analysed the effect of water content in the sandstone on the EMR emission during uniaxial compression. The EMR signals' analysis and their generation mechanism have been analysed in order to develop a damage evaluation method for waterbearing rocks [110].

Kong et al. have investigated the EMR emission by subjecting the sandstone to deformation after hightemperature treatment. During initial loading, increasing the temperature increases the EMR signal intensity as well as frequency but as the sandstone progresses towards the fracture the frequency and intensity of the signals have been found to fluctuate significantly [111], whereas Yavorovich et al. have investigated different rock samples (skarn, sandstone and magnetite ore samples) for the EMR emission when these are subjected to acoustic excitation. For the skarn and sandstone samples the EMR signal was found to show a decreasing pattern with increase in the strength of the samples, while no such correlation has been observed for the magnetite ore samples [112]. Trca et al. have used a newly developed prototype of EME data logger and have continually recorded the electromagnetic radiation emission in Obir caves (Austria) located at an active tectonic plate

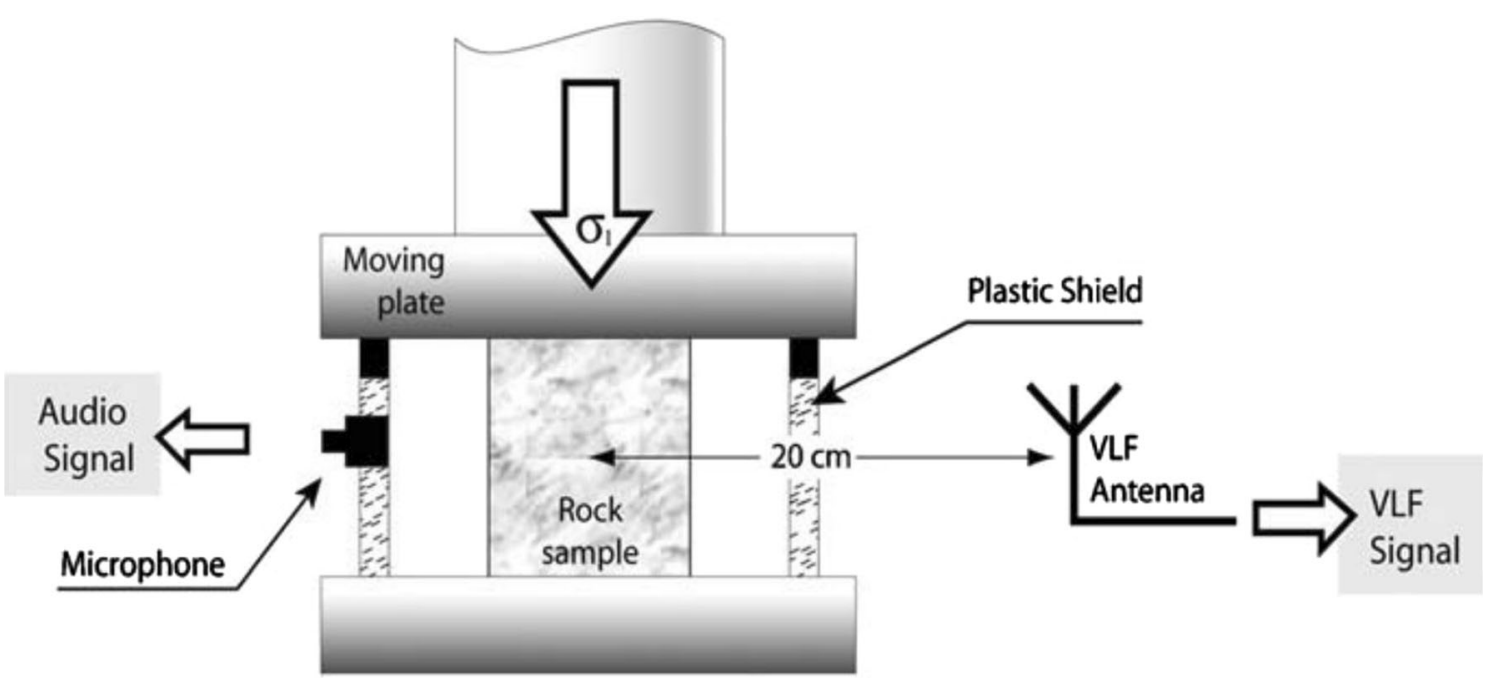

Figure 10 Schematic diagram of experimental diagram setup used for uniaxial compression of rocks (used with permission from Elsevier) [104]. 
[113]. Cantzos et al. have also performed the field measurement of seismic activity in the eastern Aegean sea [114], whereas Liu et al. have measured the changes in the microwave radiation in terms of microwave brightness temperature from loaded granite samples. Microwave radiations associated with the fracturing of these rocks have various dependent factors which need further exploration [115].

Rabinovitch et al. have stated that the fracture-induced electromagnetic radiation has better strength than those obtained in the seismic measurements due to the less attenuation property of the fracture-induced EMR [116]. Fujinawa and Noda have presented a study of 13 electric field monitoring stations in Japan near earthquake zone and have discussed the progress in the use of electromagnetism for the earthquake prediction and earlier warning [117]. Singh and Hobara studied the ultra-low-frequency (ULF) and very low-frequency (VLF) signals during a series of a major earthquakes in Japan (2010-2012) [118]. These signals have been found to enhance the accuracy of prediction of precursors for the earthquake. Apart from the earthquake forecasting the fracture-induced electromagnetic radiation emission has been studied by a group of researchers to develop a technique for the prediction of landslides by identifying the weak slip planes responsible for landslides [119]. Study of field measurements of 2004 Parkfield earthquake by Bakun et al. has revealed that magnitude and extent of rupture were predicted correctly; however, prediction of time of occurrence was not possible at all. They suggested that firstly to predict earthquakes correctly underlying phenomenon causing these should be known clearly and rigorous models are required for incorporating multiple variables. They proposed that still we have to work more diligently to understand and study large earthquakes in order to predict them correctly [120]. Thomas et al. in 2008 published a report where they have examined the data (magnetic field data) collected related to Loma Prieta earthquake and have concluded that anomalous magnetic noise identified at that time is not related to the earthquake but is a result of sensorsystem malfunction. This re-examination has made seismologists sceptic about the direct usage of this technique and are continuously exploring the reliability and possibility of EME signals in relation to earthquake forecast [121].
Friedemann Freund from NASA Ames Research Center has performed laboratory experiments and has rigorously studied the phenomenon of electrical current, voltage and several other factors in relation to earthquake predictions [122]. During the experimental studies 4-m-long granite beam was subjected to compressive loading at the one end, and current signals were collected from the other end. The schematic diagram of the experimental setup is shown in Fig. 11. The current signals were observed during the loading process. During the application of stress the electron-hole pair generation takes place and unstressed part becomes positively charged (due to the flow of holes towards the free end) in comparison with the stressed part which is negatively charged due to the presence of electrons [123]. The load versus current patterns have been obtained in this experiment. Performing experiments on the air-dried granite at room temperature, the maximum current of $1 \times 10^{-9} \mathrm{~A}$ was achieved. Given a cross section of about $300 \mathrm{~cm}^{2}$, this corresponds to a modest current density of only $30 \mathrm{~mA} / \mathrm{km}^{-2}$. However, the conductivity of rocks increases exponentially with increasing temperature. The hypocentral depth range for most crustal earthquakes is about $10-35 \mathrm{~km}$ where temperatures of $250-450{ }^{\circ} \mathrm{C}$ are present. These higher temperatures and resulting higher conductivity will allow for significantly higher currents to flow. Freund has tried to explore the earthquake from many perspectives which also involve the study of luminescence during earthquake, study of atmospheric and ionospheric signals, effect of pre-earthquake phenomenon on living organisms, etc. [124-127]. Freund has suggested that when rocks inside the earth (several $\mathrm{kms}$ in depth) when get stressed the flow of charges takes place towards the surface of the earth. These charges further ionize the oxygen in the atmosphere and huge potential gets developed between the earth's surface and the ionosphere. Thus the current waves inside the earth change the atmospheric chemistry. These changes can be detected in terms of different measurement factors, and analysis of these factors can possibly give us information of the upcoming earthquake.

Lacidogna et al. have also worked extensively on the electromagnetic emissions from various types of rocks and brittle materials. Laboratory experiments of low-frequency electromagnetic radiation have been done on rock samples, viz. concrete, Syracuse limestone, Carrara marble and green Luserna granite 
Figure 11 Setup to measure the positive surface potential, due to $\mathrm{h}^{+}$, on a flat rock surface with a non-contact capacitive sensor (redrawn with permission from Elsevier) [123].

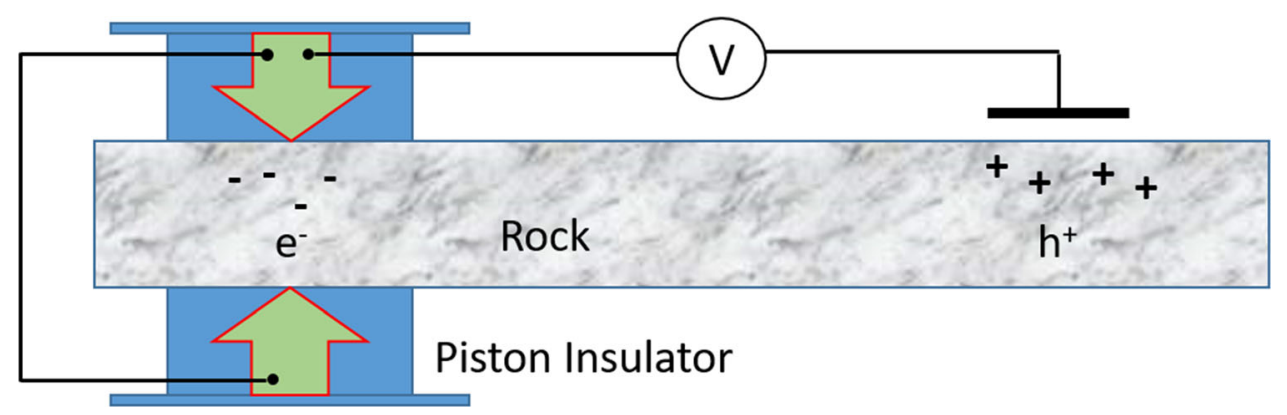

to investigate these emissions as failure predictors [23]. Lacidogna and group have also studied the electrical emission phenomenon as a failure [128] precursor as well as with respect to the prognosis of the seismic activities [24, 129-133]. Carpinteri and Borla performed the field activities where fractoemissions (electromagnetic, neutron and acoustic emissions) have been recorded at a gypsum mine where signal detection unit was placed $100 \mathrm{~m}$ below the ground surface to prevent external interferences [134]. Recently Wei et al. in 2020 presented the experimental study where EMR signals have been detected from different types of rocks. They have discussed the relationship between the EMR intensity with respect to elastic modulus, compressive strength and quartz content of the rocks. Through their analysis they found that the quartz content is not a decisive factor for the EMR signals, but these signals are more dependent on the complex stress-induced cracks and their propagation [135].

To know about and to evaluate the damage process electric resistance measurement has also been studied intermittently by some groups of researchers. King and Luo have performed laboratory experiments on concrete specimens (subjected to uniaxial compression). The change in resistance has been observed when the applied stress reaches $20-90 \%$ of the failure stress. This has been attributed to the accelerated formation of microcracks [136]. Wang and Chung have tested unidirectional carbon fibre epoxy-matrix composite under uniaxial and fatigue testing under tensile stresses, and resulting change in electrical resistance is measured. Increasing electrical resistance is obtained at increasing stresses as the conductivity decreases due to the broken fibres [137]. Todoroki and Yoshida have also tested the carbon fibre-reinforced plastic under uniaxial loading (tensile and shear) for the measurement of change in resistance [138].
Chen and Lui have performed laboratory experiments where carbon fibre-reinforced concrete was tested under uniaxial compression and three-point bending [139]. Change in electrical resistance was recorded along with the variation in the external load applied. It was observed that at low stress levels the fraction of change in resistance decreases, while it increases when the stress level reaches around $60 \%$ of the fracture stress. The initial decrease in change in electrical resistance is due to the fact that during external loading the distance between the carbon fibres becomes small and consequently they come close. Moreover, during externally applied load the carbon fibres have the tendency to align themselves along the loading direction which increases overall conductivity or otherwise the fractional change in the electrical resistance decreases, while the increase in stress level increases the generation of cracks and flaws which decreases the overall conductivity of the carbon fibres and hence increase in the fractional change of resistance is observed. The simultaneous measurement of the acoustic emissions also supported the pattern observed during the measurement of change in electrical resistance [139].

Niccolini et al. have also used the technique of electrical resistance measurement. The group has tested granite and mortar specimens under uniaxial compression. In these cases, the change in the electrical resistance has shown its dominance at loads approaching the fracture regime for both the specimens. This group has also measured acoustic emissions simultaneously, and these signals have also shown their increasing strength when the load approaches the fracture regime [140]. In the literature, the four-probe method was usually referred in order to measure the electric resistance where two probes were used to measure the current, whereas the other two were used for the voltage measurements. Thus, the EME signals detection from rocks 
and brittle materials has remained an active research area and efforts to understand its physics and application are still going on.

\section{Coal}

Coal has also remained as an interesting material for the exploration of electromagnetic emissions. During continuous mining in coal mines stresses increase in the coal/rocks which sometimes lead to devastating failure causing several causalities. Figure 12 shows a tunnel before and after rock burst due to the stress development as a result of continuous mining [141]. For developing a preventive and alarming technique various authors have performed laboratory experiments in which various types of coals were tested under different types of mechanical loads and related electromagnetic emissions were detected [142-144]. Song et al. in 2015 during experimental investigations found out that the EMR intensity is proportional to the applied stress and there is a dependence of
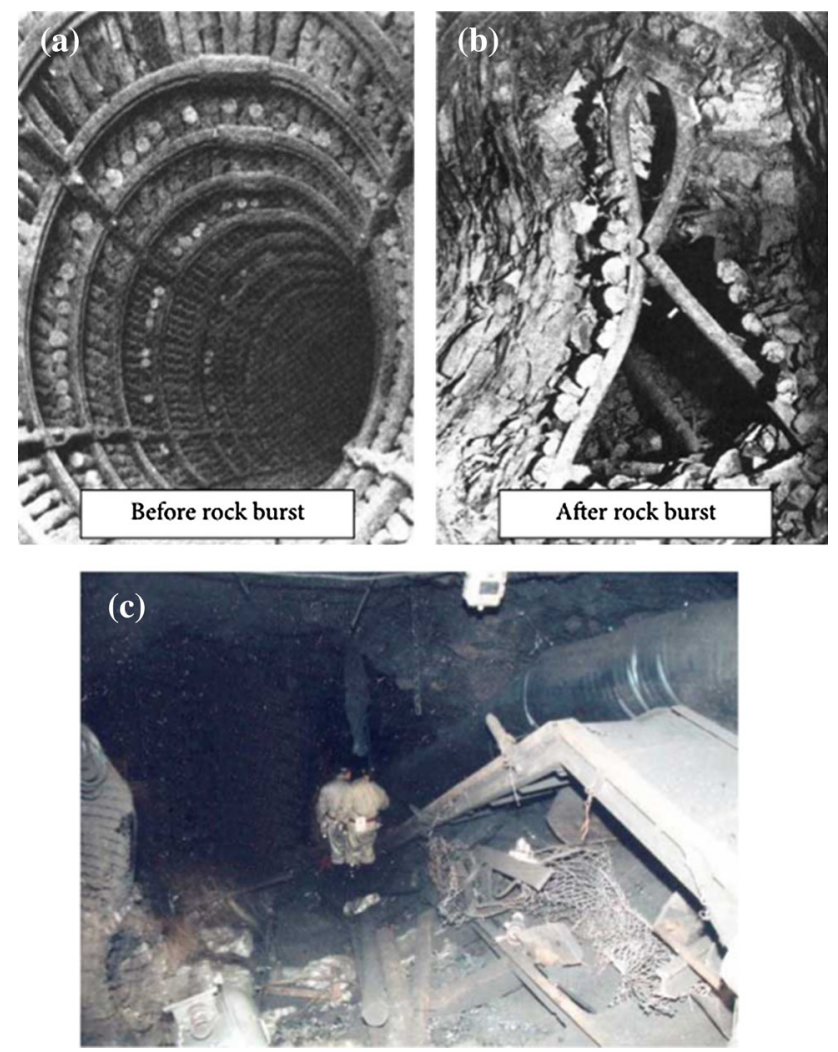

Figure 12 Rock burst disaster: (a) tunnel before rock burst, (b) damaged tunnel after rock burst and (c) damaged equipment (used with permission from Springer) [141]. frequency of these signals on the applied stress. The frequency of EMR signals increases during linear elastic deformation regime and decreases suddenly around the fracture regime [145]. Song et al. in 2017 tested coal samples (outburst coal and rockburst coal) under uniaxial loading and characteristics of EMR signals were recorded. It was observed that outburst coal is soft and EMR signal increases slowly with the loading. However, the rockburst coal was observed to be brittle and corresponding EMR increases quickly and EMR peaks appearing, while the coal breaks are larger than the outburst coal [29, 141, 146-150]. Figure 13 shows the experimental setup used by $\mathrm{Li}$ et al. for the detection of electrical current from coal samples when subjected to uniaxial compression [141]. In case of coal triboelectrification of coal particles and charge separation during crack propagation has been discussed as the dominant mechanism for the observed signals. Moreover, these electrical currents have been proposed as the tool for monitoring the failure process of coal as well as roof rock. Qui et al. have performed the field experiments and have also studied the EMR response law related to the coal and gas outburst. Changes in coal from the stable state to the unstable one increase the amplitude of the signals. Signals observed in the regime close to the outburst are complicated in comparison with the signals obtained during previous stages [151]. Sometimes complex reaction between coal and oxygen results in spontaneous combustion which is quite unfavourable during mining, and this coal-field fire at high temperatures is a challenge. Kong et al. have worked on directing the EMR method for analyzing the coal oxidation process for developing a technique in determining fire hazards in the coal mines $[152,153]$. Wide research on EMR from rocks and coal to provide early warning on coal and rock dynamic disaster led Kong et al. to test coal samples during heating and detected corresponding EMR signals. These EMR emissions during heating process have been proposed for forecasting and predicting coalfield fire and coal-concealed fire, etc. [154]. Li et al. have tested coal samples under impact loading. Friction between the minerals contained, charge separation, crack growth and free electron movement have been found to give rise to EMR. Moreover, the energy of EMR signals increases with increase in the impact energy which suggests that use of this technique in the prediction of coal mine impact disaster is possible [155]. Guan et al. have tested the coal 


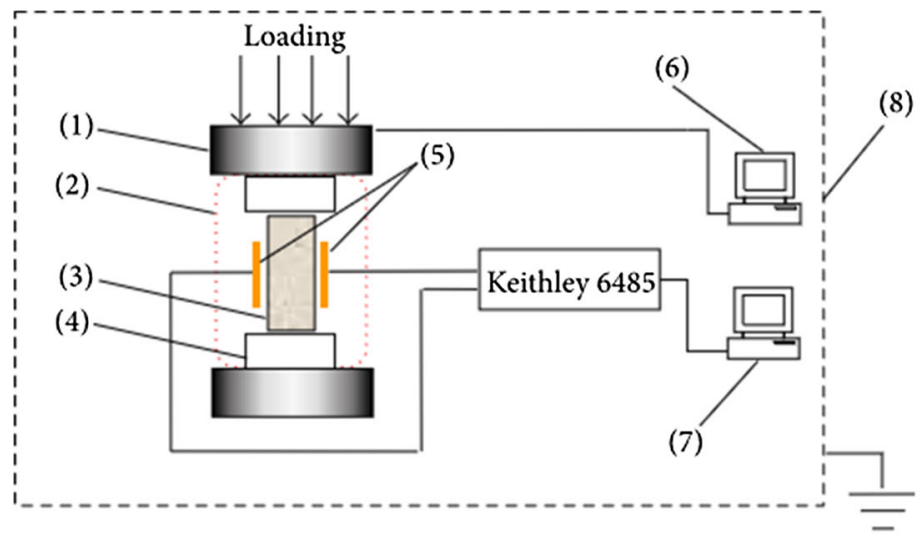
(1) Testing machine
(5) Electrode
(2) Shielding net
(6) Loading control system
(3) Coal and rock samples
(7) Electric current data collecting system
(4) Insulation block
(8) Electromagnetic shielding room

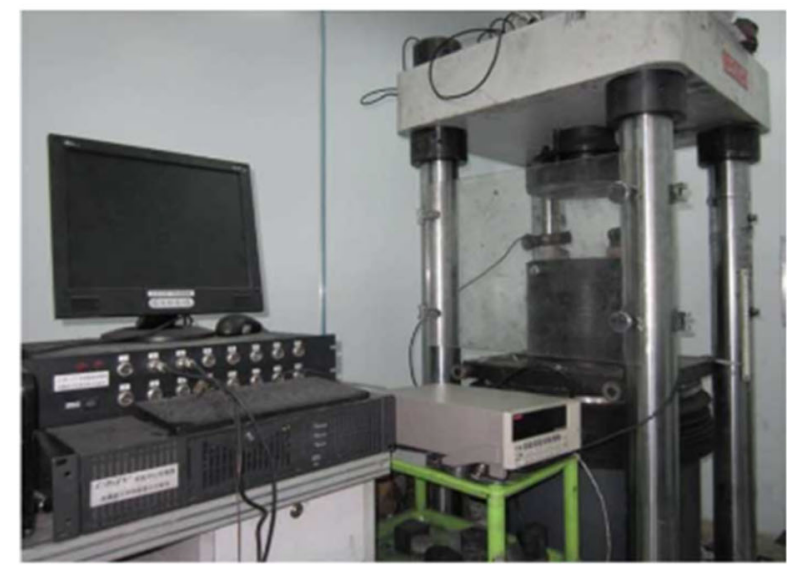

Figure 13 Experimental setup for electromagnetic radiation detection from coal samples (used with permission from Springer) [141].

samples under uniaxial compression which have the crack propagation parallel and perpendicular to the bedding direction. They have compared the transient charge signals observed on the surface of the coal samples during deformation and have thus suggested this technique for the prediction of coal and rock disaster arising from the crack propagation which is usually the case [156]. Similarly, Liu et al. have tested rock and coal samples under uniaxial compression and have detected the resulting EMR signals beginning from deformation and up to failure. They have analysed the EMR signals in terms of the Hurst index [157]. Pasiou et al. have performed compression test on brittle materials including marble, mortar and glass specimens under compression and have detected electrical signals known as pressure-stimulated currents (PSC) [158, 159]. Owing to increase in the interest of researchers for the detection of electromagnetic radiation emission during microcracking Krumbhloz et al. presented a rigorous discussion on EMR method and concluded that current state of the knowledge about this field still restricts the use of these radiations for the determination of the main horizontal stress directions in earth crust [160]. Thus, this method is being explored in predicting rock mining failure, coal mining failure and fire prediction in coal mines as well as to know about complex fracture process.

\section{Electromagnetic effects in metals and alloys}

One of the most interesting effects of plastic deformation on metal is the cold emission of free electrons from the surface. In 1949, Kramer developed these observations into a method for studying the plastically deformed surfaces. Later in early 1970s Misra et al. presented the first reporting on the EMR emission from metals during plastic deformation and fracture. With the first publication of Misra in 1975 reporting the electromagnetic effects in metals [161] investigation of these emissions has gained impetus, and these have been explored extensively by his research group and other researchers as well [162-171]. Misra and Ghosh in 1980 also observed EMR emission during fatigue crack propagation in plain-carbon steel. They observed that formation of each new crack tip during fatigue emitted distinct electromagnetic pulse of recordable amplitude [172]. Misra et al. have used semi-cylindrical copper sheet antenna of internal diameter $30 \mathrm{~mm}$ and length $50 \mathrm{~mm}$ as sensor, kept close to the specimen. They have used DC microvoltmeter and $30 \mathrm{MHz}$ capacity Hewlett Packard storage oscilloscope to detect the EMR signals along with the electromagnetic shields to get rid of external electromagnetic noise [169].

Tudik and Valuev fractured the metal specimens under tension and detected the EMR signals with a photomultiplier. The EMR signals were passed through interchangeable band filters (transmission range $\sim 160$ to $3000 \mathrm{~nm}$ ), pulse amplifier, pulseheight discriminator and count-rate meter placed in 
series before finally recording on storage oscilloscope. They have reported that linear fracture of metals is accompanied by the emission of electromagnetic radiation of wavelengths from $\sim 300 \mathrm{~nm}$ to $>1500 \mathrm{~nm}$ for iron and its alloys and from $650 \mathrm{~nm}$ to $>1500 \mathrm{~nm}$ for aluminium and its alloys. They interpreted these results reflecting a relaxation of excited electronic states at the surface which is formed during the rupture of interatomic bonds [173]. Dickinson et al. reported the emissions of electron and photons associated with long wavelength electromagnetic radiation during the failure of interfaces between aluminium and epoxy [174]. Dickinson et al. (1985) have used 2000 turns solenoid of No. 30 magnet wire placed $2 \mathrm{~mm}$ from the specimen to detect the EMR emission. The coil antenna was connected to the input of a wideband differential amplifier with high common mode rejection to minimize the pick-up noise. The EMR signal was digitized once every $20 \mu$ s and stored on a computer over the duration of the experiment (approximately $100 \mathrm{~ms}$ ).

Jagasivamani and Iyer carried out simultaneous investigation on acoustic emission and electromagnetic radiation emission during crack propagation and fracture of metals. They also investigated the effects of heat treatment, grain size and low temperature on EMR emission and have reported that maximum energy burst in heat-treated spring steel was in $\mathrm{kHz}$ range [175]. They have also discussed about the importance of design of the receiving antenna to collect maximum emissions. In their experimental investigations they also found the copper antenna used by Misra as frequency independent and used this in cylindrical form to detect the EMR signals. They wrapped the external surface first with an insulating sheet and then with a copper foil to provide an electrostatic shield from external interferences. The signal received was amplified by a wide band amplifier system with an input impedance of $1 \mathrm{M} \Omega$. Alekseev and Egorov presented a study on the shape of pulses of electromagnetic emission generated by a moving crack [87, 176]. Misra and Kumar reported further investigations on the EMR emission during crack propagation and fracture of several metals and alloys. They correlated the EMR peak amplitude and dominant frequency with the bond energy, lattice parameter, tensile strength, electrical conductivity and Debye frequency of metals. Considering the previous reported studies Misra and
Kumar also used a $U$-shaped antenna made of copper sheet. A $1 \mathrm{M} \Omega$ co-axial cable of $1 \mathrm{~m}$ length was used to feed the signal to the data acquisition system (DAS) during the experiments.

Meanwhile Srilakshmi and Misra have reported an additional new phenomenon of secondary electromagnetic radiation (EMR) emission when the deformation load is kept stationary. They attributed the secondary EMR emission to the micromechanism of dislocation relaxation dynamics in metallic materials [162]. Srilakshmi and Misra have also presented some interesting results on EMR emissions in commercially pure aluminium. In single-edge notch specimens, a compression zone is developed towards the edge opposite to the initial notch. It has been observed that the EMR responses (amplitude and frequency) are directly proportional to compression zone size [177]. Same authors also reported some significant characteristics of EMR emitted from commercially pure aluminium strips under opening and shearing modes of fracture at elevated temperatures. It was observed that elevated temperatures affect only the $\mathrm{kHz}$ component of frequency pertaining to EMR [178]. This EMR emission was also examined by Venkataraman et al. while characterizing tensile deformation of AISI type 316 nuclear grade stainless steel by infrared technique [179].

Figure 14 shows the schematic diagram of specimen configuration and associated setup used by Srilakshmi and Misra for the investigations of EMR from fracture of metals under opening and shearing mode where notch marks the fracture point and the antenna is placed near the notch to detect the electromagnetic radiation emitted during plastic deformation [178]. Kumar and Misra presented experimental results correlating the effect of modes of fracture, thickness and notch depth ratio with the emission of electromagnetic radiation (EMR) during crack propagation and fracture in commercial (68-32) brass sheets. It was observed that tearing mode of fracture emits the lowest amplitude of EMR signals. Variation of maximum EMR amplitude appears to characterize the transition from plane-stress to planestrain condition as thickness increases with initial crack length to specimen width ratio of 0.5 [180]. Kumar and Misra in 2006 reported investigations on the effect of processing parameters on the emission of EMR during plastic deformation and crack propagation in copper-zinc alloys. It has been reported that the EMR emissions are highly anisotropic in nature, 


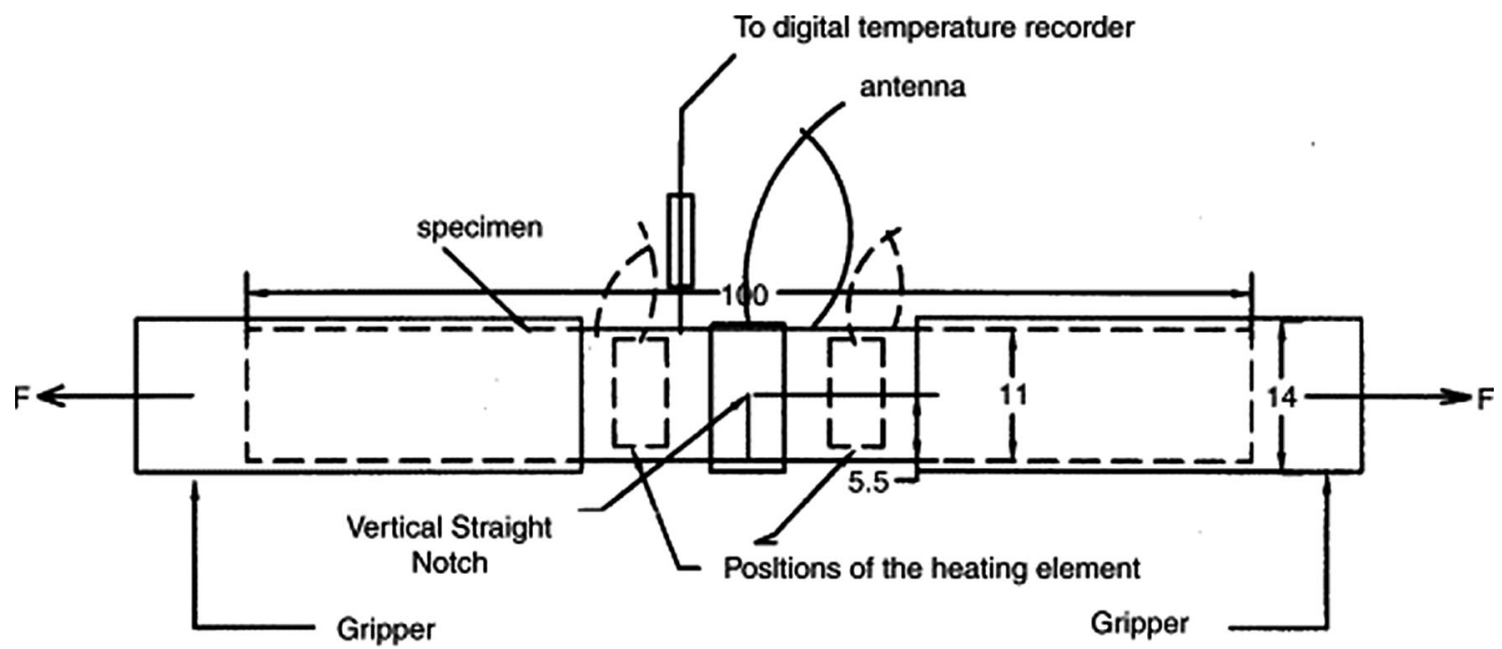

All dimensions in $\mathrm{mm}$

\section{Opening Mode}

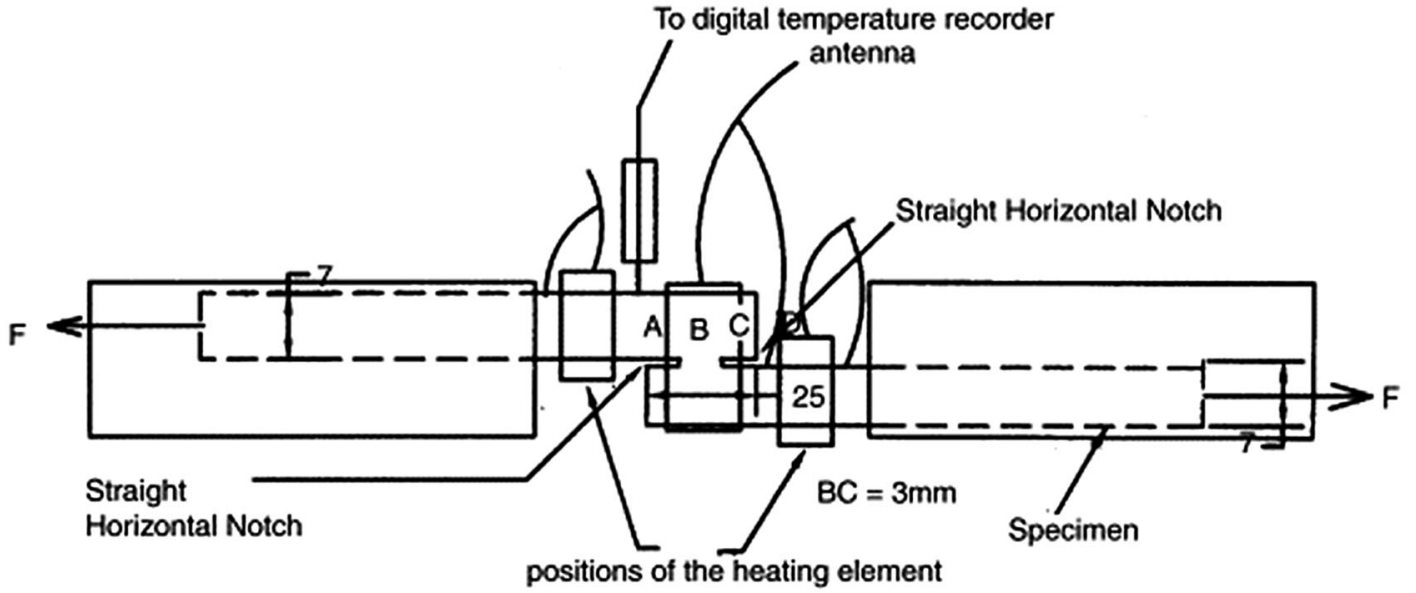

All dimensions in mm

\section{Shearing Mode}

Figure 14 Metal specimens in opening and shearing mode for detecting electromagnetic radiation (EMR) emission (used with permission from Elsevier) [178].

and there are changes in mechanical and electromagnetic parameters between $45^{\circ}$ and $60^{\circ}$ angles to the rolling direction. Further, they observed welldefined patterns of EMR at different annealing temperatures [181]. Kumar and Misra in 2007 reported that the electromagnetic energy release rate has direct correlation with elastic strain energy release rate in 68-32 $\mathrm{Cu}-\mathrm{Zn}$ alloy, which can prove to be a novel technique for the evaluation of fracture toughness [182]. Figure 15 shows a typical EMR signal observed along with its FFT during opening mode of fracture
[182]. Chauhan et al. in 2010 reported EMR emissions from metals and alloys during deformation under unrestricted quasi-static compression. Lubricated or non-lubricated condition of the compressing platens and the crystal structure were found to influence the EMR emission characteristics. Shape anisotropy of the EMR signals has been observed under compression [164].

Singh et al. in 2014 explored metals having different types of crystal structures for the intermittent electromagnetic radiation (EMR) signals obtained 


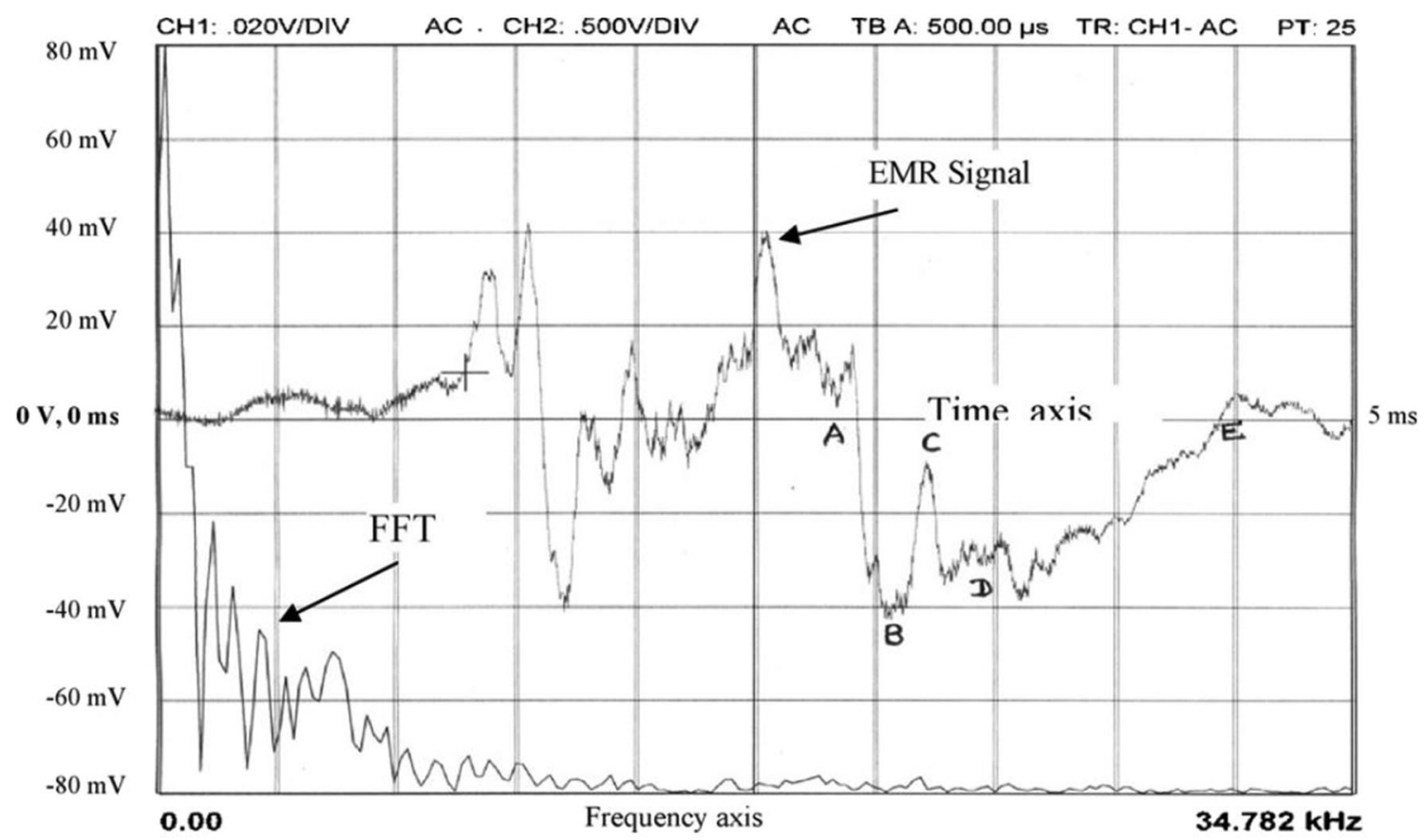

Figure 15 EMR signal along with FFT obtained during opening mode of fracture (used with permission from Elsevier) [182].

during tension and compression of metals. The intermittent EMR signals are found to be generally of oscillatory or exponential nature except a few which have shown random variations [183]. Singh et al. in 2019 have studied the effect of notch/depth ratio on the EMR emission from tensile test specimens made up of $\mathrm{Cu}-\mathrm{Ni}$ alloy. It was observed that the changes in the ratio change the nature of EMR, i.e. from oscillatory to exponential, and have also helped to develop the correlation between the EMR emission parameters and the radius of the plastic zone [184]. Recently Oraon and Sharma presented an experimental investigation to determine EMR radiation during incremental microforming of a thin aluminium sheet. Formation of electric dipoles ahead of crack tip has been discussed as the main cause of these emissions, and it was independent of the surface finish of the metal. EMR signals were found to be influenced by the microstructural changes rather than forming parametric conditions. This investigation has proposed to develop an online inspection tool for the incremental microforming process [185]. Hence, it can be inferred that the design of antenna and the noise isolation is necessary in order to analyse the EMR signals thoroughly.

\section{Electrical and electromagnetic response} of polymeric and composite materials

Polymers and fibre-reinforced composites nowadays are finding a lot of applications nowadays and have become of researchers' interest because of the properties such as light weight, less stiffness, formability [186]. Emissions of particles (electrons, ions, radicals, photons, etc.) during fracture of materials, known as fractoemissions, have been reported in literature extensively $[5,187,188]$ to understand the dynamics of crack propagation and failure.

Dickinson et al. during 1982-2000 in a series of papers presented data on these emissions during fracture of polymeric materials [189-192] and semiconductors [193-195]. These fractoemissions have been discussed as a useful tool to know about the chaotic process of fracture. They concluded that fluctuations in photon emission intensity during fracture reflect the features of produced fractal surface and thus provide important information on the process of dynamic crack growth [196].

Dickinson et al. reported the measurements of fractoemissions during fracture of polybutadiene and a styrene-butadiene copolymer, where the degree of cross-linking has been altered either by varying the concentration of the cross-linking agent or by exposure of the material to ultraviolet or $\gamma$ radiation. 
Result analysis shows that over the range of crosslink densities studied, both electron and positive ion emission increase with increasing cross-link density [197]. Crasto et al. performed tension test on unidirectional composite made up of 300 fibres embedded in a single dog-shaped epoxy matrix. Strength of the fibre matrix was varied by different surface treatments. Photoemissions (in some cases electron emissions) were detected before, during and after fracture. It was observed that photoemissions are prevalent for the weak bonds which fail due to adhesive failure, whereas strong bonds have cohesive failure with less photon emissions [198, 199]. Dickinson and co-workers have found that during fracture adhesive bonds and peeling pressure-sensitive adhesives involve large amounts of charge separation and the emission of charged particles, excited neutrals, light and radio waves. Dickinson et al. have examined the electron, photon and radiofrequency emissions from two situations that lead to interfacial or adhesive failure: the fracture of model propellants loaded with cyclotriethylene-trinitramine (RDX), and the peeling of binder material from macroscopic single crystals of RDX. Two binder materials are examined: hydroxy-terminated polybutadiene/isophorone diisocyanate and polyglycidyl azide prepolymer cured with a multifunctional isocyanate [200].

Gade et al. performed three-point bending test on epoxy resin specimens, and corresponding EME signals were detected. From the experimental results it was observed that the signal strength of the recorded EME signals is highly dependent on the source-sensor distance and the orientation between sensor and crack surface. EME signals are only detectable within a range of a few millimetres, and the strongest signals are measured with the sensor plate being parallel to the fracture surface [201]. The schematic of experimental setup used is shown in Fig. 16 where the EME sensor and the specimen are forming a capacitor. Gade et al. also studied the electromagnetic emission generated by fracture of carbon fibre-reinforced polymers (CFRP) induced by three-point bending. Here also sensor based on capacitive coupling has been used for the detection of EMEs. To understand the crack surface orientation using electromagnetic emissions different source to sensor orientations and distances of antenna have been used. Consequently, a method has been developed in which crack orientation can be known based on the directionality of electromagnetic fields [199]. Langford et al. have investigated the photon emissions from fracture of epoxy and have proposed a method to probe fractal surface of the epoxy through the accompanying photoemissions. It was observed that fractal characters obtained through slit island technique match with the observed photon emission data [196].

Sause has performed various tests depicting the EME measurement due to the crack propagation in polymeric materials such as epoxy resins (RTM6), polypropylene, polyether ketone and polytetrafluoroethylene, fibre filaments and polymeric composites. For the purpose of comparability compact-tension, double-edge notched tension and tapered doublecantilever beam specimens were prepared and checked for EME signals. He has also discussed the sensors used for electromagnetic emission (EME) signals detection. He has presented a discussion on (i) capacitance plate sensor working on the principle of parallel plate capacitor, wire sensor which contains a single strand of conductive wire that can be held around the material under investigations in open- or closed-loop conditions and (iii) coil sensor which in contrast to the single strand of wire contains all sorts of coil configurations comprising closed end conditions. In addition importance of electromagnetic shielding during the EME detection is also discussed and elaborated [13].

\section{Electromagnetic emission from cement- based materials}

Nowadays civil infrastructures are sprawling at a much bigger rate and are transforming into megastructures with technological advancement. Cement and cement-based materials are an important part of any construction in one or another form. Larger the structure higher is the number of persons using it, thus safe working of the structures is necessary for the well-being of everyone. In order to provide longevity to the infrastructures made from cement as a base materials knowledge of properties and behaviour of cement is essential. Keeping this in mind it has been explored widely for strength and crack propagation behaviour [202-209]. On the other hand cement and its composites have been explored widely for the determination of their piezoelectric properties in order to use it as a smart material [210-215]. Researchers have explored various techniques to monitor the deformation and stress state in 
Figure 16 Schematic diagram of setup consisting of universal testing machine, test fixture, electromagnetic shielding and EME and AE sensors with measurement equipment [201].

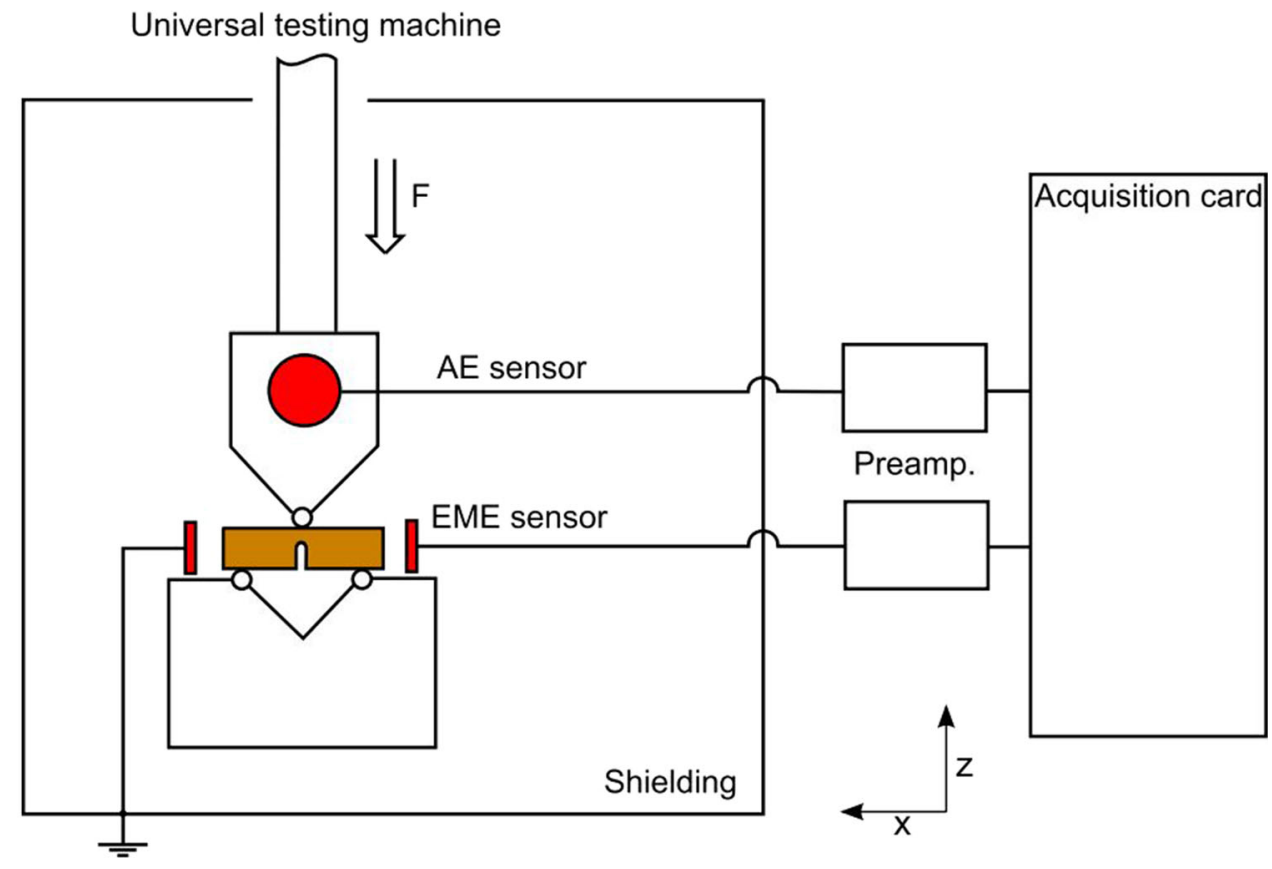

cement and cement-based materials [10, 12, 216, 217]. Electromagnetic emission detection technique representing the stress state and condition of structure has also been explored in the literature on cement-based materials and is discussed hereafter.

Before moving on to the discussion of electromagnetic emission (EME) detection it is worthy to go through some of the reportings pertaining to the basic properties of the cement one of which is conductivity of the cement. Reportings on the detection of current signals based on the conductive properties of the cement-based materials have been a driving force to explore this material for the related electrical and electromagnetic emissions when exposed to external loading. The conductive properties of the cement have been explored by various researchers [218-221]. Whittington et al. performed a set of experiments to know about the conductive characteristics of pure cement and concrete and have published a rigorous discussion regarding the same [222]. F. H. Whittman tested the rectangular specimens of cement paste under bending. In the experiments it was observed that the voltage obtained during bending increases proportionally with increase in the load. Generally during bending there is development of tension and compression zones above and below the neutral axis. A voltage signal of $\sim 200 \mu \mathrm{V}$ has been observed when the external load applied was $2000 \mathrm{~g}$ [223]. During the application of compressive load Dann et al. observed electrical signals from concrete specimens. Electrical signals obtained during form installation, quasi-elastic deformation and at the moment of fracture have been analysed. A frequency of $15.8 \mathrm{kHz}$ has been observed during the first two phases, while during the last phase of fracture it falls below $15 \mathrm{kHz}$ [224].

When subjected to compressive loading Triantis et al. detected current signals from cement mortar specimens when the loading condition was low $(0.1 \mathrm{MPa} / \mathrm{s})$, abrupt (2 and $5 \mathrm{MPa} / \mathrm{s})$ and constant stress near the failure region. Near the failure region the stress value of $37.2 \mathrm{MPa}$ resulted in current signals of $76 \mathrm{pA}$. It was observed that the signals fluctuate during last $10 \mathrm{~s}$ of the failure and is correlated with the generation of microcracks [225]. In another study Triantis et al. tested the prismatic cementmortar specimens when subjected to 3-point bending. PSC (pressure-stimulated current) and acoustic emissions were detected simultaneously during the failure of cement-mortar specimen. Acoustic emissions were also explored by some researchers for the condition monitoring of the structures. In this area experimental investigations have been carried out to find the correlation between the acoustic signals and PSC signals in terms of released energy [226]. Qingping et al. have also tested different samples of concrete viz. plain mortar, plain concrete, carbon fibrereinforced mortar and reinforced concrete in three- 
point bending. Electrodes attached on the end sides of the beam act as flat plate capacitor, and the beam acts as the dielectric medium. Cracking of beam resulted in the appearance of signals. There was a simultaneous appearance of crack and the signals which confirmed that the propagating cracks act as the source of the observed electromagnetic signals [227]. For studying the electromechanical effect in cement paste $\mathrm{Li}$ et al. applied electric field on the samples and consequently shape changes induced due to the applied electric field have been observed in the order of $100 \AA$. This phenomenon was exhibited by the samples which contained moisture and was not observed in dry samples. As cement is a porous structure electro-osmotic-induced swelling of pores due to the applied electric field has been discussed as the reason behind the shape change of cement [228].

Kyriazoopoulos et al. subjected the cubical cement samples $(40 \mathrm{~mm} \times 40 \mathrm{~mm} \times 40 \mathrm{~mm}$ ) to three types of loading conditions viz. i) increasing stress at a constant rate, ii) maintaining significant high stress level for a long period of time and iii) increasing the stress state up to the failure limit. Figure 17 shows the experimental setup where the sample placement, load application and mounting of electrodes can be visualized. Under these loading conditions current signals in the range of $\mathrm{pA}$ have been measured. Increasing the stress to a higher level results into primary PSC emissions. Secondary emissions have been detected by keeping the stress levels at a constant higher amplitude. This has been attributed to the opening of new cracks and propagation of the existing one. In the vicinity of failure stresses the PSC emissions attain higher value due to further crack propagation. This study has been concluded as a non- destructive technique for the health monitoring of cement paste [229]. Kyriazoopoulos et al. (2011) have also detected the current signals from the concrete specimen when subjected to uniaxial and three-point bending [230]. The variation of the observed current signals is found to be proportional to the strain rate $(\mathrm{d} \varepsilon(t) / \mathrm{d} t)$. With strain rate ranging from $1.5 \mathrm{E}-6$ to $2.5 \mathrm{E}-6$ the maximum current amplitude was found to be varying from 60 to $100 \mathrm{pA}$ [230]. Sklarczyk and Altpeter have also reported the electrical emission (EE) from mortar and concrete during impact loading. Resulting signals were not consistent with the repetitive impacts, and it was concluded that more number of impacts are required to use these emissions for the monitoring of compressive strength [231], whereas Fursa et al. show the electromagnetic emissions generated due to the adhesion characteristics of the metallic substrate stuffed in cement. These electromagnetic emission signals have been used as a method for assessing the quality of adhesive bonds [232]. Influence of humidity was also analysed, and EE signals were found to decrease with increase in humidity of air. Rapid movement of double electric layers under the impact loading has been discussed as the contributing factor for the EE signals [210]. Mingqing Sun and co-workers have also reported electrical emissions from cement under repeated compressive loading (maximum load of $10 \mathrm{MPa}$ ). The schematic of the experimental setup is shown in Fig. 18. By applying the cyclic stress of $10 \mathrm{MPa}$ the average recorded electrical current signal was observed to be $1.0 \times 10^{-8} \mathrm{~A}$. Figure 19 shows the electric current vs. time when the applied stress up to the breaking stress is applied. It can be observed that electrical current increases with the increase in stress
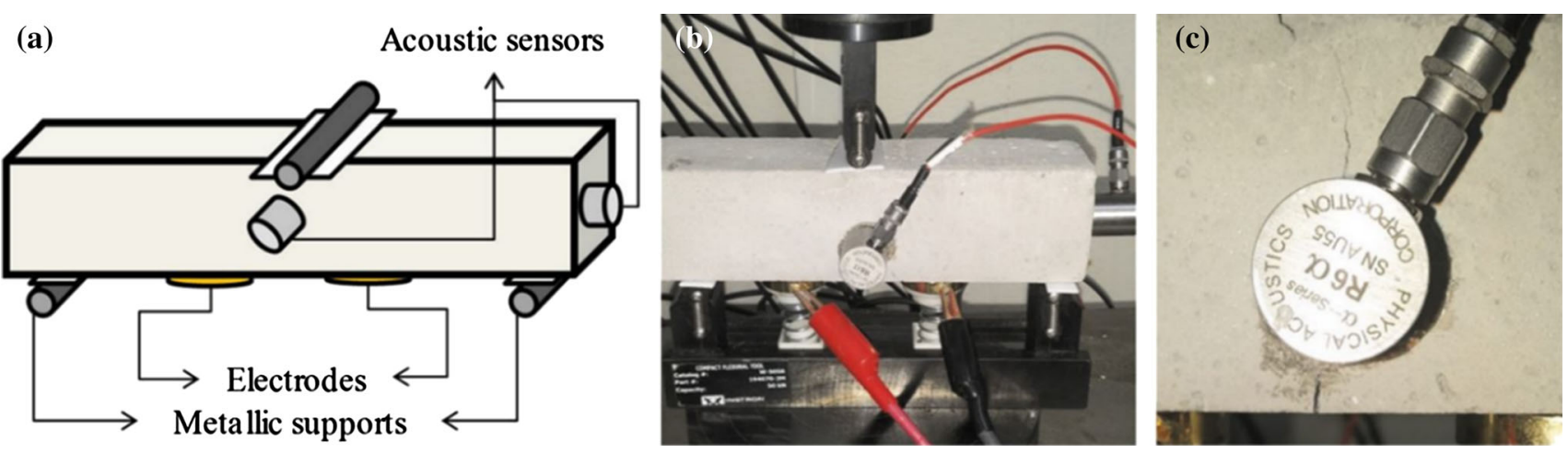

Figure 17 a, b The experimental setup and the location of the PSC electrodes and the AE sensors; (c) the fracture plane of a typical specimen [226]. 
Figure 18 Schematic diagram of electromagnetic radiation detection from cement samples (used with permission from Elsevier) [233].

\section{P Thin Copper platen}

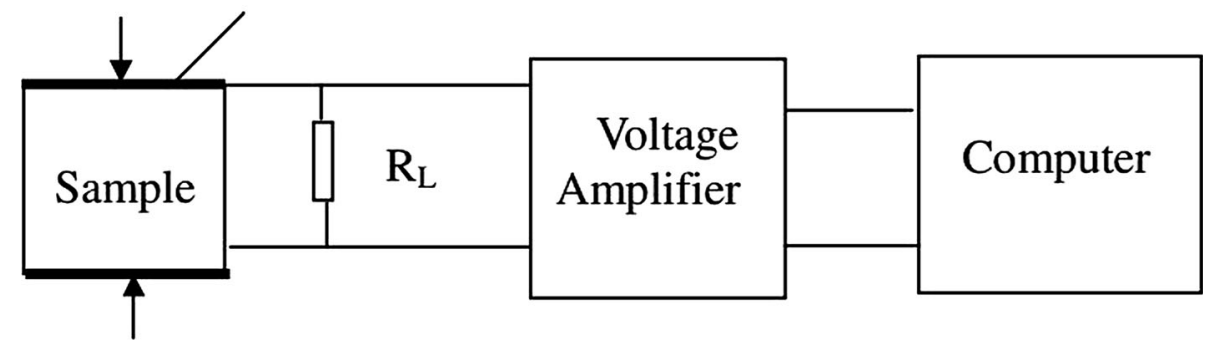

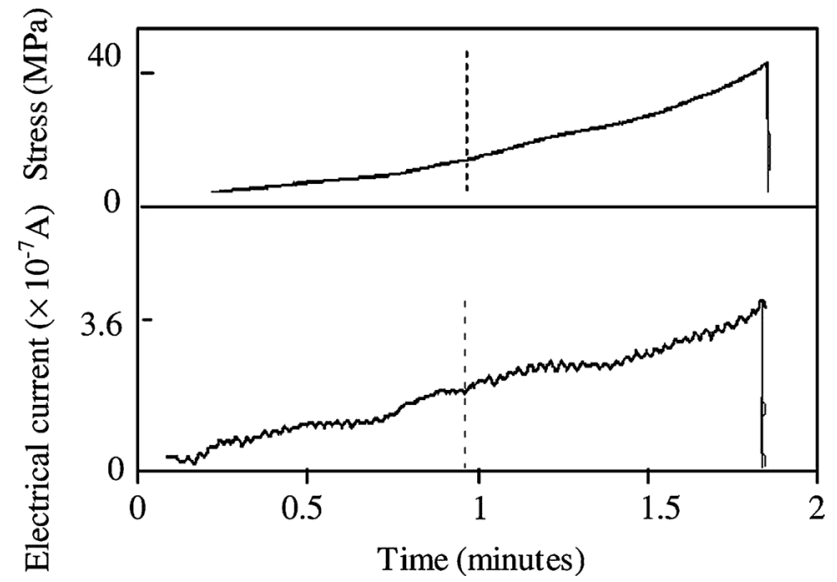

Figure 19 Compressive stress, electrical current vs. time till the breaking stress (used with permission from Elsevier) [233].

and drops during the failure because of the wide crack opening [233].

Stergiopoulos et al. detected electrical and acoustic emissions in rectangular cement mortar specimens under three-point bending load. Acoustic and electrical emissions were recorded with the help of electrodes which were placed inside the bulk samples. Recorded signals were analysed in order to develop understanding of crack formation and damage evolution [234]. Malyshkov et al. have reported the electromagnetic emission in concrete under quasistatic loading and mechanical impact. Under mechanical impact, the amplitude of electromagnetic emission was related to mechanical properties of concrete such as compressive strength and bond strength between stiffened cement and fillers. Therefore it is proposed that electromagnetic emission signals from concrete can be used to detect crack initiation, crack propagation and mechanical strength of concrete [235]. Cao and Song have performed the uniaxial compression test on cemented tailings backfill for the EMR detection and have observed the increased pulse count and energy for the resulting EMR signals [236].

Kumar et al. detected electromagnetic radiation (EMR) emissions from the pure cement and cementfly ash samples subjected to curing time of 3, 7, 14 and 28 days. The EMR voltage from cement samples was observed to decrease with increase in curing days. When the samples are tested after drying in oven for $6 \mathrm{~h}$ at $100{ }^{\circ} \mathrm{C}$ the maximum peak voltage reduces, while addition of water to the dried samples causes a linear increase in EMR. Proportional increase of EMR signals with increase in the height of impact has been observed for both pure Portland Pozzolana cement samples and samples with fly ash addition [237]. In a subsequent study EMR signals from cement- $\mathrm{BaTiO}_{3}$ (cement-BT) composites under impact loading has been reported by the same research group. Significant increase in the amplitude of EMR signals in the cement- $\mathrm{BaTiO}_{3}$ composites with increase in BT content (5-40\%) has been observed. Increase in the impact height and BT content in the composite has shown increment in the EMR signals. This enhancement in EMR voltage with the addition of BT powder has been attributed to increment in the number of ferroelectric dipoles existing in BT [238]. Similar study of EMR detection under impact loading has also been performed in case of $0-3$ cement PZT composite where PZT is the popular lead-based piezoceramic lead zirconate titanate [239].

To determine the feasibility of using EMR to evaluate the condition of concrete after high-temperature events, like structure fires, Dexing et al. tested three groups of concrete specimens under uniaxial compression after being heated to elevated temperatures; the EMR signals were recorded and analysed. Lowfrequency EMR ( 10.9-131.5 kHz) was observed during loading. For specimens heated to different temperatures the EMR waveforms were observed to 
have similarity in shape and variation in intensity. The frequency and the maximum amplitude of the EMR signal are found to increase with the exposure to temperature [240]. Thus a variety of studies have been performed on cement-based materials in order to understand their EMR emission characteristics under different stimulus. Presence of water content in cement-based materials has been shown to have an important role in the generation of electrical signals. From all these experimental observations it can be noticed that there is a general trend of increase in the EMR signals' amplitude with increase in the externally applied stress up to a certain limit which is beneficial in terms of the practical implications of using EMR detection technique.

\section{Physical mechanisms for genesis of electromagnetic emissions}

For understanding the EMR emissions from the materials thoroughly first it is imperative to understand the cause of these emissions. In order to understand this, different physical mechanisms have been proposed in case of different materials. Despite this there is still no particular unified theory which clearly explains the EMR emissions occurring from all types of materials. In this section a discussion on different types of proposed models is presented which will be helpful for developing a better understanding of the cause of these observed emissions.

Majority of the models presented in the past are based on the plastic deformation, crack propagation and permanent failure of the materials. Further in general sense the phenomenon of crack propagation and plastic deformation is related to the breakage of bonds which is further related to the formation of electrical charges at the cracked surfaces. There is no single universal theory explaining these electromagnetic emissions; thus, this section provides a discussion on the existing models for the EMR emissions.

Before discussing the models for the electromagnetic radiation (EMR) emissions it is important to go through the Maxwell's equations which lay the foundation of classical electrodynamics. The wellknown Maxwell's equations are given as [241]:

$\nabla \cdot E=\frac{\rho}{\varepsilon_{0}}$ $\nabla \cdot B=0$

$\nabla \times E=-\frac{\partial B}{\partial t}$

$\nabla \times B=\mu_{0}\left(J+\varepsilon_{0} \frac{\partial E}{\partial t}\right)$

where $E=$ is the electric field, $B=$ Magnetic field, $\varepsilon_{0}=$ Permittivity of free space, $\mu_{0}=$ Permeability of free space, $\rho=$ Electric charge density and $J=$ Electric current density.

It is a well-known fact which can also be seen from the first of the Maxwell's equations that a spatial oscillation of electric charges with time produces corresponding electric field.

Some of the theories proposed for the electromagnetic radiation (EMR) emissions based on the experimental findings can be broadly classified as mentioned below:

(i) Dislocation model

(ii) Discharge model

(iii) Charge separation model/capacitor model

(iv) Surface oscillation wave model

(v) Moving charge dislocation model

The above-mentioned models are being explained in the following sections.

\section{Ionic crystals/materials}

Electrical phenomena observed in case of ionic crystals mainly include the enhancement in ionic conductivity and the appearance of an electric potential on the surface of the specimens during plastic deformation. These electrical phenomena observed during the deformation of ionic crystals have been explained through different hypotheses by various researchers which also have contradictions. The hypotheses proposed in literature are being discussed here.

Very first explanation for increase in conductivity of ionic crystals was given by Guylai and Hartly in 1928. They proposed that there is an appearance of loosened sites during deformation, and these loosened sites give rise to increase in the conductivity of ionic crystals [17]. Joffe who described the phenomenon of increase in conductivity due to piezoelectric effect in 1930 has been proven wrong by Remaut et al. in 1960 who have performed bending experiments in which no piezoeffect has been 
observed in rock salt, and it was confirmed that charges of similar type (positive or negative) appear on the compressed and bent sites of a bent specimen $[242,243]$. Stepanow proposed that the increase in ionic conductivity is due to the local melting of the crystal along the slip bands which was confirmed experimentally by Jhonston in 1955 [16, 35]. Johnston extensively discussed the conductivity of silver bromide $(\mathrm{AgBr})$ arising due to the plastic deformation. He stated that during plastic deformation increase in dislocation density occurs and also vacancies and interstitial ions are produced due to the dislocations; these two factors contribute to the increasing conductivity [35]. However, it was objected by various other researchers as well [244-246]. Liberation of electrons upon dislocation movement has been suggested as the reason for the increase in conductivity during deformation which is based on the fact that there is an increase in conduction current upon irradiation or additive coloration [247-249]. However, Kassel stated that the increase in the conductivity is due to the detachment of number of conduction ions from lattice defects which is also directly related to the numerous defects the crystal contains [250].

Seitz performed the constant load experiments and observed the migration of positive vacancies towards the negative ones and form neutral pairs of vacancies. During experimental observations it was calculated that $10 \%$ of deformation gives rise to $10^{18}$ vacancies/ $\mathrm{cm}^{3}$. So, he finally concluded that the increase in conductivity is due to the increase in the number of vacancies and dislocations owing to deformation [251]. Experimentations of Kanzaki concluded that only during the initial stage of deformation the release of charges takes place which corresponds to the sharp increase in conductivity [36]. R.W. Whitworth has provided an extensive review of the charged dislocations formed in ionic crystals [53]. He compared the charge generation on the surface and the dislocations in $\mathrm{AgCl}$ and $\mathrm{AgBr}$ with that of alkali halides. He proposed that in order to study the charged dislocation one needs to study the dislocation-point defect interaction which becomes intricate because of the difficulty in finding the concentrations of point defects. To overcome this more experiments need to be performed to better understand the phenomenon.

Fifolt et al. in 1993 observed simultaneous appearance of electrical signals and visible cracks during compressive loading of the ice samples from which they concluded that the microcracking is one of the responsible mechanism for electrical emissions from ice [60]. However, these microcracks actually lead to electrical signals explained in the series of papers explained hereafter. Petrenko proposed theoretical analysis to describe the electrical signals from ice based on the electrical polarization of ice due to strong inhomogeneous elastic strains caused by cracks [252]. Petrenko used the deformation potential approximation for the calculations of charge carrier motion under the action of inhomogeneous elastic stresses existing around crack tips. This mechanism is fundamentally similar to the pseudo-piezoelectric effect in ice observed by Evtushenko et al. (1987) [253]. The second mechanism assumes that ice which is being split by a crack has already been electrically polarized, owing to factors such as variation of impurity concentration or temperature gradient. These observations were employed by Petrenko for determination of crack parameters viz. velocity, width and elastic strain [60]. A simpler theory is proposed by $\mathrm{O}^{\prime}$ Keefe et al. which states that during crack propagation the charges get separated along the newly developed charged faces. The reason for this charge separation includes bond breaking, dislocation termination and piezoelectric effects. The charge separated along the two faces results in the generation of a potential difference. The charge then decays with time as the crack propagates which follows the lumped impedance transmission line model [63].

Although a concrete model has not been proposed, from the discussion it can be inferred that in case of ice the possible mechanism revolves around the crack propagation, the consequently generated surfaces and appearance of surface charges over them. In case of $\mathrm{Pb}\left(\mathrm{Zr}_{0.52} \mathrm{Ti}_{0.48}\right) \mathrm{O}_{3}$ the electric pulses are reported due to the competition between newly, stress-induced polarized state and older state maintained by opposing electric fields forming at grain boundaries. In simpler way these pulses can be understood in terms of polarization and repolarization processes induced by loading [77]. However, recent investigations of EMR from ferroelectric ceramics without subjecting them to plastic deformation (discussed in "Electrical and electromagnetic effects in ionic crystals/materials" section) have shown different phenomenon responsible for EMR emission [32, 84]. Ferroelectric materials have spontaneous polarization due to the presence of electric dipoles which can 
respond to the external loading by the change in the dipole moment and result into the well-known direct and indirect effect [254, 255]. Thus Sharma et al. have considered the time-varying dipole moment as the possible source of electromagnetic radiation signals observed in case of ferroelectrics which will be discussed hereafter.

A theoretical model considering the $180^{\circ}$ dipole oscillations as the genesis for the occurrence of electromagnetic radiation from ferroelectric ceramics under the influence of alternating electric field has been presented by Sharma et al. in 2018. Schematic diagram explaining the experiments performed and the formulation of the theoretical model is shown in Fig. 20. Equation 1 shows the charge collected due to the oscillation of one dipole.

$Q(t)=\frac{p_{0}}{2}\left(-\frac{2 \omega}{c} \sin (\omega t)+\frac{3}{r} \cos (\omega t)\right) \int_{\theta_{1}}^{\theta_{2}} \frac{[1+\cos (2 \theta)]}{2} \mathrm{~d} \theta$

As per the model the $\mathrm{BaTiO}_{3}$ (BT) sample surface and the copper loop will together form a cylindrical capacitor.

Considering the case of a cylindrical capacitor and putting the value of capacitance equals to $\frac{2 \pi \varepsilon_{0} L}{\ln (b / a)}$, voltage $V(t)$, due to the oscillation of one dipole, can be calculated as:
$V(t)=\left(\frac{\ln (b / a)}{2 \pi \varepsilon_{0} L}\right) Q(t)$

The EMR voltage from the ferroelectric sample is believed to have contributing factors like number of dipoles, extent of polarization and skin depth, where skin depth of the material has come out to be the most influencing parameter for the EMR voltage magnitude. Similar model has been used by the same group for comparing the experimental result obtained for the soft (SP 5A) and hard (SP 4) PZT when subjected to alternating electric field [256]. The experimental results have been found to be in agreement with the theoretical results.

On the other hand, in case of impact loading domain wall movement and generation of timevarying charges due to the time rate of change of dipole movement has been considered as the source of electromagnetic emissions. In case of EMR detection at low temperatures the restricted domain wall movement leading to less displacement of charges and consequent less dipole oscillation has been considered responsible for low amplitude of EMR signals. Restricted domain wall movement is in line with increase in Young's modulus at lower temperatures which has been obtained experimentally [85].

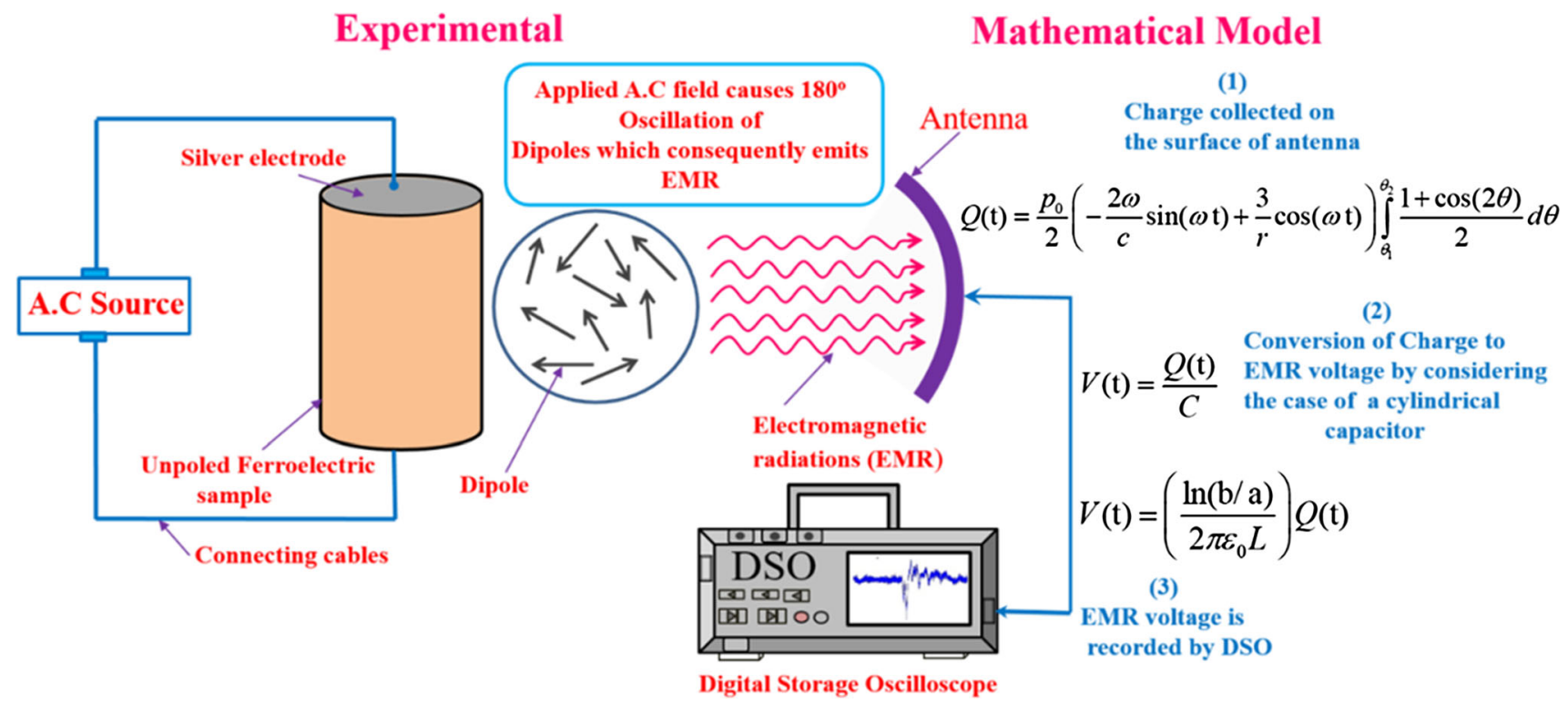

Figure 20 Overview of EMR detection from ferroelectrics when subjected to alternating electric field (used with permission from Elsevier) [289]. 


\section{Rocks, granite, coal and other brittle materials}

Electromagnetic radiation emissions from rocks have been explained using different physical models such as discharge model, capacitor model, surface oscillation model and moving charge dislocation model. Ogawa et al. in 1985 detected EMR signals from rocks by conducting different set of experiments. These electrical signals detected from granites have been discussed in terms of (i) contact or separate electrification and (ii) piezoelectricity [91]. They explained that when two types of rocks, having different work functions make contact with each other, flow of electrons occurs from the rock having lower work potential barrier to the one having higher work potential which produces a potential difference between the two rocks. In a way through contact electrification they have proposed the idea of capacitor model possibility of which was further explored by other researchers discussed hereafter. Using piezoelectricity, they explain the formation of dipole moment of the order of $3 \times 10^{9} \mathrm{Cm}$ occurring due to the charge separation which consequently emits electromagnetic radiation (EMR) [91]. The directional property of EMR from crack propagation has been explained by Krumbholz et al. using crack-related model which shows that during microcrack formation electric potentials are generated perpendicular to the crack walls and the magnetic component is produced parallel to the crack surface, whereas electromagnetic wave propagates parallel to the crack propagation direction which can be seen in Fig. 21 [160]. It is more clearly discussed below in the section describing surface oscillation model. $\mathrm{Li}$ et al. observed the increase in electric current with increase in stress on the coal samples which is due to the large number of free charges generated with increase in number of cracks due to increasing load as shown in Fig. 22. The increment of free electrical charges with increase in deformation leads to the increase in the intensity of electric current.

The electromagnetic emissions from rocks have primarily been explained in the literature with the help of the following mentioned mechanisms.

\section{Discharge model}

Finkel et al. in 1975 have described the electric discharge occurring during crack propagation as the source of electromagnetic emissions [257]. During crack propagation in the alkali halide crystal there is stochastic arrangement of negative and positive electric charges on either sides of the crack wall. The arrangement of these electric charges across the crack walls develops an electrostatic field of the potential of the order of $10^{7} \mathrm{~V} / \mathrm{cm}$. Finkel et al. at that time speculated that this much of potential in between the crack walls can lead to the electric discharge because of small separating distance between the crack walls (Fig. 23), and this electric discharge may lead to the electromagnetic emissions. However, Miroshnichenko and Kuksenko [258] noted that spectrum of discharge radiation has much resemblance with that of 'white noise' [259] and is independent of mechanical properties of materials, whereas the EMR signals do not have these features. Rabinovitch et al. $[97,260,261]$ through their experiments observed that the EMR signals are dependent on fracture which can occur in different ways for different types of materials and is also dependent on elastic properties of the materials. Their analysis of the EMR signal shapes and frequencies reveals that it does not have any resemblance with that of 'white noise' and EMR

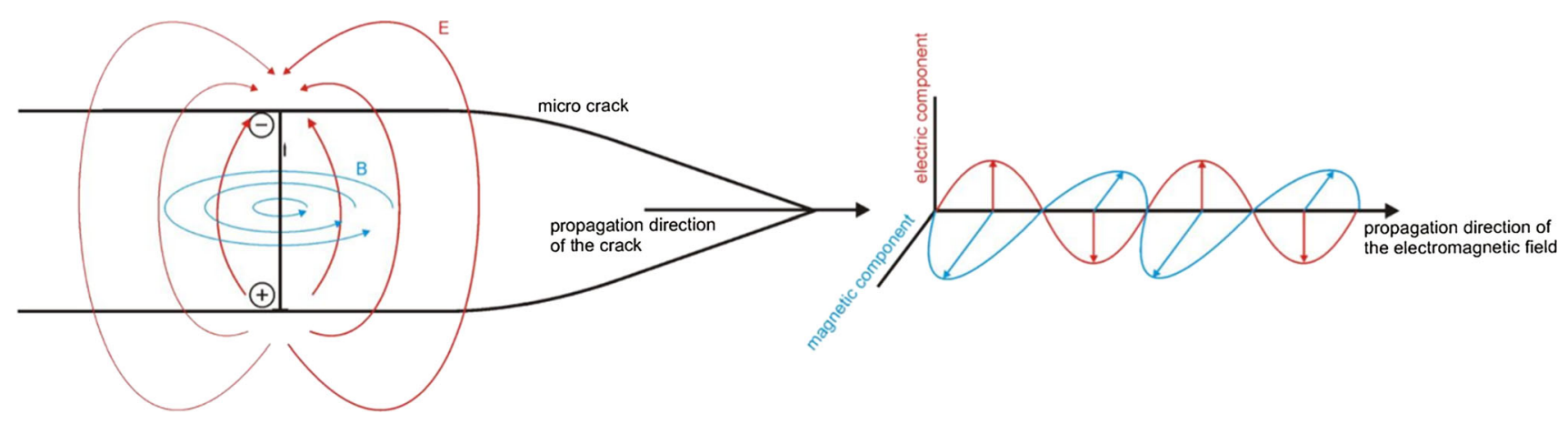

Figure 21 Polarization of microcrack associated with electromagnetic emissions [160]. 
Figure 22 Distribution of free charges during (a) elastic deformation and (b) elasticplastic deformation [141].

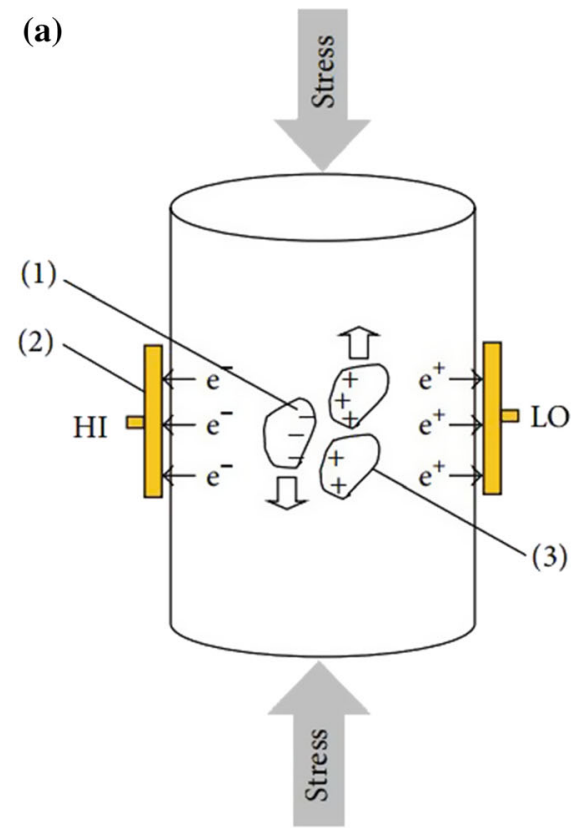

$\begin{array}{ll}\text { (1) Electrons } & \text { (3) Mineral grains } \\ \text { (2) Copper electrode } & \text { (4) Crack }\end{array}$ (b)

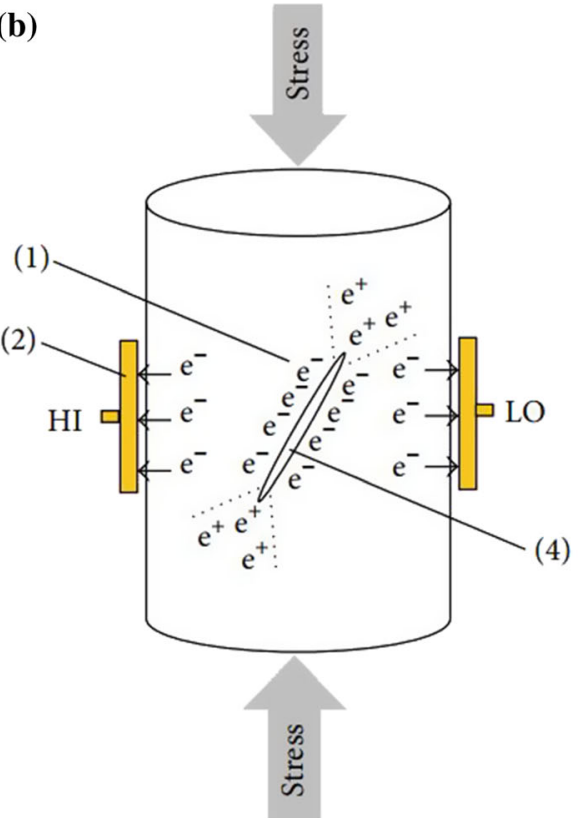
(1) Electrons
(3) Mineral grains
(2) Copper electrode
(4) Crack

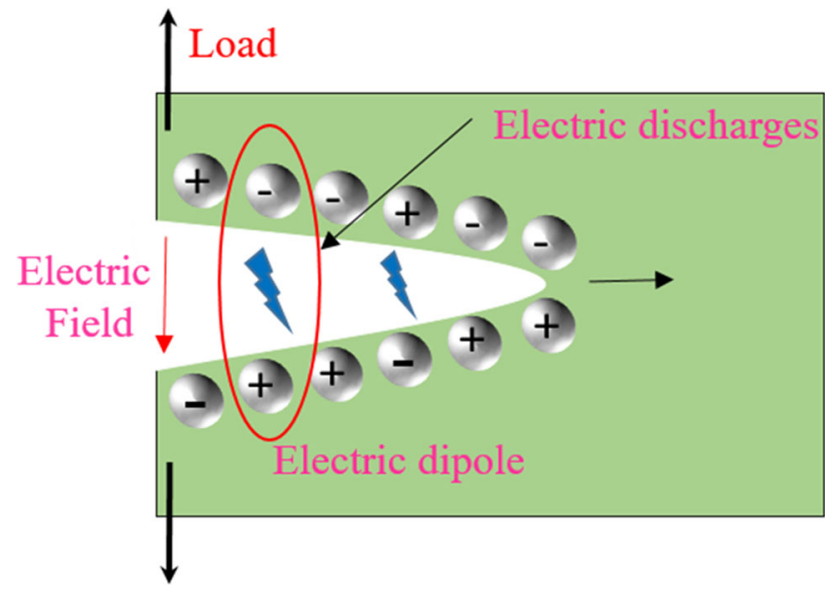

Figure 23 Discharge model describing electromagnetic emissions [13].

signal spectrum is much concentrated about single. Considering this the discharge model was not able to gain popularity and was not much talked about in the researchers' community dealing with findings of electromagnetic emissions from rocks and other brittle materials.

\section{Capacitor model}

Another model is the capacitor model, which considers some of the ideas of Finkel et al. and experimental results of Miroshnichenko et al. $[257,258]$. Idea of the presence of electric charges on the either side of the propagating crack wall was also proposed by O'Keefe and Thiel [7]. This is schematically shown in Fig. 24. During the crack propagation the crack walls act as the plates of a parallel plate capacitor. As the crack propagates the distance between the walls increases which decreases the

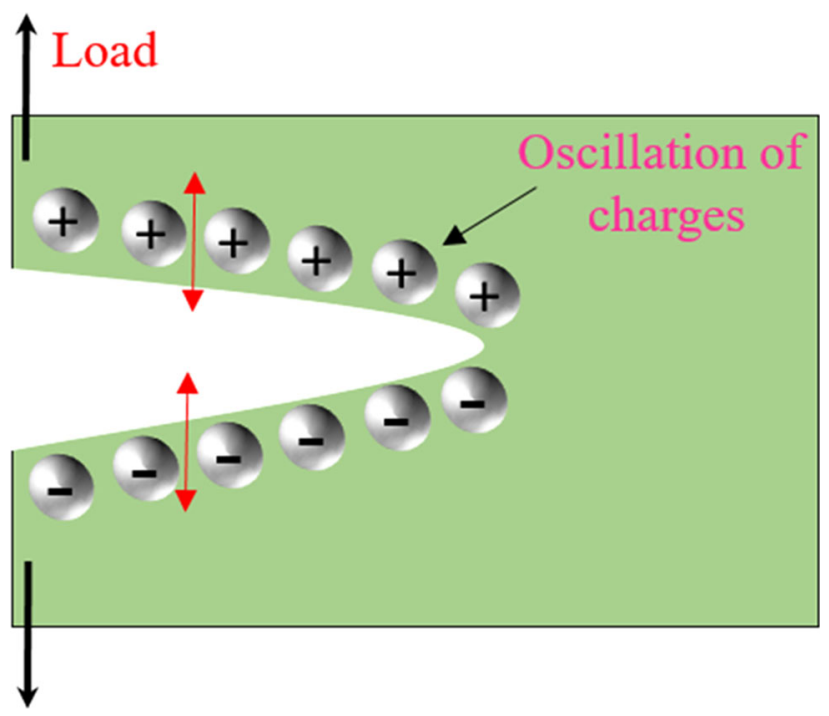

Figure 24 Capacitor model for the electromagnetic emissions [13]. 
capacitance and increases the voltage due to the presence of electric field between the walls. However, this increase in potential is limited up to a slight increase in separation distance $(\sim 10 \AA)$ and it reduces afterwards. The reduction in EMR signal amplitude obtained during the experiments is supported by the capacitor model [91]. Consideration of the electrical charge formation on the crack walls leads to the breakage of electrical symmetry which was the main argument against this model which was discussed by Sause [13], and phenomenon such as pre-polarization of the material, pseudo-piezoelectricity, temperature gradients, deformation gradients or impurity concentration gradients has been proposed to support the argument of electrical symmetry [262]. Inhomogeneous elastic strains around the crack walls and contact (or separating) electrification are also considered reasons for the appearance of electric charges on the crack walls [252]. However, Frid et al. raised question about the applicability of this model in case of shear cracks. According to Frid et al. relative movement of charges along the crack propagation direction will not produce EME signals of similar strength as obtained in case of tensile loading. Also the absence of EME signals under simultaneous occurrence of $\mathrm{AE}$ (acoustic emission) signals and vice versa was not justified by using capacitor model $[13,263]$.

\section{Surface oscillation model}

Based on the inconsistencies of previous models Rabinovitch et al. in 2006 proposed a model known as surface oscillation model which incorporates the following arguments for maintaining its wide applicability [264] (Fig. 25).

1. The model proposed should be invariant to the changes in loading conditions and the material used.

2. No preferred crack side should obtain a specific charge; thus, it has to follow the symmetry rule to maintain the charge neutrality.

3. It should be able to give information about the crack parameters associated with the failure.

4. It has to describe the shape of EMR signals in a way which is independent of the scale of the fractures inducing them.

They considered the idea of relation between the crack length and generated EME signals reported in

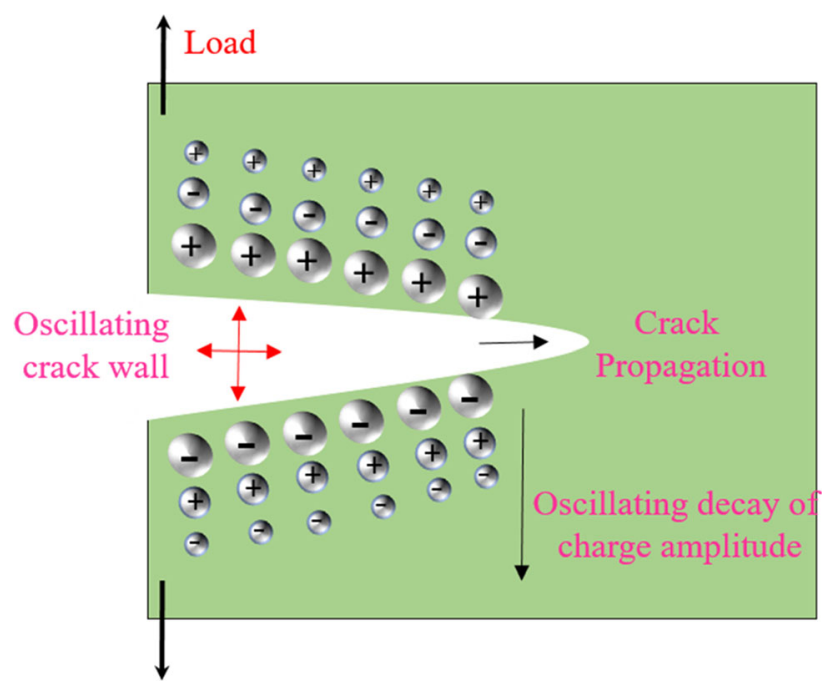

Figure 25 Surface oscillation model for electromagnetic radiation emissions [13].

literature as well as the crack arrest phenomenon which has also shown relation with the decreasing amplitude of signals. From these they concluded that progression of crack tip is responsible for the newly generated surface charges [13]. During fracture the rupture of atomic bonds forms electric charges which get disturbed from their equilibrium position. The positive charges move in unison in one direction, while the negative charges move in opposite direction maintaining the electric charge neutrality and forming the surface vibrational wave whose amplitude follows the exponentially decaying pattern into the bulk material. The decaying pattern of the surface oscillation waves is dependent on the electrical conductivity of the material. Rabinovitch et al. have compared the experimental results with the theoretical model and found them to be in line as shown in Fig. 26 [264]. Other than this Rabinovitch et al. have also focussed on the directionality of the fracture-induced electromagnetic radiation emission considering their importance for the tectonic analyses in structural geology and geo-engineering planning. The EMR was found containing both electrical and magnetic components at distances larger than the crack dimensions, and these fields are found to be dependent on the oscillating frequency of dipole as well as the dipole moment [265]. This model does not have any counter arguments by the researchers' community so far. 


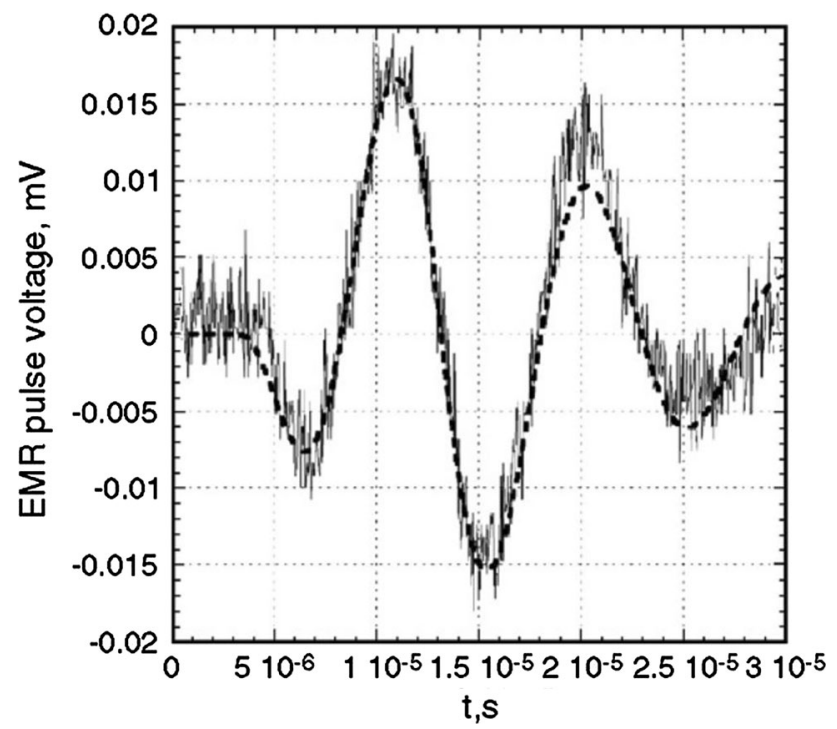

Figure 26 An experimental EMR pulse (full line) and its numerical fit (dashed line) (used with permission from Elsevier) [264].

\section{Moving charged dislocations (MCD) model}

One of the several theories to explain the electric current generated in the brittle materials is the moving charged dislocations model (MCD) which was firstly proposed by Vallianatos and Tzanis in 1998 [266]. According to this model movement of arrays of charged edge dislocations during the microfracture of the material leads to the electric current density. The MCD model also explains the relationship between the current density and the strain rate. Before the fracture, stress and strain increase due to which microfracture begins with large number of propagating cracks. These microcracks increase the number of dislocations as well as formation of charge carriers which consequently give rise to electric current. According to the model proposed the motion of dislocations occurs parallel to the applied shear stress. Figure 27 shows the schematic of the charge formation on the tip of dislocation. This allows for the generation of a dipole electric field, parallel to the slip vector of the moving dislocations, hence quasi-parallel to the slip vector of shear cracks and to the slip vector of the upcoming fracture [267]. Charkina and Chisko have also worked on the theoretical formulation of the electromagnetic emissions from mobile edge dislocations in case of ionic crystals. This model was completely theoretical and was not supported by experimental results [268].

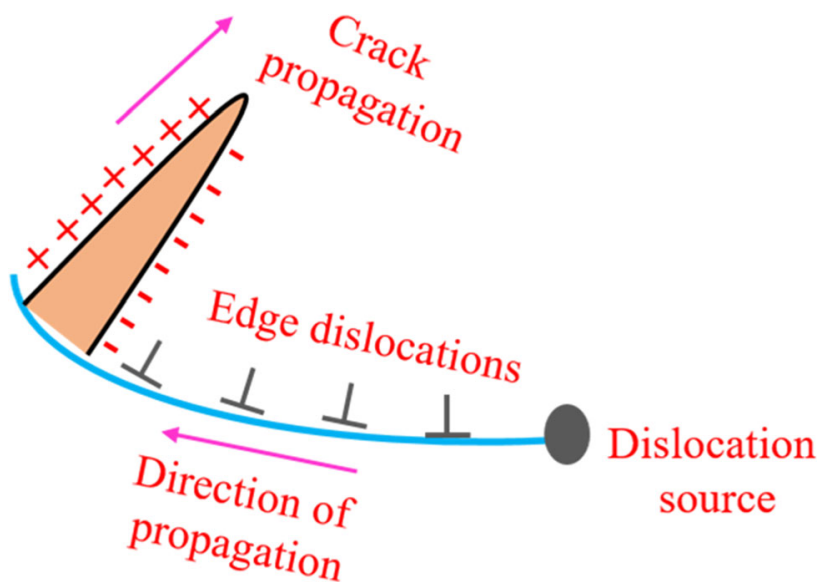

Figure 27 Crack generation and propagation (Mode I) at the tip of dislocation array [267].

However, it was proposed that for obtaining electromagnetic signals of sufficient strength simultaneous and coherent excitation of large no. of dislocations is required. Teisseyre and Ernst have also done the theoretical formulation of electromagnetic radiation emission from pre-seismic events considering the dislocation dynamics [269]. These experiments lack in thorough experimental validations. Moreover, brittle materials are known to have few mobile dislocation densities [259] which is somewhat difficult to estimate in case of brittle materials (e.g. glass and most geological materials) except for laboratory studies. Frid et al. have observed that EMR signals increase with increase in the brittle behaviour and decrease during transition from brittle to ductile behaviour which has revealed the weakness of the model [259]. Thus this establishes a need to understand the dislocation dynamics in case of brittle materials and thorough experimental as well as theoretical investigations are required in order to have wide applicability of this model.

\section{Metals and alloys}

Misra and group have performed an extensive research on the electromagnetic radiation response of metals and alloys and were the first to discuss the genesis of EMR emissions from metals. Srilakshmi and Misra based on the experimental observations of EMR emission from metals during plastic deformation proposed that there can be different combinations of possible interactions between dislocation, solute and electrons which can be dislocation-dislocation, dislocation-solute, dislocation-electron, 
electron-electron interactions or any combination involving one or more of these. Srilakshmi and Misra in 2005 and Misra in 1978 used the dislocation-electron interactions as the possible source for the electromagnetic emissions and have confirmed this approach through a series of experiments [178, 270]. When a dislocation moves through sudden changes of high and low energy positions due to the crystal lattice arrangement; then, sometimes it gets trapped and needs external force to make any further movement. Due to the trapping of the dislocation the conduction electrons associated with the dislocation also come to rest. This sudden stop of these conduction electrons suffer from Bremsstrahlung effect which leads to EMR emissions. Based on the discussed model the frequencies of the EMR signals have been calculated and found to be in line with experimental results [270]. A schematic diagram of the model has been provided and discussed by Sause et al., and schematic of the same is shown in Fig. 28 [13]. A dislocation mechanism for this EMR emission was also proposed by Molotskii in 1980 which stated that rather than the acceleration of conduction electrons the cause of EMR emissions is due to the increase in the total dislocation length and transient velocity during different stages of deformation. Molotskii considered that during plastic deformation the formation of dislocations, multiplication of dislocations (increasing the dislocation density) and interactions between dislocations become significantly enhanced. Acceleration of dislocations and formation of linear dipoles due to the conduction electrons associated with the dislocation have been considered as the source of EMR. Considering the line dipole formed due to the conduction electrons he showed that during plastic deformation there is a change in the length of dislocation line which changes the dipole moment and consequently emits electromagnetic radiation (EMR) [168].

On the other hand, Tudik and Valuev argued that during plastic deformation and fracture of metals there is breakage of atomic bonds which leads the electrons to excited states. When these excited electrons come to the relaxed/ground state, it is accompanied by the electromagnetic emissions [173]. The resulting electromagnetic emission has the frequency spectrum equivalent to the binding energy of the atoms, whereas during further investigation, the experimental results of Misra and Kumar in 2004 show that the maximum amplitude of EMR signals has a linear variation with the bond energy, while the dominant frequency of EMR shows a parabolic variation with respect to the bond energy of the metals [182]. Perelman and Khatiashivili considered the breaking of the interatomic bonds during fracture which, they argued, leads to the fluctuation of charges arising on the fracture surfaces leading to the electromagnetic radiation having the frequency range

Figure 28 Dislocation model for electromagnetic radiation detection [13].

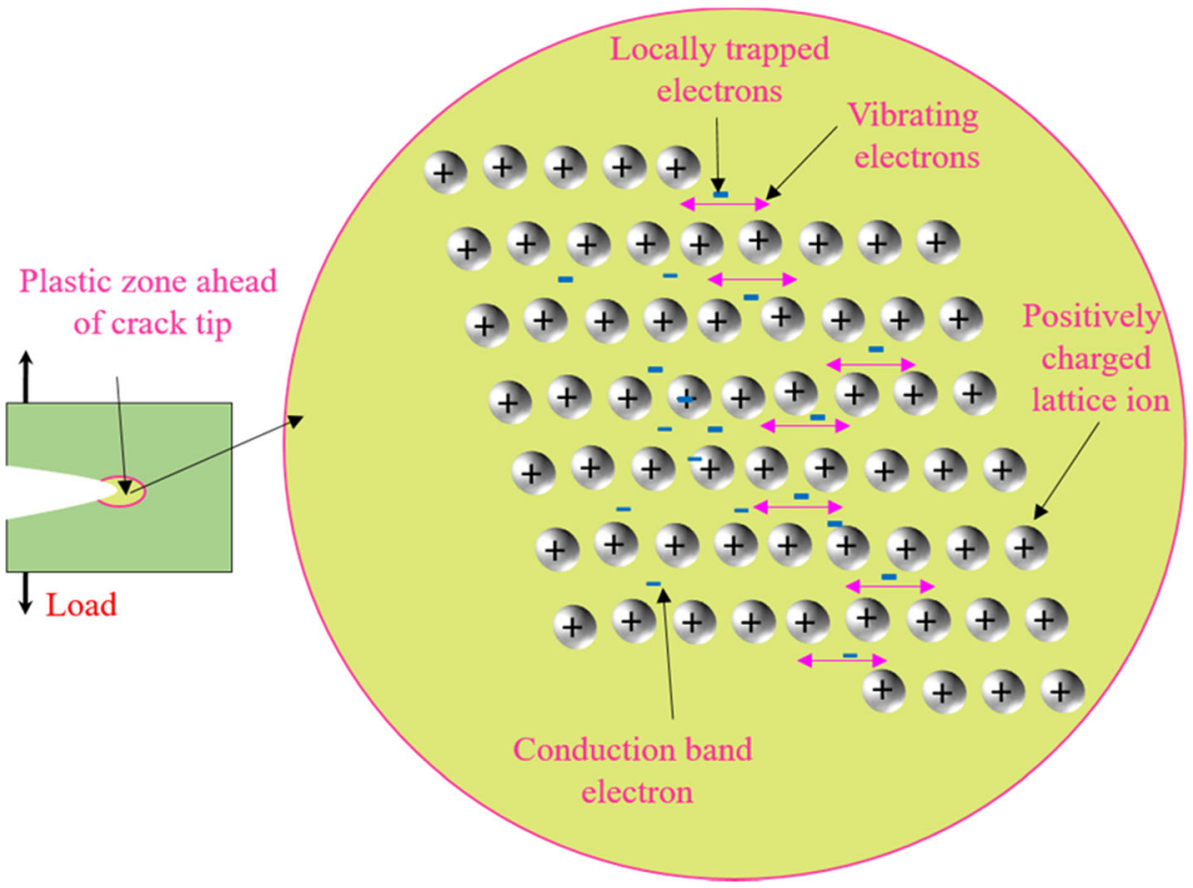


of $1-10^{3} \mathrm{MHz}$ region [271]. Another physical model was proposed by Misra and Ghosh in 1980 to explain the higher frequency of EMR emission [272]. The model proposed uses the laws of classical electrodynamics and particle model of solid-state plasma. Quantitative results were obtained by assuming the independent particle model of solid-state plasma. The theoretical results were verified with the experimental ones where parabolic variation of the EMR rms amplitude was obtained with the angular Debye frequency of the metals [272].

Earlier results have focused on the movement of edge dislocations which is a quite generalized phenomenon observed in case of ductile materials. However, experimental investigations of Jagasivamani and Iyer on heat-treated spring steel have shown that EMR signals of reasonable amplitude have been obtained in case of brittle materials and the EMR amplitude is found to increase with the brittleness of the material under investigation. They attributed the observed EMR signals to the sudden deceleration of the accelerated dislocations during crack propagation. They also found that various parameters like breaking stress, mode of fracture, grain size, crystal structure, texture and temperature also affect the observed EMR emissions [175].

Misra et al. in 2007 have proposed theoretical model for the EMR emission during plastic deformation and crack propagation in metallic materials which states that edge dislocations within the plastic zone surrounding the crack tip form accelerated electric line dipoles which gives rise to EMR emissions. Vibrations of dislocations pinned at their ends have been considered responsible for the EMR during deformation. Using the model in terms of vibrating dislocation by taking into consideration the mass per unit length of the dislocation, viscous damping during motion and line tension on dislocation EMR characteristics have been obtained. Also it has been shown that the model presented by Molotskii is a special case of their model [169]. Further Misra et al. in 2010 have developed a theoretical model which takes into account the effect of Peierls' stress on the EMR emission during yielding of materials [170]. Peierls' stress plays significant role in case of metals/alloys with body-centred cubic structure. This has been proposed as a technique for the effective evaluation of the Peierls' stress in metals. Kothari et al. have proposed extended theoretical models to predict the nature and amplitude of EMR from metals and alloys during progressive plastic deformation. Effect of Peierls' stress and strainhardening parameters was incorporated in the theoretical models for materials with large Peierls' stress $[273,274]$. Alekseev et al. in 1984 proposed the theory of electromagnetic effects accompanying the dynamic deformation of metals. They presented analytical equations which relates the electric field intensity to the current density in metal undergoing deformation. The equations for the current density are then again used to analyse the electromagnetic effects in metals when subjected to impact loading [176]. Burak et al. in 1985 presented the possible mechanisms of electromagnetic emission in the process involving formation of discontinuities in metals. Thus, discontinuities in the metals have been considered as the possible source of the EMR emission [275].

From the above discussion, it is obvious that the phenomenon of the electromagnetic radiation is important for understanding the physics of plastic deformation, crack propagation and fracture. However, further investigations are necessary for bringing out a significant and comprehensive picture.

\section{Polymeric and composite materials}

Polymeric materials are reported for the electromagnetic emission when subjected to plastic deformation. The genesis of these electromagnetic emissions in case of polymeric materials generally revolves around the phenomenon of the microcracking involving crack initiation and propagation. However, there are only few reports available which have mostly focussed on discussing the cause of these emission which are being discussed here. Vorob'ev in 1977 considered the crack formation and propagation as the main source of electromagnetic radiation (EMR) emission. During crack propagation the electric charges generated also move and generate electromagnetic field. The development of high electric charge density during crack formation may lead to electric discharge causing EMR emission. He also suggested that non-uniform heating of the dielectrics is also accompanied by crack growth which also generates electromagnetic emissions [276].

Dickinson et al. have tested different ceramic samples for the related fractoemissions. They interpreted their results in terms of a conceptual model involving the following steps: (i) fracture leading to charge separation, (ii) desorption of gases from 
material into the crack tip, (iii) a gas discharge in the crack, (iv) energetic bombardment of the freshly created crack walls and (v) thermally stimulated electron emission accompanied by electron-stimulated desorption of ions and excited neutrals [277-279]. Momose and Noguchi in 1984 have presented the measurements of electron emission during frictional contact between metals and polymers [280]. Nakahara et al. in 1988 reported electron emission from epoxy-based composites at cryogenic temperatures [281]. Koktavy has performed experimental investigation of EMR emissions from glass-fibrepolyester-based composite materials where electromagnetic emissions have been detected during the crack propagation. Following conclusions have been drawn from the observed electromagnetic emissions which can be used to predict the genesis of these EM emission [282].

(a) Crack formation leads to the change in the dipole moment at the crack location.

(b) Charges developed at the capacitance sensor during crack formation are sufficient for the generation of significant EMR amplitude and sufficient measureable EMR voltage.

(c) The parameters of the signal such as magnitude and time duration are dependent on the velocity of crack face propagation.

(d) Capacitance sensor is effective for the study of behaviour of material towards crack development.

(e) High EME signal amplitude in composite materials is due to the bond breakage at the reinforcement of binder and fibre.

The influences of the orientation and the distance of the crack surface on the detectable EME signals obtained during the three-point flexure tests on epoxy resin specimens have been investigated by Gade et al. using a capacitive sensor for EME. Electric field generated due to the time-dependent surface charge on the cracked surface has been considered as the source of EME [201]. Gade et al. showed that there are three contributions to the EME signal detected, viz. (i) charge separation resulting from crack growth, (ii) charge relaxation resulting from conductivity of the material which leads to the damped nature of the signals and (iii) oscillation of charges due to the vibration of the crack walls. During modelling they have considered all of these aspects and evaluated the experimentally obtained signal with the computed charge densities in the respective cases. Detection of photon emissions from glass nanofilaments embedded in the epoxy matrix showed that if the interfacial bond is weak, then at fibre fracture, the resulting interfacial debonding and subsequent motion of the fibre relative to the resin matrix yield easily measured photon emissions. Further increase in the deformation builds up the stress in the remaining fibre lengths leading to fracture and the process is again repeated [198]. Gade et al. have also considered the formation of dipoles on the surface of crack as the possible source of electromagnetic emissions and have modelled the electromagnetic source as electrical dipole like sources [199].

Thus from the above discussion it can be concluded that the electromagnetic emissions from the polymeric materials are due to the microcrack propagation, occurring due to the increase in the plastic deformation in the polymeric materials, and there are no signals during elastic deformation. These microcracks develop charges on the crack walls which form dipoles, and their oscillations and movements emit electromagnetic radiation.

\section{Cement-based materials}

Generation of weak electric current signals from brittle materials such as rocks known as pressurestimulated current (PSC) signals is reported to have genesis in the charge separation and polarization. PSC technique is also being used in case of cementbased materials for detecting signals [225, 229, 230]. During the observation of electrical signals from cement paste under compressive loading electrical double-layer formation and motion of ions have been discussed as the possible cause of the observed electromagnetic emissions [233, 283]. The formation of electric double layer and accumulation of opposite charges is explained by Sharma et al. schematically in Fig. 29. During experimental study involving bending of cement paste specimens F.H Whittman observed a direct proportionality between the applied load and the voltage recorded [223]. The genesis of the measured voltage has been attributed to the moisture content contained in the cement bar. The converse phenomenon was also observed by him in which he managed to bend the bar with the applied voltage. The phenomenon of electric charge movement through the liquid region is known as 
Figure 29 a Charge acceleration and (b) dipole oscillation model for EMR emission from cement-based materials (used with permission from Taylor and Francis) [290].

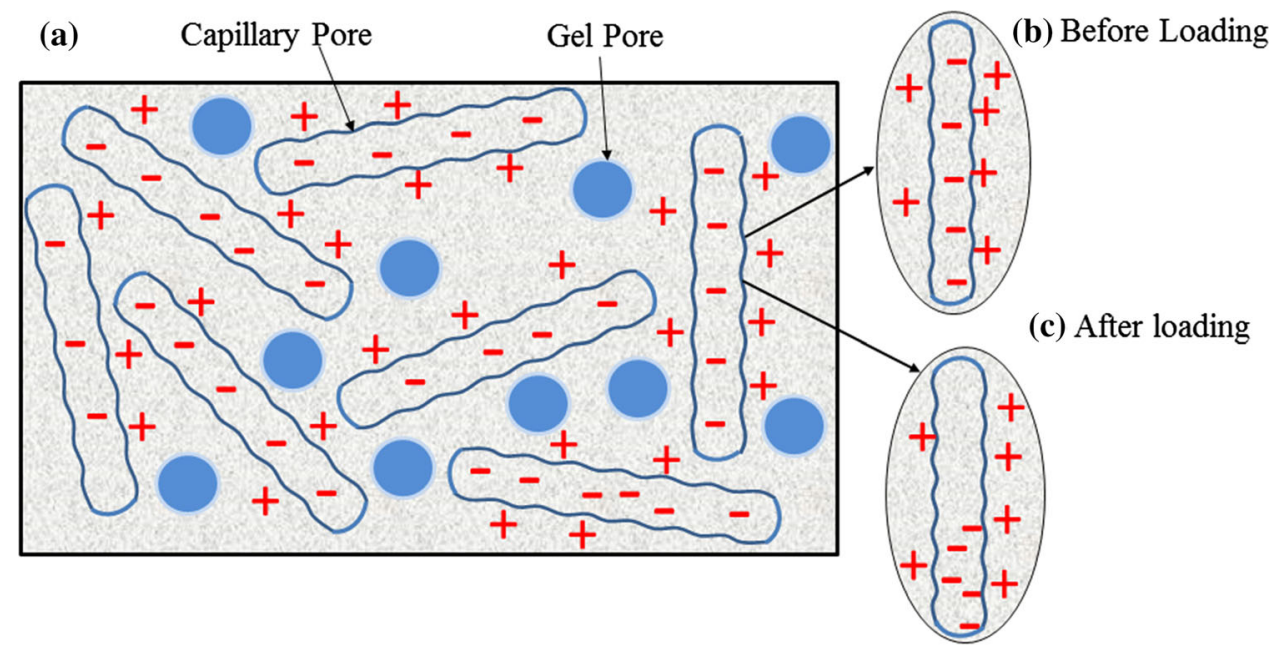

(d)

(e)

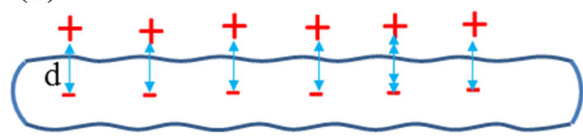

$\frac{t_{2}+t_{2}+t_{1}}{\mathrm{~d}_{1} t_{1}}$ electro-osmosis [223]. In case of cement-based materials electrical double layer, motion of ions in the pores of cement and crack propagation involving charge separation have been discussed in the majority of the reportings for the electrical emissions from cement-based materials [223, 235, 284, 285].

In the experimental investigations $\mathrm{Li}$ et al. observed the large field-induced shape changes in the hardened cement pastes. The observed electromechanical phenomenon in cement paste samples was found to be dependent on measurement frequency, dc electrical bias and last but not the least the presence of moisture. Interestingly the shape change due to the applied electrical bias was observed for the samples which contained moisture and was not observed in case of dry samples. Its genesis was discussed due to the long-range water motion as well as electro-osmotic-induced swelling of the pores under electrical field involving both weak and strong ac and dc bias [228]. Mingqing Sun and co-workers have also reported electrical emissions from cement under repeated compressive loading (maximum load of $10 \mathrm{MPa}$ ). They showed that there is an increase in electrical current with increase in stress and amplitude of current drops as the specimen approaches failure which is due to the wide opening of cracks [283]. Sun et al. discussed the movement of electrical double layer and consequent motion of ions as the cause of electrical emissions [233, 283].

Dipole Oscillation Model

Moving charge dislocation model [discussed in "Rocks, granite, coal and other brittle materials" section (iv)] and the pressure-stimulated currents (PSC) have been compared by Kyriazopoulos et al. Due to the presence of different mechanical imperfections when the material is subjected to loads, then neutrality of the defect cannot be maintained and there is generation of electric dipoles leading to net nonzero polarization. Net electrical polarization in the material is the result of a net excess of charged dislocations which are produced due to the mechanical deformation. Further it is well-known fact that motion of electric charges generates electric current; thus, electric current emissions can be expected during the application of mechanical loading on a sample. According to this moving charged dislocations (MCD) model, the pressure-stimulated electrical currents (PSC $(t)$ ) are related to the strain rate as per the following mentioned equation [230]:

$\operatorname{PSC}(t) \alpha \frac{\mathrm{d} \varepsilon}{\mathrm{d} t}$, where $\frac{\mathrm{d} \varepsilon}{\mathrm{d} t}$ is the strain rate.

The MCD model and the PSC have been highlighted for their potential in monitoring the stress state of the cement paste in a non-destructive test $[229,230]$.

Based on the motion of ions (such as $\mathrm{Ca}^{2+}, \mathrm{Mg}^{2+}$ $\mathrm{Na}^{+}, \mathrm{K}^{+}, \mathrm{OH}^{-}$) [286] in the pores of the hydrated cement paste Kumar et al. 2019 presented two 
hypotheses for the observed EMR emissions, schematically shown in Fig. 29 [237].

\section{Acceleration of ions}

First hypothesis involves the acceleration of ions in the pores of the hydrated cement paste. Figure 29a shows the portion of hydrated cement paste containing ions inside it, whereas parts (b) and (c) show the before and after loading configurations. Impact loading allows the movement of ions as the water moves inside the microchannels as shown in Fig. 29c. This motion of the ions in the microchannels will involve acceleration which consequently gives rise to EMR [255].

\section{Dipole oscillations}

The second possible hypothesis of EMR emission from cement paste revolves around the dipole formation and oscillation as shown in parts (d) and (e) of Fig. 29. Due to the phenomenon of electric doublelayer formation oppositely charged ions get lined up in the liquid region inside capillary pores along the solid region adjacent to them [223, 235, 284, 285] as can be seen in Fig. 29d. These oppositely charged ions (Fig. 29e) constitute electric dipoles. During load application (here in case of impact loading) there is a movement of the mobile ions present in the pore solution due to which there is a cyclic variation of distance for a short interval of time which results in time-varying dipole moment and hence dipole oscillation. Since the oscillations of dipoles result in EMR [255], it is expected that the oscillations of the dipoles induced due to the applied impact loading cause the EMR observed in the experiments.

Based on these experiments the same group has proposed an analytical model which explains the EMR emissions from the time-varying dipole movement [241]. Accumulation of electric charges on the surfaces of the capillary pores is shown in Fig. 30 . The following final equations have been derived which will show the EMR voltage obtained during impact loading.

Charge collected on the copper antenna is:

$$
\begin{aligned}
Q= & \int_{\theta_{1}}^{\theta_{2}} \frac{\mu_{0} \varepsilon_{0}}{4 \pi r}\left[\left\{\ddot{p}\left(t_{0}\right) \sin \theta \cos \theta\right\}+\frac{c_{0}}{r}\left\{3 \dot{p}\left(t_{0}\right) \sin \theta \cos \theta\right\}\right] \\
& \left\{2 \pi r^{2} \cot \theta \mathrm{d} \theta\right\}
\end{aligned}
$$

EMR voltage can be obtained by considering the case of cylindrical capacitor formed due to the sample and the antenna as shown below:

$V=\frac{\ln (b / a)}{2 \pi \varepsilon l} Q$

where $a, b$ and $l$ are the inner radius, outer radius and length of the cylindrical capacitor.

Here Eq. 3 represents the charge collected over the antenna which has been converted into the measurable voltage by considering the case of cylindrical capacitor. The experimentally obtained EMR signals and theoretically calculated ones show the same damped oscillating nature [287]. Later cement$\mathrm{BaTiO}_{3}$ (cement-BT) composites have been explored for the EMR detection. In the experimental investigations the BT content was varied from 5 to $40 \%$. The favourable variations in the piezoelectric properties and the increment in the number of dipoles due to the increase in the BT content are the possible reasons for increase in EMR signal amplitude with increase in BT content [238]. Similar theoretical model has also been used by Sharma et al. in case of EMR signals detected from cubical mortar samples under impact loading [288].

Thus the above discussion reveals that the cement and cement-based materials also exhibit electromagnetic emission when deformed and are the potential candidates to be used as a sensor themselves eliminating the use of external sensors on cement-based structures. In this way cement-based infrastructure can serve the purpose of load bearing which is the primary purpose as well as can tell the stress state and state of deformation through the study of these electromagnetic signals. Summary of the various types of electromagnetic emissions observed in different materials is shown in Table 1.

\section{Future research lines and challenges}

As we have seen, a variety of materials are capable of generating electromagnetic emissions and these can be correlated with the state of stress of the material or 
(a)

(b)

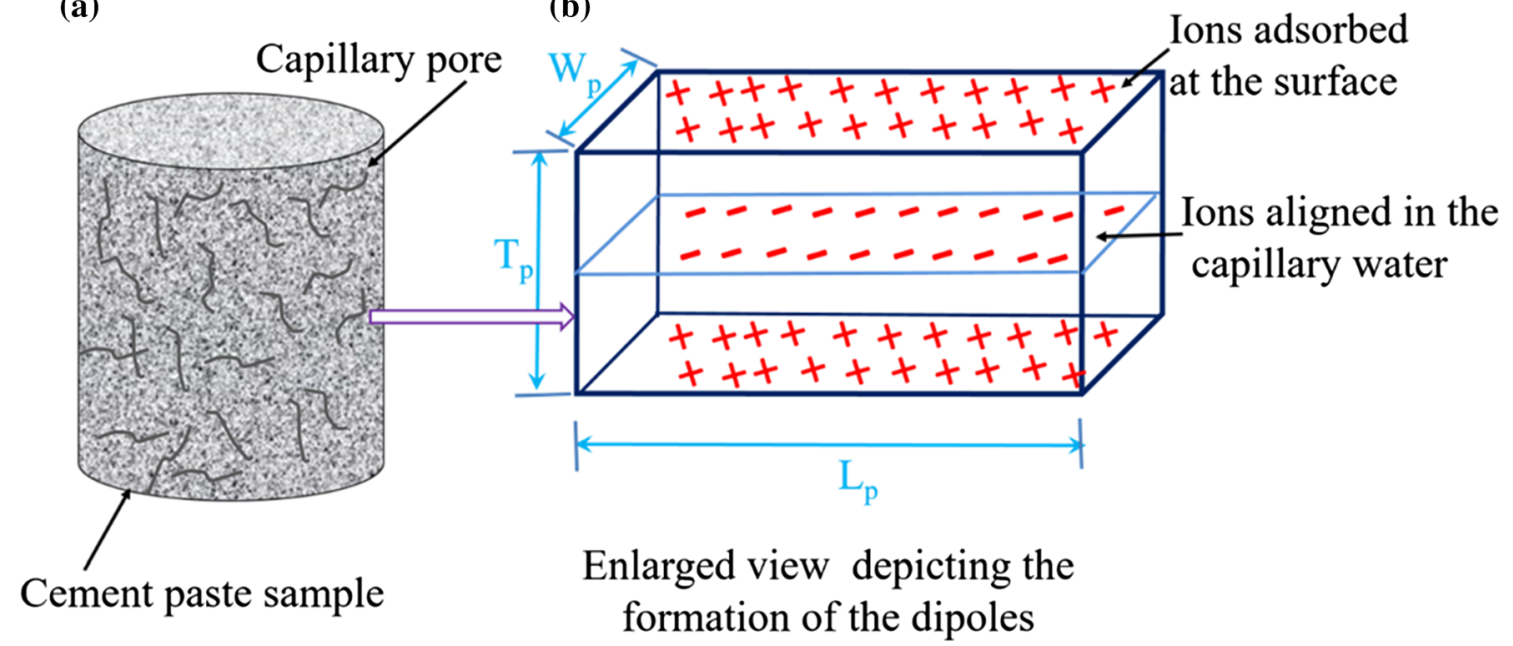

Figure 30 Schematic diagram depicting the ions in the capillary pores and the solid phase of hydrated cement paste [287].

to know about the dynamics of fracture. Still in the twenty-first century we are facing some challenges in terms of precursors, mechanisms, measurement/detection technique and its real-time application. Till now lack of standard methods pertaining to this technique makes it difficult to put it in real practical applications (despite some successful laboratory experiments) in comparison with other well-established techniques such as digital image correlation, ultrasonic testing [13]. Thus this technique demands more rigorous research and development of standard methods for its wide applicability. Thus, the ultimate pursuit is to improve the level of this non-destructive technique and achieve a successful prediction of disasters beforehand. From authors point of view some crucial points which should be considered to make timely progress in this area of research in order to use this technique in solving real-time problems of failure are mentioned below.

\section{Mechanism and precursors of EMR}

Though wide variety of materials have been explored regarding the electromagnetic emissions during plastic deformation, crack propagation or failure still a lot of work needs to be done to investigate the physical mechanisms involved in electromagnetic emissions from different materials. Based on experiments performed for different sets of materials different mechanisms have been proposed which in majority of the cases are applicable on a particular class of materials. Still there is no proper unified theory, but only thing which can be correlated with all the proposed theories is that acceleration of charges (stimulated by different factors) is a common precursor to the occurrence of EMR from any material. Interestingly a wide variety of materials show that their failure in general involves the acceleration of charges although the physical situation leading to the acceleration of charges is different in different classes of materials. Thus unification of possible precursors as well as the mechanisms for different classes of materials should be done. Moreover, amplitude and frequency of the electromagnetic signals are the important parameters. Out of the two frequency of the signals is the more important parameter which can be filtered from the noise signals and can be used to know about the current state of the material.

\section{Devices and techniques for measuring EMR}

To utilize this technique up to its greatest potential, devices for detecting low-amplitude signals are really an open area to be worked upon. The EME sensors are susceptible to all incident electromagnetic radiation, no matter whether it is from EME source or not. In laboratory experiments this problem can be solved up to some extent with the use of shielding, but for outdoor and real-time applications we need to think of some other solutions. Increasing the signal-to-noise ratio and source to sensor distance is some basic and important factors to be looked upon. With respect to the device development, signals' filtering in terms of their frequency components to give real-time information is also an important factor which should be 
Table 1 Electromagnetic emissions and their related properties observed in case of various types of materials [electromagnetic radiation (EMR); electromagnetic emissions (EME); PSC (pressure-stimulated current)]

\begin{tabular}{|c|c|c|c|c|c|}
\hline Material & Loading type & Signal observed & Signal amplitude & $\begin{array}{l}\text { Signal } \\
\text { frequency }\end{array}$ & References \\
\hline Ionic crystals $\left(\mathrm{MgO}, \mathrm{MgF}_{2}\right)$ & Three-point bending & Fractoemissions & - & - & {$[79,80,291]$} \\
\hline Ice & Scouring & EME & $0-400 \mathrm{mV}$ & - & [63] \\
\hline Ice & Uniaxial compression & EME & 4-70 mV & - & {$[60,292]$} \\
\hline Ice and Snow & Friction & Electric fields & $\begin{array}{l}\text { Up to } 2 \times 10^{6} \mathrm{~V} / \\
\mathrm{m} \text {, Potential of } \\
1.6 \mathrm{kV}\end{array}$ & - & {$[28]$} \\
\hline Ice & Uniaxial compression & Fractoemissions & $\begin{array}{l}\text { Up to } 100,000 \\
\text { counts }\end{array}$ & - & [293] \\
\hline Sodium silicate glasses & Bending & $\begin{array}{l}\text { Fractoemissions } \\
\text { and electric } \\
\text { current }\end{array}$ & 0-900 nA & - & {$[294]$} \\
\hline Ceramics & $\begin{array}{l}\text { Impact loading, quasi-static } \\
\text { loading and three-point } \\
\text { bending }\end{array}$ & Fractoemissions & - & - & {$[76,83]$} \\
\hline Ceramic (PZT) & $\begin{array}{l}\text { Compressive loading and } \\
\text { shock loading }\end{array}$ & $\begin{array}{l}\text { Electromagnetic } \\
\text { emissions }\end{array}$ & $0.5-4 \mathrm{~V}$ & - & {$[77,78]$} \\
\hline Rocks & $\begin{array}{l}\text { Uniaxial compression up to } \\
\text { failure }\end{array}$ & EME & - & $0.8-12 \mathrm{kHz}$ & {$[104]$} \\
\hline Rocks & Compression & $\begin{array}{l}\text { Electric field } \\
\text { intensity }\end{array}$ & $60-85 \mathrm{~dB} \mu \mathrm{V} / \mathrm{m}$ & - & [103] \\
\hline Rocks & Compression & EMR & $0.2-2 \mathrm{mV}$ & - & {$[264]$} \\
\hline Rocks & Impact loading and bending & EMR & $0.5-5 \mathrm{mV}$ & $\begin{array}{l}10 \mathrm{~Hz}- \\
100 \mathrm{kHz}\end{array}$ & [91] \\
\hline Coal and rock & Compression & Electric current & $8-600 \mathrm{nA}$ & - & {$[141]$} \\
\hline Rocks & Uniaxial compression & PSC & In $\mathrm{pA}$ & & {$[105,226]$} \\
\hline Rock (luserna granite) & Compression & $\begin{array}{l}\text { EME (electrical and } \\
\text { magnetic } \\
\text { components) }\end{array}$ & - & $\begin{array}{c}160 \mathrm{kHz}- \\
5 \mathrm{MHz}\end{array}$ & {$[295]$} \\
\hline Rocks (carbonate rocks) & $\begin{array}{l}\text { Compression drilling and } \\
\text { blasting }\end{array}$ & EMR & In $\mathrm{mV}$ & $\begin{array}{l}5 \mathrm{kHz}- \\
25 \mathrm{MHz}\end{array}$ & [296] \\
\hline Rock (marble) & Compression & Neutron emissions & - & - & [297] \\
\hline Brittle materials & Indentation & Fractoemissions & - & - & [298] \\
\hline $\begin{array}{l}\text { Brittle materials (concrete, } \\
\text { syracuse limestone and Carrara } \\
\text { marble, etc.) }\end{array}$ & Compression up to failure & $\begin{array}{l}\text { EME (magnetic } \\
\text { component) }\end{array}$ & $1-2 \mu \mathrm{T}$ & $\begin{array}{l}1 \mathrm{~Hz}- \\
10 \mathrm{kHz}\end{array}$ & [299] \\
\hline Metal & $\begin{array}{l}\text { Opening, shearing and } \\
\text { tearing mode }\end{array}$ & EMR & $1-250 \mathrm{mV}$ & $20-120 \mathrm{kHz}$ & {$[300]$} \\
\hline Metal (aluminium) & Opening and shearing mode & EMR & $20-70 \mathrm{mV}$ & $40-70 \mathrm{kHz}$ & {$[178]$} \\
\hline Metals (tin-coated carbon steel) & Opening and shearing mode & EMR & $4-25 \mathrm{mV}$ & $\begin{array}{l}50 \mathrm{kHz}- \\
14 \mathrm{MHz}\end{array}$ & {$[162]$} \\
\hline Metals (copper zinc alloys) & Tension & EMR & $4-80 \mathrm{mV}$ & $1-4 \mathrm{kHz}$ & {$[181]$} \\
\hline Metals (titanium sheets) & Tension & EMR & $2-200 \mathrm{mV}$ & $1-4 \mathrm{kHz}$ & {$[163]$} \\
\hline Metals & Tension and compression & EMR & $1.6-30 \mathrm{mV}$ & $22-49 \mathrm{kHz}$ & {$[183]$} \\
\hline Metal (aluminium) & Compression & EMR & $4-12 \mathrm{mV}$ & $6-42 \mathrm{kHz}$ & {$[166]$} \\
\hline
\end{tabular}


Table 1 continued

\begin{tabular}{|c|c|c|c|c|c|}
\hline Material & Loading type & Signal observed & $\begin{array}{l}\text { Signal } \\
\text { amplitude }\end{array}$ & $\begin{array}{l}\text { Signal } \\
\text { frequency }\end{array}$ & References \\
\hline $\begin{array}{l}\text { Polymers (polytetrafluoroethylene (PTFE), } \\
\text { polyether ether ketone (PEEK), etc.) }\end{array}$ & Tensile test & EME & $2-80 \mathrm{mV}$ & $\begin{array}{r}0.1 \mathrm{kHz}- \\
1 \mathrm{MHz}\end{array}$ & {$[14]$} \\
\hline Polymers & Tension & Fractoemissions & - & - & {$[279]$} \\
\hline Polymer (epoxy resin material) & $\begin{array}{l}\text { Three-point } \\
\text { bending }\end{array}$ & EME & $40 \mathrm{mV}-6 \mathrm{~V}$ & $\mathrm{kHz}$ range & {$[201]$} \\
\hline $\begin{array}{l}\text { Composite (glass-fibre-polyester-based } \\
\text { composite material) }\end{array}$ & Compression & EME & $0.2 \mathrm{mV}-4 \mathrm{~V}$ & - & [282] \\
\hline Cement mortar & $\begin{array}{l}\text { Uniaxial } \\
\text { compression and } \\
\text { bending }\end{array}$ & PSC & $0.1-1000 \mathrm{pA}$ & - & {$[230,301]$} \\
\hline Cement-based materials & $\begin{array}{l}\text { Uniaxial } \\
\text { compression }\end{array}$ & PSC & In $\mathrm{pA}$ & - & {$[225,229,230]$} \\
\hline Cement paste & $\begin{array}{l}\text { Uniaxial } \\
\text { compression }\end{array}$ & Electric current & $0.07-0.1 \mathrm{~mA}$ & - & {$[233]$} \\
\hline Cement & $\begin{array}{l}\text { Uniaxial } \\
\text { compression }\end{array}$ & $\begin{array}{l}\text { Electrical } \\
\text { emission }\end{array}$ & $100-700 \mathrm{mV}$ & - & [283] \\
\hline Cement paste & Impact loading & EMR & $60-300 \mathrm{mV}$ & - & {$[237]$} \\
\hline Cement-based piezoelectric composites & Impact loading & EMR & $0.05-2.4 \mathrm{~V}$ & - & {$[238,239]$} \\
\hline Concrete & $\begin{array}{l}\text { Uniaxial } \\
\text { compression }\end{array}$ & EMR & $0.28-1.86 \mathrm{mV}$ & $10.9-131.4 \mathrm{kHz}$ & {$[240]$} \\
\hline
\end{tabular}

considered. Compact devices having the capability of signal storage and filtering (from external noise sources) need to be designed. In real operating conditions the ambient temperature condition varies which can also affect the material response in terms of emitted signals. Thus proper laboratory studies of the effect of these environmental conditions need to be carried out, and sensors and data acquisition should be designed to consider these factors. This phenomenon is being observed in a variety of materials; thus, placement of EMR measuring device also varies from deep inside the mines to the open environment such as bridges or other civil infrastructures which need small modifications to be considered accordingly. Majority of the laboratory-based studies have been done in the near-field region where source to sensor distance is very small (usually less than $1 \mathrm{~m})$. If signal measurement techniques can be worked out which can measure signals at larger distances (which can allow enough room for the placement of the detector including acquisition systems), then this will be a significant contribution to the EME detection technique. Machine learning and artificial intelligence are entering in every sector nowadays. These tools can be utilized in the EMR detection technique where real-time data from the laboratory experiments or the actual infrastructure can be used as the training data for making future predictions. This will significantly help to reduce human interactions with the acquisition systems. Thus researchers involved in this field should also think in this direction.

\section{Multidisciplinary efforts}

This area requires collaborative efforts of the researchers' community beginning from materials/ mineral scientists to physicists and engineers from different disciplines to add value to the research work which is being done and work which is in the pipeline. Collaborative research can definitely transform this technique from merely an application in materials research to a technique which can solve real-world problems such as early failure prediction and monitoring.

\section{Early warning methods and engineering applications}

Freund research group from NASA Ames Research Center has shown the possibility of early prediction of earthquakes 3-6 days in advance with the help of satellite imaging and IR imaging technique (which 
will also include other important parameters to be observed simultaneously) which gives encouragement to the community of the researchers about the potential of this technique. The underlying motivation for the emergence of this technique was laboratory experiments where a granite beam under compressive load was tested to produce electrical signals. These experiments were supported with physical mechanism and are now into the development of earthquake prognosis technique. Use of ferroelectric ceramics for wireless sensing application is also promising one wherever sensing effect is to be utilized for applications such as structural health monitoring and design of low-cost dynamic load sensors. Wireless signals of amplitude in volts give promising scope in order to use ferroelectric ceramics for detecting dynamic loads. Wireless signals detection can help to eliminate various electronic accessories which otherwise are required for signals measurement in contact mode which may help to reduce the cost. Cement-based piezocomposites may become a feasible option to be utilized in health monitoring of the cement-based structures. Embedding these composites in cement-based structures will not introduce any discontinuity and strength issues. From other perspective this technique can be utilized to know about the complex dynamics of fracture in different materials which otherwise seems difficult. This technique should be explored for laminate composites which nowadays are finding huge applications. Thus the electromagnetic emissions can be an important tool to know about the overall mechanical behaviour of materials. On the other hand, advancement of electromagnetic emissions detection will help in the development of wireless damage detection technique, prefailure predictions and will also be an aid to get rid of the cumbersome wired sensors tangled around the infrastructures of interest.

\section{Summary and conclusion}

A variety of materials ranging from rocks, coals, ceramics to polymers and composites all have been studied for electromagnetic emissions during failure. The detected electromagnetic signals have different source mechanisms and have weak interaction with the medium surrounding the material, and this can be used as an important tool to investigate the mechanisms involving crack formation and propagation. Moreover, proper understanding of the physical mechanisms, their unification and mathematical models for different classes of materials will also be an aid to develop this phenomenon as a deformation monitoring technique and to know about the complex dynamics of fracture. Ceramics, dielectrics and polymeric materials can act as sensors which can tell us about the stress state or deformation in structures into which they are incorporated or bonded.

Further, non-contact electromagnetic radiation detection can be used to get rid of the complex wired structures and wireless signals can be used to monitor the deformations. Sensors technology is a perspective into which researchers are looking into, and for this different high-end sensors are also being investigated. But looking from the other perspective if we can use the base material of any infrastructure for serving the purpose of deformation monitoring, then it can save cost and efforts on creating and incorporating the external sensors in the infrastructures. Prediction of earthquake and mine failure are the hot areas into which rigorous work is going on and on-site experiments have been performed, demonstrating the potential of this technique. Researchers' community is continuously exploring EME signals from rocks and coal in order to develop a technique which is capable of warning about the upcoming disasters such as earthquake and mine failure. So far there is no well-established technique although numerous groups are exploring the possibility and some laboratory experiments have also shown promising results. Still it is an open research problem and EME technique is continuously being explored for this aspect.

As EME detection is still in its research phase, thus for implementation of this technique as a proper deformation monitoring tool rigorous experimental studies as well as development of knowledge base using mathematical and simulation-based techniques are required to be done. Also now the utilization of this technique in terms of prototypes or in applications replicating real-world scenario needs to be taken up as a further step. Thus this review would be a great aid in order to collect an overview of the 
research done in this field and for carrying out further advancement in the deformation monitoring practices using the deformation-induced electromagnetic emissions as the precursory signals.

\section{Funding}

Open Access funding enabled and organized by Projekt DEAL.

\section{Compliance with ethical standards}

Conflict of interest The authors declare that they have no conflict of interest.

Open Access This article is licensed under a Creative Commons Attribution 4.0 International License, which permits use, sharing, adaptation, distribution and reproduction in any medium or format, as long as you give appropriate credit to the original author(s) and the source, provide a link to the Creative Commons licence, and indicate if changes were made. The images or other third party material in this article are included in the article's Creative Commons licence, unless indicated otherwise in a credit line to the material. If material is not included in the article's Creative Commons licence and your intended use is not permitted by statutory regulation or exceeds the permitted use, you will need to obtain permission directly from the copyright holder. To view a copy of this licence, visit http://creativecommons.org/licen ses/by/4.0/.

\section{References}

[1] Courtney TH (2005) Mechanical behavior of materials, 2nd edn. Waveland Press, USA

[2] Surkov V, Hayakawa M (2014) Laboratory study of rock deformation and fracture. ultra and extremely low frequency electromagnetic fields. Springer Geophysics, Japan, pp 335-372. https://doi.org/10.1007/978-4-431-54367-1

[3] De Groot PJ, Wijnen PA, Janssen RB (1995) Real-time frequency determination of acoustic emission for different fracture mechanisms in carbon/epoxy composites. Compos Sci Technol 55(4):405-412. https://doi.org/10.1016/02663538(95)00121-2
[4] Giordano M, Calabro A, Esposito C, Damore A, Nicolais L (1998) An acoustic-emission characterization of the failure modes in polymer-composite materials. Compos Sci Technol 58(12):1923-1928. https://doi.org/10.1016/S02663538(98)00013-X

[5] Dickinson J, Donaldson E, Park M (1981) The emission of electrons and positive ions from fracture of materials. J Mater Sci 16(10):2897-2908. https://doi.org/10.1007/ BF00552976

[6] Evans AG, Linzer M (1973) Failure prediction in structural ceramics using acoustic emission. J Am Ceram Soc 56(11):575-581. https://doi.org/10.1111/j.1151-2916.1973. tb12419.x

[7] Ramirez-Jimenez C, Papadakis N, Reynolds N, Gan T, Purnell P, Pharaoh M (2004) Identification of failure modes in glass/polypropylene composites by means of the primary frequency content of the acoustic emission event. Compos Sci Technol 64(12):1819-1827. https://doi.org/10.1016/j.c ompscitech.2004.01.008

[8] Mohammad I, Huang H (2010) Monitoring fatigue crack growth and opening using antenna sensors. Smart Mater Struct 19(5):055023. https://doi.org/10.1088/0964-1726/19 /5/055023

[9] Jones M (2008) Structural-health monitoring: a sensitive issue. Nat Photonics 2(3):153. https://doi.org/10.1038/nph oton. 2008.20

[10] Sohn H, Farrar CR, Hemez FM, Czarnecki JJ (2002) A review of structural health review of structural health monitoring literature 1996-2001. No. LA-UR-02-2095. Los Alamos National Laboratory

[11] Farrar CR, Worden K (2006) An introduction to structural health monitoring. Philos Trans R Soc A Math Phys Eng Sci 365(1851):303-315. https://doi.org/10.1098/rsta.2006. 1928

[12] Chang PC, Flatau A, Liu S (2003) Health monitoring of civil infrastructure. Struct Health Monit 2(3):257-267. h ttps://doi.org/10.1177/1475921703036169

[13] Sause MGR (2016) In Situ monitoring of fiber-reinforced composites. Springer Ser Mater Sci. https://doi.org/10.100 7/978-3-319-30954-5

[14] Gade S, Sause M (2017) Measurement and study of electromagnetic emission generated by tensile fracture of polymers and carbon fibres. J Nondestr Eval 36(1):9. h ttps://doi.org/10.1007/s10921-016-0386-0

[15] Joffé A, Zechnowitzer E (1926a) The electrical conductivity in single crystal and crystal aggregates. Mag Phys 35(6):446-448 
[16] Stepanow A (1933) On the mechanism of plastic deformation. J Phys A Hadrons Nuclei 81(7):560-564

[17] Gyulai Z, Hartly D (1928) Electrical conductivity of deformed stone salt crystals. J Phys A Hadrons Nuclei 51(5):378-387

[18] Quittner F (1929) Field strength dependence of the electrical ion conductivity of single crystals. J Phys Chem Solids 56:597-603. https://doi.org/10.1007/BF01339914

[19] Quittner F (1931) Plasticizing effect of the electrolytic conductivity $\mathrm{NaCl}$. J Phys 68:796

[20] Caffyn J, Goodfellow T (1955) Electrical effects associated with the mechanical deformation of single crystals of alkali halides. Nature 176(4488):878. https://doi.org/10.1038/17 $6878 \mathrm{a} 0$

[21] Caffyn J, Goodfellow T (1962) The movement of charged dislocations in sodium chloride. Proc Phys Soc 79(6):1285. https://doi.org/10.1088/0370-1328/79/6/325

[22] Caffyn J, De Freitas J, Goodfellow T (1965) Charged dislocations in sodium chloride crystals containing sodium hydroxide. Phys Status Solidi (b) 9(2):333-340. https://doi. org/10.1002/pssb.19650090204

[23] Carpinteri A, Lacidogna G, Manuello A, Niccolini G, Schiavi A, Agosto A (2012) Mechanical and electromagnetic emissions related to stress-induced cracks. Exp Tech 36(3):53-64. https://doi.org/10.1111/j.1747-1567.2011.007 09. $\mathrm{x}$

[24] Mori Y, Obata Y, Sikula J (2009) Acoustic and electromagnetic emission from crack created in rock sample under deformation. Acoust Emiss 27:157-166

[25] Gokhberg M, Morgounov V, Yoshino T, Tomizawa I (1982) Experimental measurement of electromagnetic emissions possibly related to earthquakes in Japan. J Geophys Res Solid Earth 87(B9):7824-7828. https://doi.org/10.1029/ JB087iB09p07824

[26] Oike K, Ogawa T (1986) Electromagnetic radiations from shallow earthquakes observed in the LF range. J Geomagn Geoelectr 38(10):1031-1040

[27] Berri B, Gribov V (1982) Radio irradiations of glaciers and snow avalanches. Glaciol Res Mater 44:150-156 (In Russian: Materiali Glatsiologicheskih Issledovanii)

[28] Petrenko VF, Colbeck SC (1995) Generation of electric fields by ice and snow friction. J Appl Phys 77(9):4518-4521. https://doi.org/10.1063/1.359448

[29] Wang E, Jia H, Song D, Li N, Qian W (2014) Use of ultralow-frequency electromagnetic emission to monitor stress and failure in coal mines. Int $\mathrm{J}$ Rock Mech Min Sci 70:16-25. https://doi.org/10.1016/j.ijrmms.2014.02.004

[30] Frid V (1997a) Rockburst hazard forecast by electromagnetic radiation excited by rock fracture. Rock Mech Rock Eng 30(4):229-236. https://doi.org/10.1007/BF01045719
[31] Frid V (1997b) Electromagnetic radiation method for rock and gas outburst forecast. J Appl Geophys 38(2):97-104. h ttps://doi.org/10.1016/S0926-9851(97)00017-7

[32] Sharma SK, Chauhan VS, Kumar A (2016) Detection of electromagnetic radiation in ferroelectric ceramics for noncontact sensing applications. J Alloy Compd 662:534-540. https://doi.org/10.1016/j.jallcom.2015.12.026

[33] Joffé A, Zechnowitzer E (1926b) The electrical conductivity in single crystals and in crystal aggregates. Z Phys 35(6):446-448. https://doi.org/10.1007/BF01385421

[34] Quittner F (1932) On the question of the dependence of the conductivity on the field strength in rock salt crystals. Z Phys 74(5-6):344-349. https://doi.org/10.1007/ BF01337793

[35] Johnston WG (1955) Effect of plastic deformation on the electrical conductivity of silver bromide. Phys Rev 98(6):1777. https://doi.org/10.1103/PhysRev.98.1777

[36] Kanzaki H (1955) On the Plasticity of Silver Bromide. J Phys Soc Jpn 10(8):663-668. https://doi.org/10.1143/JP SJ.10.663

[37] Fischbach D, Nowick A (1955) Deformation-induced charge flow in $\mathrm{NaCl}$ crystals. Phys Rev 99(4):1333. http s://doi.org/10.1103/PhysRev.99.1333

[38] Fischbach D, Nowick A (1958) Some transient electrical effects of plastic deformation in $\mathrm{NaCl}$ crystals*. J Phys Chem Solids 5(4):302-315. https://doi.org/10.1016/0022-3 697(58)90034-9

[39] Sproull R (1960) Charged dislocations in lithium fluoride. Phil Mag 5(56):815-831. https://doi.org/10.1080/ 14786436008241220

[40] Tyapunina N, Belozerova ÉP (1988) Charged dislocations and properties of alkali halide crystals. Sov Phys Usp 31(12):1060. https://doi.org/10.1070/ PU1988v031n12ABEH005660

[41] Schwensfeir R Jr, Elbaum C (1965) Electrical charge on grain boundaries in sodium chloride. J Phys Chem Solids 26(4):781-782. https://doi.org/10.1016/0022-3697(65)900 $33-8$

[42] Dupuy C, Schaeffer B, Saucier H (1966) Interaction of dislocations and point defects in plastically deformed lithium fluoride crystals. J Phys Colloq 27(C3):C3-21-C2324. https://doi.org/10.1051/jphyscol:1966303

[43] Lifshits IM, Geguzin YE (1965) Surface phenomena in ionic crystals. Solid State Phys 7(1):62-74 (In Russian: Fizika tverdogo tela)

[44] Martyshev YN (1965) Investigation of luminescence and electrification of LiF crystals with their deformation. Crystallography 1:224-226 (In Russian: Kristallografiya) 
[45] Sonoike S (1962) Charged dislocations in silver halide crystals. J Phys Soc Jpn 17(3):575-576. https://doi.org/10. 1143/JPSJ.17.575

[46] Rueda F, Dekeyser W (1961) Charged dislocations in ionic crystals. J Appl Phys 32(9):1799-1799. https://doi.org/10. 1063/1.1728457

[47] Rueda F, Dekeyser W (1963) Charged dislocations in pure and doped rocksalt single crystals. Acta Metall 11(1):35-41. https://doi.org/10.1016/0001-6160(63)901226

[48] Davidge R (1963) The temperature dependence of the charge on dislocations in $\mathrm{NaCl}$ and the determination of the separate free energies of formation of positive- and negative-ion vacancies. Phys Status Solidi 3:1851-1856. http s://doi.org/10.1002/pssb.19630031009

[49] Rueda F (1963) On the charge flow during plastic deformation in rocksalt. Phil Mag 8(85):29-42. https://doi.org/ $10.1080 / 14786436308212485$

[50] Urusovskaya A (1969) Electric effects associated with plastic deformation of ionic crystals. Sov Phys Usp 11(5):631-643. https://doi.org/10.1070/ PU1969v011n05ABEH003738

[51] Potirakis S, Mastrogiannis D (2017) Critical features revealed in acoustic and electromagnetic emissions during fracture experiments on LiF. Phys A 485:11-22. https://doi. org/10.1016/j.physa.2017.05.025

[52] Eshelby J, Newey C, Pratt P, Lidiard A (1958) Charged dislocations and the strength of ionic crystals. Phil Mag 3(25):75-89. https://doi.org/10.1080/14786435808243228

[53] Whitworth R (1975) Charged dislocations in ionic crystals. Adv Phys 24(2):203-304. https://doi.org/10.1080/ 00018737500101401

[54] Poletaev A, Shmurak S (1984) Dislocation exoelectron emission of colored alkali-halide crystals. Sov Phys JETP 60:376-379

[55] Onsager L, Staebler DL, Mascarenhas S (1978) Electrical effects during condensation and phase transitions of ice. J Chem Phys 68(8):3823-3828. https://doi.org/10.1063/1. 436189

[56] Kachurin L, Grigoriev N, Kuzin I, Psalomshchikov V, Stepaniuk I (1979) Electromagnetic-radiation of snow and ice during the dynamic processes. Rep USSR Acad Sci 248(3):583-585 (In Russian: Doklady Akademii Nauk SSSR)

[57] Kachurin LG, Psalomshikov VF, Stepanyuk IA (1984) Nonthermal radio-emission of intensively deforming ice covers of the Earth. Earth exploration from space. The USSR Ac. of Sc. No. 3, pp. 60-65 (In Russian: Issledovanie Zemli iz Kosmosa)
[58] Berri B, Grigorov I, Kachurin L (1986) Problems of engineering glaciology. Nauka Novosibirsk 24:32

[59] Petrenko V, Whitworth R (1983) Electric currents associated with dislocation motion in ice. J Phys Chem 87(21):4022-4024

[60] Fifolt D, Petrenko V, Schulson E (1993) Preliminary study of electromagnetic emissions from cracks in ice. Philos Mag B 67(3):289-299. https://doi.org/10.1080/ 13642819308220133

[61] Weyl W (1951) Surface structure of water and some of its physical and chemical manifestations. J Colloid Sci 6(5):389-405

[62] Fletcher N (1962) Surface structure of water and ice. Phil Mag 7(74):255-269. https://doi.org/10.1080/ 14786436208211860

[63] O'Keefe SG, Thiel DV (1996) Conductivity effects on electromagnetic emissions (EME) from ice fracture. J Electrostat 36(3):225-234. https://doi.org/10.1016/03043886(95)00046-1

[64] Ninos D, Tombras GS, Mavromatou C, Hadjicontis V (2004) On the detection of acoustic and electromagnetic signals before fracture of dielectric crystalline materials. IEEE Geosci Remote Sens Lett 1(3):162-165. https://doi. org/10.1109/LGRS.2004.828912

[65] Zhou D, Kamlah M (2006) Room-temperature creep of soft PZT under static electrical and compressive stress loading. Acta Mater 54(5):1389-1396. https://doi.org/10.1016/j.acta mat.2005.11.010

[66] Wang H, Singh RN (1997) Crack propagation in piezoelectric ceramics: effects of applied electric fields. J Appl Phys 81(11):7471-7479. https://doi.org/10.1063/1.365290

[67] Sosa H (1992) On the fracture mechanics of piezoelectric solids. Int J Solids Struct 29(21):2613-2622. https://doi. org/10.1016/0020-7683(92)90225-I

[68] Park S, Sun CT (1995) Fracture criteria for piezoelectric ceramics. J Am Ceram Soc 78(6):1475-1480. https://doi. org/10.1111/j.1151-2916.1995.tb08840.x

[69] Sharma A, Kumar R, Vaish R, Chauhan VS (2015a) Performance of $\mathrm{K} 0.5 \mathrm{Na} 0.5 \mathrm{NbO} 3(\mathrm{KNN})$-based lead-free piezoelectric materials in active vibration control. Int $\mathrm{J}$ Appl Ceram Technol 12(S1):E64-E72. https://oi.org/10. 1111/ijac. 12231

[70] Sharma A, Kumar R, Vaish R, Chauhan VS (2015b) Performance hierarchy of piezoelectric materials for active vibration control application. Ferroelectrics 478(1):140-156. https://doi.org/10.1080/00150193.2015.1011563

[71] Sharma A, Kumar R, Vaish R, Chauhan VS (2014) Leadfree piezoelectric materials' performance in structural active vibration control. J Intel Mater Syst Struct 25(13):1596-1604 
[72] Sharma A, Kumar R, Vaish R, Chauhan VS (2015c) Active vibration control of space antenna reflector over wide temperature range. Compos Struct 128:291-304. https://d oi.org/10.1016/j.compstruct.2015.03.062

[73] Gao H, Zhang T-Y, Tong P (1997) Local and global energy release rates for an electrically yielded crack in a piezoelectric ceramic. J Mech Phys Solids 45(4):491-510. http s://doi.org/10.1016/S0022-5096(96)00108-1

[74] Suo Z, Kuo C-M, Barnett D, Willis J (1992) Fracture mechanics for piezoelectric ceramics. J Mech Phys Solids 40(4):739-765. https://doi.org/10.1016/0022-5096(92)900 02-J

[75] Weitzing H, Schneider G, Steffens J, Hammer M, Hoffmann M (1999) Cyclic fatigue due to electric loading in ferroelectric ceramics. J Eur Ceram Soc 19(6):1333-1337. https://doi.org/10.1016/S0955-2219(98)00429-4

[76] Dickinson J, Jensen L, Williams WD (1985) Fractoemission from lead zirconate-titanate. J Am Ceram Soc 68(5):235-240. https://doi.org/10.1111/j.1151-2916.1985.t b15315.x

[77] Ašmontas S, Anisimovas F, Dapkus L, Gradauskas J, Kiprianovič O, Senulis M (2010) Electromagnetic radiation of ferroelectric PZT ceramics under pulsed compressive stress. Mater Sci 16(3):264-267

[78] Anisimovas F, Ašmontas S, Kiprijanovič O, Maneikis A, Vengalis B (2013) Broadband electromagnetic emission from PZT ferroelectric ceramics after shock loading. Mater Sci 19(4):433-437. https://doi.org/10.5755/j01.ms.19.4. 3137

[79] Langford SC, Dickinson J, Jensen L (1987) Simultaneous measurements of the electron and photon emission accompanying fracture of single-crystal MgO. J Appl Phys 62(4):1437-1449. https://doi.org/10.1063/1.339650

[80] Yoo K, Rosemeier R, Dickinson J, Langford S (1989) Anisotropy effects on fracto-emission from $\mathrm{MgF} 2$ single crystals. Appl Phys Lett 55(4):354-356. https://doi.org/10. 1063/1.102419

[81] Bahat D, Frid V, Rabinovitch A, Palchik V (2002) Exploration via electromagnetic radiation and fractographic methods of fracture properties induced by compression in glass-ceramic. Int J Fract 116(2):179-194. https://doi.org/ 10.1023/A:1020182728971

[82] Gonzalez A, Pantano C (1990) Fractoemission during crack propagation in glass. Appl Phys Lett 57(3):246-248. http s://doi.org/10.1063/1.103704

[83] Enomoto Y, Chaudhri MM (1993) Fracto-emission during fracture of engineering ceramics. J Am Ceram Soc 76(10):2583-2587. https://doi.org/10.1111/j.1151-2916.19 93.tb03984.x
[84] Kumar A, Chauhan VS, Sharma SK, Kumar R (2017) Deformation induced electromagnetic response of soft and hard PZT under impact loading. Ferroelectrics 510(1):170-183. https://doi.org/10.1080/00150193.2017. 1328726

[85] Sharma SK, Sivarathri AK, Chauhan VS, Sinapius M (2018) Effect of low temperature on electromagnetic radiation from soft PZT SP-5A under impact loading. J Electr Mater. https://doi.org/10.1007/s11664-018-6464-6

[86] Nitsan U (1977) Electromagnetic emission accompanying fracture of quartz-bearing rocks. Geophys Res Lett 4(8):333-336. https://doi.org/10.1029/GL004i008p00333

[87] Egorov P, Vasilev O, Korneichikov V, Korneichikova N, Nesterov V (1978) Space-charge formation in rocks under mechanical load. Sov Min 14(5):520-523. https://doi.org/ 10.1007/BF02499708

[88] Gokhberg M (1979) On the high frequency electromagnetic radiation during seismic activity. Rep Acad USSR 248:1077-1081 (In Russian: Dokladi Acad. Sci. USSR)

[89] Warwick JW, Stoker C (1960) TR Meyer (1982) Radio emission associated with rock fracture: possible application to the great Chilean earthquake of May 22. J Geophys Res Solid Earth 87(B4):2851-2859. https://doi.org/10.1029/ JB087iB04p02851

[90] Johnston M (1997) Review of electric and magnetic fields accompanying seismic and volcanic activity. Surv Geophys 18(5):441-476. https://doi.org/10.1023/A:1006500408086

[91] Ogawa T, Oike K, Miura T (1985) Electromagnetic radiations from rocks. $\mathrm{J}$ Geophys Res Atmos 90(D4):6245-6249. https://doi.org/10.1029/ JD090iD04p06245

[92] Ogawa T, Tanaka Y, Miura T, Yasuhara M (1966) Observations of natural ELF and VLF electromagnetic noises by using ball antennas. J Geomagn Geoelectr 18(4):443-454. https://doi.org/10.5636/jgg.18.443

[93] Cress GO, Brady B, Rowell GA (1987) Sources of electromagnetic radiation from fracture of rock samples in the laboratory. Geophys Res Lett 14(4):331-334. https://doi. org/10.1029/GL014i004p00331

[94] Frid V, Bahat D, Goldbaum J, Rabinovitch A (2000) Experimental and theoretical investigations of electromagnetic radiation induced by rock fracture. Isr J Earth Sci 49(1):9-19

[95] Rabinovitch A, Bahat D, Frid V (2002) Similarity and dissimilarity of electromagnetic radiation from carbonate rocks under compression, drilling and blasting. Int J Rock Mech Min Sci 39(1):125-129

[96] Rabinovitch A, Shay A, Liraz R, Frid V, Bahat D (2005) Electromagnetic radiation emitted during friction process. 
Int J Fract 131(2):L21-L27. https://doi.org/10.1007/s1070 4-005-2596-9

[97] Frid V (2000) Electromagnetic radiation method water-infusion control in rockburst-prone strata. J Appl Geophys 43(1):5-13. https://doi.org/10.1016/S0926-9851(99)000294

[98] Mavromatou C, Hadjicontis V, Ninos D, Mastrogiannis D, Hadjicontis E, Eftaxias K (2015) Understanding the fracture phenomena in inhomogeneous rock samples and ionic crystals, by monitoring the electromagnetic emission during their deformation. Phys Chem Earth Parts A/B/C 29(4-9):353-357. https://doi.org/10.1016/j.pce.2003.11. 011

[99] Hadjicontis V, Mavromatou C, Ninos D (2004) Stress induced polarization currents and electromagnetic emission from rocks and ionic crystals, accompanying their deformation. Nat Hazards Earth Syst Sci 4(5/6):633-639 (Copernicus Publications on behalf of the European Geosciences Union)

[100] Kasahara K (1981) Earthquake mechanics. Cambridge University Press, Cambridge

[101] Mastrogiannis D, Antsygina T, Chishko K, Mavromatou C, Hadjicontis V (2015) Relationship between electromagnetic and acoustic emissions in deformed piezoelectric media: microcracking signals. Int J Solids Struct 56:118-125. h ttps://doi.org/10.1016/j.jisolstr.2014.11.027

[102] Li D, Wang E, Li Z et al (2018) a causal mechanism for anomalous electromagnetic radiations from coal and rock failure. Geophysics 83(6):1-65. https://doi.org/10.1190/ge o2018-0360.1

[103] Fukui K, Okubo S, Terashima T (2005) Electromagnetic radiation from rock during uniaxial compression testing: the effects of rock characteristics and test conditions. Rock Mech Rock Eng 38(5):411-423. https://doi.org/10.1007/s0 0603-005-0046-7

[104] Nardi A, Caputo M (2009) Monitoring the mechanical stress of rocks through the electromagnetic emission produced by fracturing. Int J Rock Mech Min Sci. https://doi. org/10.1016/j.jirmms.2009.01.005

[105] Han J, Huang S, Zhao W, Wang S, Deng Y (2018) Study on electromagnetic radiation in crack propagation produced by fracture of rocks. Measurement 131:125-131. https://doi. org/10.1016/j.measurement.2018.06.067

[106] Kong B, Wang E, Li Z (2018) The effect of high temperature environment on rock properties - an example of electromagnetic radiation characterization. Environ Sci Pollut Res 25(29):29104-29114. https://doi.org/10.1007/s 11356-018-2940-z

[107] Song X, Li X, Li Z, Cheng F, Zhang Z, Niu Y (2018) Experimental research on the electromagnetic radiation
(EMR) characteristics of cracked rock. Environ Sci Pollut Res 25(7):6596-6608. https://doi.org/10.1007/s11356-0171012-0

[108] Zhao F, Li Y, Ye Z et al (2018) Research on acoustic emission and electromagnetic emission characteristics of rock fragmentation at different loading rates. Shock Vib. h ttps://doi.org/10.1155/2018/4680879

[109] Liu X, Wang E (2018) Study on characteristics of EMR signals induced from fracture of rock samples and their application in rockburst prediction in copper mine. J Geophys Eng 15(3):909-920. https://doi.org/10.1088/1742-21 40/aaa3ce

[110] Li H, Shen R, Wang E et al (2020) Effect of water on the time-frequency characteristics of electromagnetic radiation during sandstone deformation and fracturing. Eng Geol 265:105451. https://doi.org/10.1016/j.enggeo.2019.105451

[111] Kong B, Wang E, Li Z et al (2016) Electromagnetic radiation characteristics and mechanical properties of deformed and fractured sandstone after high temperature treatment. Eng Geol 209:82-92. https://doi.org/10.1016/j.enggeo.201 6.05 .009

[112] Yavorovich LV, Bespalko AA, Fedotov PI, Baksht RB (2016) Electromagnetic radiation generated by acoustic excitation of rock Samples. Acta Geophys 64(5):1446-1461. https://doi.org/10.1515/acgeo-20160081

[113] Trčka T, Macků R, Koktavý P, Škarvada P, Baroň I, Stemberk J (2017) Field measurement of natural electromagnetic emissions near the active tectonic and massmovement fractures in caves. Solid State PhenomTrans Tech Publ 258:460-464. https://doi.org/10.4028/www.scie ntific.net/SSP

[114] Cantzos D, Nikolopoulos D, Petraki E, Yannakopoulos P, Nomicos C (2018) Earthquake precursory signatures in electromagnetic radiation measurements in terms of day-today fractal spectral exponent variation: analysis of the eastern Aegean 13/04/2017-20/07/2017 seismic activity. J Seismolog 22(6):1499-1513. https://doi.org/10.1007/s10 950-018-9781-6

[115] Liu S, Xu Z, Wei J, Huang J, Wu L (2016) Experimental study on microwave radiation from deforming and fracturing rock under loading outdoor. IEEE Trans Geosci Remote Sens 54(9):5578-5587. https://doi.org/10.1109/T GRS.2016.2569419

[116] Rabinovitch A, Frid V, Bahat D (2018) Use of electromagnetic radiation for potential forecast of earthquakes. Geol Mag 155(4):992-996. https://doi.org/10.1017/ S0016756817000954 
[117] Fujinawa Y, Noda Y (2020) Progress of applied seismoelectromagnetism. Open J Earthq Res 9(1):1-18. https://d oi.org/10.4236/ojer.2020.91001

[118] Singh V, Hobara Y (2020) Simultaneous study of VLF/ULF anomalies associated with earthquakes in Japan. Open J Earthq Res 9(2):201-215. https://doi.org/10.4236/ojer.202 0.92012

[119] Das S, Mallik J, Dhankhar S et al (2020) Application of fracture induced electromagnetic radiation (FEMR) technique to detect landslide-prone slip planes. Nat Hazards 101:505-535. https://doi.org/10.1007/s11069-020-03883-3

[120] Bakun W, Aagaard B, Dost B et al (2005) Implications for prediction and hazard assessment from the 2004 Parkfield earthquake. Nature 437(7061):969-974. https://doi.org/10. 1038/nature04067

[121] Thomas JN, Love JJ, Johnston MJ (2009) On the reported magnetic precursor of the 1989 Loma Prieta earthquake. Phys Earth Planet Inter 173(3-4):207-215. https://doi.org/ 10.1016/j.pepi.2008.11.014

[122] Freund F (2010) Toward a unified solid state theory for preearthquake signals. Acta Geophysica 58(5):719-766. http s://doi.org/10.2478/s11600-009-0066-x

[12] Freund F (2011) Pre-earthquake signals: underlying physical processes. J Asian Earth Sci 41(4-5):383-400. https://d oi.org/10.5194/eed-1-97-2006

[124] Freund FT, Takeuchi A, Lau BW et al (2007) Stimulated thermal IR emission from rocks: assessing a stress indicator. eEarth 2(1):7-16. https://doi.org/10.5194/eed-1-972006

[125] Freund F, Ouillon G, Scoville J, Sornette D (2017) Earthquake precursors in the light of peroxy defects theory: critical review of systematic observations. arXiv preprint $h$ ttps://arxiv.org/1711.01780

[126] Freund F (2019) Co-seismic earthquake lights: the underlying mechanism. Pure Appl Geophys 176(8):3439-3450. h ttps://doi.org/10.1007/s00024-019-02142-2

[127] Daneshvar MRM, Freund FT (2017) The Chile-2015 (Illapel) earthquake and tsunami. Springer, Berlin. https://doi. org/10.1007/978-3-319-57822-4

[128] Wang E-y, X-q HE, B-s NIE, Liu Z-t (2000) Principle of predicting coal and gas outburst using electromagnetic emission [J]. J China Univ Min Technol 3:000. https://doi. org/10.1109/WCICA.2000.863479

[129] Lacidogna G, Carpinteri A, Manuello A et al (2011a) Acoustic and electromagnetic emissions as precursor phenomena in failure processes. Strain 47(s2):144-152. http s://doi.org/10.1111/j.1475-1305.2010.00750.x

[130] Niccolini G, Xu J, Manuello A, Lacidogna G, Carpinteri A (2012) Onset time determination of acoustic and electromagnetic emission during rock fracture. Progr Electromagn Res Lett 35:51-62. https://doi.org/10.2528/ PIERL12070203

[131] Borla O, Lacidogna G, Di Battista E, Niccolini G, Carpinteri A (2015) Electromagnetic emission as failure precursor phenomenon for seismic activity monitoring. fracture, fatigue, failure, and damage evolution, vol 5 Springer, Cham, 2015. pp 221-229. https://doi.org/10.100 7/978-3-319-06977-7_29

[132] Carpinteri A, Lacidogna G, Borla O, Manuello A, Niccolini G (2012) Electromagnetic and neutron emissions from brittle rocks failure: experimental evidence and geological implications. Sadhana 37(1):59-78. https://doi.org/10.100 7/s12046-012-0066-4

[133] Carpinteri A, Borla O (2018) Acoustic, electromagnetic, and neutron emissions as seismic precursors: the lunar periodicity of low-magnitude seismic swarms. Eng Fract Mech. https://doi.org/10.1016/j.engfracmech.2018.04.021

[134] Carpinteri A, Borla O (2017) Fracto-emissions as seismic precursors. Eng Fract Mech 177:239-250. https://doi.org/ 10.1016/j.engfracmech.2017.03.007

[135] Wei M, Song D, He X, Li Z, Qiu L, Lou Q (2020) Effect of rock properties on electromagnetic radiation characteristics generated by rock fracture during uniaxial compression. Rock Mech Rock Eng 53:5223-5238. https://doi.org/10.1 007/s00603-020-02216-x

[136] King C-Y, Luo G (1990) Variations of electric resistance and $\mathrm{H} 2$ and $\mathrm{Rn}$ emissions of concrete blocks under increasing uniaxial compression. Pure Appl Geophys 134(1):45-56. https://doi.org/10.1007/BF00878079

[137] Wang X, Chung D (1999) Fiber breakage in polymer-matrix composite during static and fatigue loading, observed by electrical resistance measurement. J Mater Res 14(11):4224-4229. https://doi.org/10.1557/JMR.1999.0572

[138] Todoroki A, Yoshida J (2004) Electrical resistance change of unidirectional CFRP due to applied load. JSME Int J Ser A Solid Mech Mater Eng 47(3):357-364. https://doi.org/10. 1299/jsmea.47.357

[139] Chen B, Liu J (2008) Damage in carbon fiber-reinforced concrete, monitored by both electrical resistance measurement and acoustic emission analysis. Constr Build Mater 22(11):2196-2201. https://doi.org/10.1016/j.conbuildmat.2 007.08 .004

[140] Niccolini G, Borla O, Accornero F, Lacidogna G, Carpinteri A (2015) Scaling in damage by electrical resistance measurements: an application to the terracotta statues of the Sacred Mountain of Varallo Renaissance Complex (Italy). Rendiconti Lincei 26(2):203-209. https://doi.org/10.1007/ s12210-014-0353-6 
[141] Li Z, Wang E, He M (2015) Laboratory studies of electric current generated during fracture of coal and rock in rock burst coal mine. J Min. https://doi.org/10.1155/2015/ 235636

[142] Frid V, Shabarov A, Proskuryakov V, Baranov V (1992) Formation of electromagnetic radiation in coal stratum. J Min Sci 28(2):139-145. https://doi.org/10.1007/ BF00710732

[143] Wang E-Y, He X-q, Dou L-M, Zhou S-N, Nie B-S, Liu Z-T (2005) Electromagnetic radiation characteristics of coal and rocks during excavation in coal mine and their application. Diqiu Wuli Xuebao (Chin J Geophys) 48(1):216-221. h ttps://doi.org/10.1002/cjg2.645

[144] Zhentang WEHXL, Shangquan NBM (2000) The regularity electromagnetic radiation of coal or rock under load and its application [J]. China Saf Sci J 2:006. https://doi.org/10. 1016/j.proeng.2010.11.052

[145] Song D, Wang E, Song X, Jin P, Qiu L (2016) Changes in frequency of electromagnetic radiation from loaded coal rock. Rock Mech Rock Eng 49(1):291-302. https://doi.org/ 10.1007/s00603-015-0738-6

[146] Song X, Li X, Li Z et al (2018) Study on the characteristics of coal rock electromagnetic radiation (EMR) and the main influencing factors. J Appl Geophys 148:216-225. https://d oi.org/10.1016/j.jappgeo.2017.11.018

[147] Liu G-J, Lu C-P, Wang H-Y, Liu P-F, Liu Y (2015) Warning method of coal bursting failure danger by electromagnetic radiation. Shock Vib. https://doi.org/10.1155/2015/583862

[148] Yavorovich L, Bespal'ko A, Fedotov P, Popelyaev A (2015) Interconnection between parameters of rock samples electromagnetic signals and content of magnetite in the samples. IOP Conf Ser Mater Sci Eng IOP Publ 81(1):012055

[149] Song D, Wang E, He X et al (2017) Use electromagnetic radiation from fractures for mining-induced stress field assessment. J Geophys Eng. https://doi.org/10.1088/17422140/aaa26d

[150] Wang E, He X, Liu X, Li Z, Wang C, Xiao D (2011) A noncontact mine pressure evaluation method by electromagnetic radiation. J Appl Geophys 75(2):338-344. https://doi. org/10.1016/j.jappgeo.2011.06.028

[151] Qiu L, Li Z, Wang E et al (2018) Characteristics and precursor information of electromagnetic signals of mininginduced coal and gas outburst. J Loss Prev Process Ind 54:206-215. https://doi.org/10.1016/j.jlp.2018.04.004

[152] Kong B, Li Z, Wang E, Lu W, Chen L, Qi G (2018) An experimental study for characterization the process of coal oxidation and spontaneous combustion by electromagnetic radiation technique. Process Saf Environ Prot 119:285-294. https://doi.org/10.1016/j.psep.2018.08.002
[153] Kong B, Wang E, Lu W, Li Z (2019) Application of electromagnetic radiation detection in high-temperature anomalous areas experiencing coalfield fires. Energy 189:116144. https://doi.org/10.1016/j.energy.2019.116144

[154] Kong B, Wang E, Li Z, Niu Y (2017) Time-varying characteristics of electromagnetic radiation during the coalheating process. Int J Heat Mass Transf 108:434-442. h ttps://doi.org/10.1016/j.ijheatmasstransfer.2016.12.043

[155] Li J, Zhao Y, Han K, Wang Z, Wang C (2020) Electromagnetic signal characteristics and energy response pattern of briquette hammer fracturing. J Geophys Eng 17(3):506-516. https://doi.org/10.1093/jge/gxaa010

[156] Li J, Guan C, Han K, Wang Z (2020) Characteristics of transient charge on Datong coal sample surfaces with different cracking propagation. PLoS ONE 15(3):e0229824. h ttps://doi.org/10.1371/journal.pone.0229824

[157] Liu X, Zhang Z, Wang E, Wang X, Yang B, Wang H (2020) Characteristics of electromagnetic radiation signal of coal and rock under uniaxial compression and its field application. J Earth Syst Sci 129(1):1-11. https://doi.org/10.1007/ s12040-019-1309-0

[158] Yamada I, Masuda K, Mizutani H (1989) Electromagnetic and acoustic emission associated with rock fracture. Phys Earth Planet Inter 57(1-2):157-168. https://doi.org/10.101 6/0031-9201(89)90225-2

[159] Molchanov O, Hayakawa M (1995) Generation of ULF electromagnetic emissions by microfracturing. Geophys Res Lett 22(22):3091-3094. https://doi.org/10.1029/ 95GL00781

[160] Krumbholz M, Bock M, Burchardt S, Kelka U, Vollbrecht A (2012) A critical discussion of the electromagnetic radiation (EMR) method to determine stress orientations within the crust. Solid Earth 3(2):401-414. https://doi.org/ 10.5194/sed-4-993-2012

[161] Misra A (1975) Electromagnetic effects at metallic fracture. Nature 254(5496):133-134. https://doi.org/10.1038/25413 $3 \mathrm{a} 0$

[162] Srilakshmi B, Misra A (2005a) Secondary electromagnetic radiation during plastic deformation and crack propagation in uncoated and tin coated plain-carbon steel. J Mater Sci 40(23):6079-6086. https://doi.org/10.1007/s10853-005-12 93-4

[163] Chauhan V, Misra A (2008) Effects of strain rate and elevated temperature on electromagnetic radiation emission during plastic deformation and crack propagation in ASTM B 265 grade 2 titanium sheets. J Mater Sci 43(16):5634-5643. https://doi.org/10.1007/s10853-008-25 90-5

[164] Chauhan VS, Misra A (2010) Electromagnetic radiation during plastic deformation under unrestricted quasi-static 
compression in metals and alloys. Int $\mathrm{J}$ Mater Res 101(7):857-864. https://doi.org/10.3139/146.110355

[165] Chauhan VS, Misra A (2011) Assessment of grain size and lattice parameters of titanium alloy through electromagnetic emission technique. Int $\mathrm{J}$ Microstruct Mater Prop 6(6):486-506. https://doi.org/10.1504/IJMMP.2011.044367

[166] Mishra SK, Sharma V, Misra A (2014) Effect of rate of deformation on electromagnetic radiation during quasistatic compression of sintered aluminium preforms. Int $\mathrm{J}$ Mater Res 105(3):265-271. https://doi.org/10.3139/146. 111014

[167] Misra A (1978a) A physical model for the stress-induced electromagnetic effect in metals. Appl Phys 16(2):195-199. https://doi.org/10.1007/BF00930387

[168] Molotskii M (1980) Dislocation mechanism for the Misra effect. Sov Tech Phys Lett 6(1):22-23

[169] Misra A, Prasad RC, Chauhan VS, Srilakshmi B (2007) A theoretical model for the electromagnetic radiation emission during plastic deformation and crack propagation in metallic materials. Int J Fract 145(2):99-121. https://doi. org/10.1007/s10704-007-9107-0

[170] Misra A, Prasad R, Chauhan VS, Kumar R (2010) Effect of Peierls' stress on the electromagnetic radiation during yielding of metals. Mech Mater 42(5):505-521. https://doi. org/10.1016/j.mechmat.2010.01.005

[171] Misra A, Singh R, Lal S (2015) A physical model for the intermittent electromagnetic radiation during plastic deformation of metals. Appl Phys A 121(2):597-605. https://doi. org/10.1007/s00339-015-9437-0

[172] Misra A, Ghosh S (1980a) Electromagnetic radiation characteristics during fatigue crack propagation and failure. Appl Phys 23(4):387-390. https://doi.org/10.1007/ BF00903221

[173] Tudik A (1980) Electromagnetic emission during the fracture of metals. Sov Tech Phys Lett 6:37-38. https://doi.org/ 10.1023/B:FRAC.0000037676.32062.cb

[174] Dickinson J, Jensen L, Bhattacharya S (1985) Fractoemission from the failure of metal/epoxy interfaces. J Vac Sci Technol A Vac Surf Films 3(3):1398-1402. https://doi.org/ 10.1116/1.572788

[175] Jagasivamani V, Iyer K (1988) Electromagnetic emission during the fracture of heat-treated spring steel. Mater Lett 6(11-12):418-422. https://doi.org/10.1016/0167-577X(88) 90043-2

[176] Alekseev O, Lazarev S, Priemskii D (1984) Theory of electromagnetic effects accompanying dynamic deformation of metals. J Appl Mech Tech Phys 25(4):639-641. h ttps://doi.org/10.1007/BF00910006

[177] Srilakshmi B, Misra A (2005b) Effects of some fracture mechanics parameters on the emission of electromagnetic radiation from commercially pure aluminum. Manuf Technol Res Int J 1:97-104. https://doi.org/10.1007/s1070 4-007-9107-0

[178] Srilakshmi B, Misra A (2005c) Electromagnetic radiation during opening and shearing modes of fracture in commercially pure aluminium at elevated temperature. Mater Sci Eng A 404(1-2):99-107. https://doi.org/10.1016/j.mse a.2005.05.100

[179] Venkataraman B, Raj B, Mukhophadyay CK (2002) Characterisation of tensile deformation through infrared imaging technique. J Korean Soc for Nondestruct Test 22(6):609-620

[180] Kumar R, Misra A (2006) A new approach for smart sensors in design against metallic failure. In: International conference on resource utilization and intelligent system, Erode, India

[181] Kumar R, Misra A (2006) Effect of processing parameters on the electromagnetic radiation emission during plastic deformation and crack propagation in copper-zinc alloys. J Zhejiang Univ Sci A 7(11):1800-1809. https://doi.org/10. 1631/jzus.2006.A1800

[182] Kumar R, Misra A (2007) Some basic aspects of electromagnetic radiation emission during plastic deformation and crack propagation in $\mathrm{Cu}-\mathrm{Zn}$ alloys. Mater Sci Eng A 454:203-210. https://doi.org/10.1016/j.msea.2006.11.011

[183] Singh R, Lal S, Misra A (2014) Variation in electromagnetic radiation during plastic deformation under tension and compression of metals. Appl Phys A 117(3):1203-1215. h ttps://doi.org/10.1007/s00339-014-8509-x

[184] Singh R, Lal SP, Misra A (2019) Effect of notch-depth ratio on intermittent electromagnetic radiation from $\mathrm{Cu}-\mathrm{Ni}$ alloy under tension. Mater Test 61(9):885-893. https://doi.org/ $10.3139 / 120.111402$

[185] Oraon M, Sharma V (2017) Investigation of electromagnetic radiation emission during sheet metal incremental micro forming. Mater Res (AHEAD) 21(1):e20170623

[186] Williams CK, Hillmyer MA (2008) Polymers from renewable resources: a perspective for a special issue of polymer reviews. Polym Rev 48(1):1-10

[187] Dickinson J, Scudiero L, Yasuda K, Kim M-W, Langford S (1997) Dynamic tribological probes: particle emission and transient electrical measurements. Tribol Lett 3(1):53-67. h ttps://doi.org/10.1023/A:1019187812406

[188] Dickinson J, Jensen L, Langford S, Hirth J (1991) Atomic and molecular emission following fracture of alkali halides: a dislocation driven process. J Mater Res 6(1):112-125. h ttps://doi.org/10.1557/JMR.1991.0112

[189] Dickinson J, Jensen L, Dion R (1993) Fracto-emission from high density polyethylene: bond breaking versus 
tribological stimulation. J Appl Phys 73(6):3047-3054. h ttps://doi.org/10.1063/1.352987

[190] Zimmerman K, Langford S, Dickinson J, Dion R (1993) Electron and photon emission accompanying deformation and fracture of polycarbonate. J Polym Sci Part B Polym Phys 31(9):1229-1243. https://doi.org/10.1063/1.352987

[191] Zimmerman K, Langford S, Dickinson J (1991) Electrical transients during interfacial debonding and pullout of a metal rod from an epoxy matrix. J Appl Phys 70(9):4808-4815. https://doi.org/10.1002/polb.1993. 090310918

[192] Dickinson J, Jensen L, Bhattacharya S (1987) Fractoemission from neat epoxy resin. In: Makromolekulare chemie. macromolecular symposia Basel: Hüthig and Wepf Verlag 7(1):129-152. https://doi.org/10.1002/masy. 19870070113

[193] Dickinson J, Jensen L (1985) Fracto-emission from filled and unfilled polybutadiene. J Polym Sci Part B Polym Phys 23(5):873-888. https://doi.org/10.1002/pol.1985. 180230504

[194] Doering D, Dickinson J, Langford S, Xiong-Skiba P (1990) Fracto-emission during the interfacial failure of a metaloxide-semiconductor system: $\mathrm{Au}-\mathrm{SiO} 2-\mathrm{Si}$. J Vac Sci Technol A Vac Surf Films 8(3):2401-2406. https://doi.org/ 10.1116/1.576705

[195] Dickinson JT (1990) Fracto-emission. non-destructive testing of fibre-reinforced plastics composites 2. Elsevier Applied Science, NY, pp 429-482

[196] Langford S, Zhenyi M, Dickinson J (1989) Photon emission as a probe of chaotic processes accompanying fracture. J Mater Res 4(5):1272-1279. https://doi.org/10.1557/JMR. 1989.1272

[197] Dickinson J, Jensen L, Jahan-Latibari A (1984a) Fractoemission: the role of charge separation. J Vac Sci Technol A Vac Surf Films 2(2):1112-1116. https://doi.org/10.1116/1. 572682

[198] Crasto A, Corey R, Dickinson J, Subramanian R, Eckstein Y (1987) Correlation of photon and acoustic emission with failure events in model composites. Compos Sci Technol 30(1):35-58. https://doi.org/10.1016/0266-3538(87)900868

[199] Gade S, Alaca B, Sause M (2017) Determination of crack surface orientation in carbon fibre reinforced polymers by measuring electromagnetic emission. J Nondestr Eval 36(2):21. https://doi.org/10.1007/s10921-017-0403-y

[200] Dickinson J, Jensen L, Miles M, Yee R (1987) Fractoemission accompanying adhesive failure between rocket propellent constituents. J Appl Phys 62(7):2965-2971. h ttps://doi.org/10.1063/1.339382
[201] Gade S, Weiss U, Peter M, Sause M (2014) Relation of electromagnetic emission and crack dynamics in epoxy resin materials. J Nondestr Eval 33(4):711-723. https://doi. org/10.1007/s10921-014-0265-5

[202] Ballarini R, Shah S, Keer L (1984) Crack growth in cement-based composites. Eng Fract Mech 20(3):433-445. https://doi.org/10.1016/0013-7944(84)90049-3

[203] Banthia N, Sheng J (1996) Fracture toughness of microfiber reinforced cement composites. Cement Concr Compos 18(4):251-269. https://doi.org/10.1016/0958-9465(95)000 30-5

[204] Banthia N, Nandakumar N (2003) Crack growth resistance of hybrid fiber reinforced cement composites. Cement Concr Compos 25(1):3-9. https://doi.org/10.1016/S0958-9 465(01)00043-9

[205] Beaudoin JJ (1985) Effect of humidity on subcritical crack growth in cement paste. Cem Concr Res 15(5):871-878. h ttps://doi.org/10.1016/0008-8846(85)90154-1

[206] Rianyoi R, Potong R, Jaitanong N, Yimnirun R, Chaipanich A (2011) Dielectric, ferroelectric and piezoelectric properties of 0-3 barium titanate-Portland cement composites. Appl Phys A 104(2):661-666. https://doi.org/10.1007/s00 339-011-6307-2

[207] Toutanji HA, El-Korchi T, Katz RN (1994) Strength and reliability of carbon-fiber-reinforced cement composites. Cement Concr Compos 16(1):15-21. https://doi.org/10.10 16/0958-9465(94)90026-4

[208] Hillerborg A, Modéer M, Petersson P-E (1976) Analysis of crack formation and crack growth in concrete by means of fracture mechanics and finite elements. Cem Concr Res 6(6):773-781. https://doi.org/10.1016/0008-8846(76)9000 7-7

[209] Karihaloo B, Carpinteri A, Elices M (1993) Fracture mechanics of cement mortar and plain concrete. Adv Cem Based Mater 1(2):92-105. https://doi.org/10.1016/1065-73 55(93)90014-F

[210] Sun M, Li Z, Liu Q (2002) The electromechanical effect of carbon fiber reinforced cement. Carbon 40(12):2273-2275. https://doi.org/10.1016/S0008-6223(02)00189-6

[211] Wen S, Chung D (2002) Piezoelectric cement-based materials with large coupling and voltage coefficients. Cem Concr Res 32(3):335-339. https://doi.org/10.1016/S00088846(01)00682-2

[212] Wen S, Chung D (2001) Effect of stress on the electric polarization in cement. Cem Concr Res 31(2):291-295. h ttps://doi.org/10.1016/S0008-8846(00)00412-9

[213] Gu P, Beaudoin J (1996) Dielectric behaviour of hardened cement paste systems. J Mater Sci Lett 15(2):182-184. h ttps://doi.org/10.1007/BF00291462 
[214] Shi Z-Q, Chung D (1999) Carbon fiber-reinforced concrete for traffic monitoring and weighing in motion. Cem Concr Res 29(3):435-439. https://doi.org/10.1016/S0008-8846(9 8)00204-X

[215] Alonso C, Andrade C, Keddam M, Novoa X, Takenouti H (1998) Study of the dielectric characteristics of cement paste. Mater Sci Forum Trans Tech Publ Ltd 289:15-28

[216] Brownjohn JM (2007) Structural health monitoring of civil infrastructure. Philos Trans R Soc Lond A Math Phys Eng Sci 365(1851):589-622. https://doi.org/10.1098/rsta.2006. 1925

[217] Rens KL, Wipf TJ, Klaiber FW (1997) Review of nondestructive evaluation techniques of civil infrastructure. J Perform Construc Facil 11(4):152-160. https://doi.org/10. 1061/(ASCE)0887-3828(1999)13:1(47)

[218] Maguire D, Olen M (1940) Report on an investigation into the electrical properties of concrete. Trans S Afr Inst Electr Eng 31:301

[219] Hammond E, Robson T (1955) Comparison of electrical properties of various cements and concretes. Engineer 199(5165):78-80

[220] Tamás FD (1982) Electrical conductivity of cement pastes. Cem Concr Res 12(1):115-120. https://doi.org/10.1016/00 08-8846(82)90106-5

[221] Morsy MS (1999) Effect of temperature on electrical conductivity of blended cement pastes. Cem Concr Res 29(4):603-606. https://doi.org/10.1016/S0008-8846(98)00 198-7

[222] Whittington H, McCarter J, Forde M (1981) The conduction of electricity through concrete. Mag Concr Res 33(114):48-60. https://doi.org/10.1680/macr.1981.33.114. 48

[223] Wittmann F (1973) Observation of an electromechanical effect of hardened cement paste. Cem Concr Res 3(5):601-605. https://doi.org/10.1016/0008-8846(73)9009 $7-5$

[224] Dann D, Demikhova A, Fursa T, Kuimova M (2014) Research of electrical response communication parameters on the pulse mechanical impact with the stress-strain state of concrete under uniaxial compression. In: IOP conference series: materials science and engineering. IOP publishing, 2014. $012036 \mathrm{https} / / /$ doi.org/10.1088/1757-899X/66/1/ 012036

[225] Triantis D, Stavrakas I, Kyriazopoulos A, Hloupis G, Agioutantis Z (2012) Pressure stimulated electrical emissions from cement mortar used as failure predictors. Int $\mathrm{J}$ Fract 175(1):53-61. https://doi.org/10.1007/s10704-012-9 701-7

[226] Triantis D, Pasiou E, Stavrakas I, Dakanali I, Kourkoulis S (2017) Correlation of pressure stimulated currents and acoustic emissions during 3PB of cement-mortar beams and the role of loading rate. Proc Struct Integr 3:346-353. h ttps://doi.org/10.1016/j.prostr.2017.04.027

[227] Qingping L, Mingqing S, Zhuoqiu L, Guoqiang L (2005) Electrical emissions from concrete under three-point bending tests. J Wuhan Univ Technol Mater Sci Ed 20(2):102-104. https://doi.org/10.1007/BF02838502

[228] Li JF, Ai H, Viehland D (1995) Anomalous electromechanical behavior of Portland cement: electro-osmoticallyinduced shape changes. J Am Ceram Soc 78(2):416-420. h ttps://doi.org/10.1111/j.1151-2916.1995.tb08817.x

[229] Kyriazopoulos A, Stavrakas I, Ninos K, Anastasiadis C (2010) D Triantis (2010) Pressure stimulated current emissions on cement paste samples under repetitive stepwise compressional loadings. Strojniški vestnik J Mech Eng 56(9):551-556

[230] Kyriazopoulos A, Anastasiadis C, Triantis D, Brown C (2011) Non-destructive evaluation of cement-based materials from pressure-stimulated electrical emission-Preliminary results. Constr Build Mater 25(4):1980-1990. https://d oi.org/10.1016/j.conbuildmat.2010.11.053

[231] Sklarczyk C, Altpeter I (2001) The electric emission from mortar and concrete subjected to mechanical impact. Scripta Mater 44(11):2537-2541. https://doi.org/10.1016/S 1359-6462(01)00952-6

[232] Fursa TV, Khorsov NN, Romanov D (2001) Relation between quality of bonds among components of composite materials and parameters of electromagnetic response to shock. Russ J Nondestr Test 37(9):618-620. https://doi.org/ 10.1023/A:1014983221950

[233] Sun M, Li Z, Song X (2004) Piezoelectric effect of hardened cement paste. Cement Concr Compos 26(6):717-720. https://doi.org/10.1016/S0958-9465(03)00104-5

[234] Stergiopoulos C, Stavrakas I, Hloupis G, Triantis D, Vallianatos F (2013) Electrical and acoustic emissions in cement mortar beams subjected to mechanical loading up to fracture. Eng Fail Anal 35:454-461. https://doi.org/10.101 6/j.engfailanal.2013.04.015

[235] Malyshkov YP, Fursa T, Gordeyev V, Kartopoltsev V, Chernykh G (1996) Sources and mechanisms of electromagnetic emission in concretes. Izvestiia-Vysshie Uchebnye Zavedeniia Stroitel'stvo, pp 31-36

[236] Cao S, Song W (2018) Medium-term strength and electromagnetic radiation characteristics of cemented tailings backfill under uniaxial compression. Geotech Geol Eng 36(6):3979-3986. https://doi.org/10.1007/s10706-018-054 2-7

[237] Kumar A, Sharma SK, Chauhan VS, Kumar R (2019) Electromagnetic radiation response from cement paste: a tool to monitor hydration and extent of deformation. 
J Sustain Cem Based Mater 8(1):20-38. https://doi.org/10. 1080/21650373.2018.1506369

[238] Kumar A, Chauhan VS, Kumar R, Prasad K (2018a) Detection of deformation induced electromagnetic radiation from cement-barium titanate composite under impact loading. Ceram Int 44(10):11711-11717. https://doi.org/10. 1016/j.ceramint.2018.03.248

[239] Kumar A, Chauhan VS, Kumar R, Prasad K (2018b) Electromagnetic radiation detection in $0-3$ cement-PZT composite under impact loading. Integr Ferroelectr 192(1):67-79. https://doi.org/10.1080/10584587.2018. 1521671

[240] Dexing L, Enyuan W, Xiangguo K et al (2018) Mechanical properties and electromagnetic radiation characteristics of concrete specimens after exposed to elevated temperatures. Constr Build Mater 188:381-390. https://doi.org/10.1016/ j.conbuildmat.2018.07.236

[241] Griffiths DJ (1962) Introduction to electrodynamics. Prentice Hall, USA

[242] Joffe A (1930) Is the electrical conductivity influenced by the irregularities of the crystal structure? Z Phys 62(11-12):730-745. https://doi.org/10.1007/BF01330435

[243] Remaut G (1960) Further observations concerning electrical effects during cyclic stressing of alkali halide single crystals. J Phys Chem Solids 16:158. https://doi.org/10.10 16/0022-3697(60)90087-1

[244] Boros J, Gyulai Z (1935) Electrical measurement of the recovery of solidified rock salt crystals. Z Phys A Hadrons Nuclei 96(5):355-358. https://doi.org/10.1007/ BF01343867

[245] Eshelby J, Pratt P (1956) Note on the heating effect of moving dislocations. Acta Metall 4(5):560-562. https://doi. org/10.1016/0001-6160(56)90056-6

[246] Cottrell AH (1953) Dislocations and plastic flow in crystals. https://doi.org/10.1126/science.119.3095.551

[247] Tyler W (1952) Plastic flow in alkali halide crystals. Phys Rev 86(5):801. https://doi.org/10.1103/PhysRev.86.801

[248] Camagni P (1960) Generation of vacancies during plastic deformation of $\mathrm{KCl}$ crystals. J Phys Chem Solids 17:165-168. https://doi.org/10.1103/PhysRev.122.1125

[249] Gyulai Z, Boros J (1940) Math, naturw. Anz. ungar. Akad. Wiss. 5_9 115. https://doi.org/10.12691/tjant-2-3-6

[250] Kassel M (1934) On the structural sensitivity of the lowtemperature ion conductivity of rock salt crystals. Z Phys 90(5-6):287-311. https://doi.org/10.1007/BF01334048

[251] Seitz F (1950) Influence of plastic flow on the electrical and photographic properties of the alkali halide crystals. Phys Rev 80(2):239. https://doi.org/10.1103/PhysRev.80.239

[252] Petrenko V (1993) On the nature of electrical polarization of materials caused by cracks. application to ice electromagnetic emission. Philos Mag B 67(3):301-315. h ttps://doi.org/10.1080/13642819308220134

[253] Evtushenko A, Maeno N, Petrenko V, Ryzhkin I (1987) Pseudopiezoelectric effects in ice. J Phys Colloq 48(C1):01-113. https://doi.org/10.1051/jphyscol:1987116

[254] Haertling GH (1999) Ferroelectric ceramics: history and technology. J Am Ceram Soc 82(4):797-818. https://doi. org/10.1111/j.1151-2916.1999.tb01840.x

[255] Chabay RW, Sherwood BA (2015) Matter and interactions. John Wiley \& Sons, USA

[256] Sharma SK, Chauhan VS, Jain SC (2019) Experimental and theoretical investigations of electromagnetic radiation emission from soft and hard PZT ceramics. J Electron Mater 48(11):7441-7451. https://doi.org/10.1007/s11664-0 19-07551-6

[257] Finkel V, Golovin YI, Sereda V, Kulikova G, Zuev L (1975) Electric effects during fracture of lif crystal in connection with problem of crack control. Fiz Tverd Tela 17(3):770-776

[258] Miroshnichenko M, Kuksenko V (1980) Study of electromagnetic pulses in initiation of cracks in solid dielectrics. Sov Phys Solid State 22(5):895-896

[259] Frid V, Rabinovitch A, Bahat D (2003) Fracture induced electromagnetic radiation. J Phys D Appl Phys 36(13):1620. https://doi.org/10.1088/0022-3727/36/13/330

[260] Rabinovitch A (1999) A note on the amplitude-frequency relation of electromagnetic radiation pulses induced by material failure. Philos Mag Lett 79(4):195-200. https://d oi.org/10.1080/095008399177435

[261] Rabinovitch A, Frid V, Bahat D, Goldbaum J (2000) Fracture area calculation from electromagnetic radiation and its use in chalk failure analysis. Int J Rock Mech Min Sci 37(7):1149-1154. https://doi.org/10.1016/S1365-1609( 00)00042-3

[262] O'Keefe SG, Thiel DV (1995) A mechanism for the production of electromagnetic radiation during fracture of brittle materials. Phys Earth Planet Inter 89(1-2):127-135. https://doi.org/10.1016/0031-9201(94)02994-M

[263] Rabinovitch A, Bahat D, Frid V (1995) Comparison of electromagnetic radiation and acoustic emission in granite fracturing. Int J Fract 71(2):R33-R41. https://doi.org/10. 1007/BF00033758

[264] Rabinovitch A, Frid V, Bahat D (2007) Surface oscillations - a possible source of fracture induced electromagnetic radiation. Tectonophysics 431(1-4):15-21. https://doi. org/10.1016/j.tecto.2006.05.027

[265] Rabinovitch A, Frid V, Bahat D (2017) Directionality of electromagnetic radiation from fractures. Int $\mathrm{J}$ Fract 204(2):239-244. https://doi.org/10.1007/s10704-016-0178-7

[266] Vallianatos F, Tzanis A (1998) Electric current generation associated with the deformation rate of a solid: preseismic 
and coseismic signals. Phys Chem Earth 23(9-10):933-938. https://doi.org/10.1016/S0079-1946(98 00122-0

[267] Tzanis A, Vallianatos F (2002) A physical model of electrical earthquake precursors due to crack propagation and the motion of charged edge dislocations. In: Hayakawa M, Molchanov OA (eds) Seismo electromagnetics: lithosphereatmosphere-ionosphere coupling. Terrapub, Tokyo, pp 117-130

[268] Charkina O, Chishko K (2001) Electromagnetic emission of mobile dislocation segments in an ionic crystal. Phys Solid State 43(10):1898-1904. https://doi.org/10.1134/1. 1410628

[269] Teisseyre R, Ernst T (2002) Electromagnetic radiation related to dislocation dynamics in a seismic preparation zone. Ann Geophys 45(2):393-399

[270] Misra A (1978b) A physical model for the stress-induced electromagnetic effect in metals. Appl Phys A Mater Sci Process 16(2):195-199. https://doi.org/10.1007/ BF00930387

[271] Perelman M, Khatiashvili N (1980) Electromagnetic radiation under joint formation and solid state brittle fracture. Bull Acad Sci Ga SSR 99(2):357-358

[27] Misra A, Ghosh S (1980b) Electron-plasma model for the electromagnetic effect at metallic fracture. Indian $\mathrm{J}$ Pure Appl Phys 18(11):851-856

[273] Kothari A, Chauhan VS, Kumar A, Kumar R, Vaish R, Abbas S (2016) Effect of Peierls stress and strain-hardening parameters on EMR emission in metals and alloys during progressive plastic deformation. Int $\mathrm{J}$ Mater Res 107(6):503-517. https://doi.org/10.3139/146.111376

[274] Kothari A, Chauhan VS, Misra A, Abbas S, Kumar R (2016) Effect of strain hardening on the electromagnetic radiation during plastic deformation of metals and alloys beyond yield point. Nonlinear Dyn 85(4):2687-2704. http s://doi.org/10.1007/s11071-016-2855-5

[275] Burak YI, Kondrat V, Chekurin V (1985) On possible mechanisms of electromagnetic emission in the process of formation of discontinuities in conducting bodies. Abstract of the All-Union Science-Engineering. In: Conference on engineering diagnostics. [in Russian], Dnepropetrovsk, p 85 https://doi.org/10.1007/s11003-007-0054-8

[276] Vorobev AA (1977) Electromagnetic-radiation in process of crack formation in dielectrics. Sov J Nondestruc Test USSR 13(3):352-353

[277] Dickinson JT, Jensen LC (1987) Fracto-emission from polymers, crystals, and interfaces. Fluoresc Detect Int Soc Opt Photon 743:68-75
[278] Dickinson JT (1984) Fracto-emission accompanying adhesive failure. Adhesive chemistry. Springer, Boston, pp 193-243

[279] Dickinson J, Jensen L, Jahan-Latibari A (1984b) The effect of cross-linking on fracto-emission from elastomers. J Mater Sci 19(5):1510-1516. https://doi.org/10.1007/ BF00563046

[280] Momose Y, Noguchi M (1984) Electron emission during frictional contact between metals and polymers. Phys Status Solidi (a) 82(1):K83-K86. https://doi.org/10.1002/pssa. 2210820159

[281] Nakahara S, Fujita T, Sugihara K, Owaki S, Katagiri K (1988) Fracto-emission from composite materials at cryogenic temperatures. Adv Cryog Eng (Mater) 34

[282] Koktavy P (2008) Experimental study of electromagnetic emission signals generated by crack generation in composite materials. Meas Sci Technol 20(1):015704. https://d oi.org/10.1088/0957-0233/20/1/015704

[283] Sun M, Liu Q, Li Z, Wang E (2002) Electrical emission in mortar under low compressive loading. Cem Concr Res 32(1):47-50. https://doi.org/10.1016/S0008-8846(01)0062 $7-5$

[284] Wittmann F, Hollenz C (1974) On the significance of electroosmosis in hardened cement paste. Cem Concr Res 4(3):389-397. https://doi.org/10.1016/0008-8846(74)9010 4-5

[285] Sun M, Liu Q, Li Z, Hu Y (2000) A study of piezoelectric properties of carbon fiber reinforced concrete and plain cement paste during dynamic loading. Cem Concr Res 30(10):1593-1595. https://doi.org/10.1016/S0008-8846(00 )00338-0

[286] Powers TC (1958) Structure and physical properties of hardened Portland cement paste. J Am Ceram Soc 41(1):1-6. https://doi.org/10.1111/j.1151-2916.1958.tb134 94.x

[287] Sharma SK, Kiran R, Kumar A, Chauhan VS, Kumar R (2018) A theoretical model for the electromagnetic radiation emission from hydrated cylindrical cement paste under impact loading. J Phys Commun 2(3):035047. https://doi. org/10.1088/2399-6528/aaf6bc

[288] Sharma SK, Kumar A, Chauhan VS, Kiran R, Kumar R (2020) Electromagnetic radiation detection from cubical mortar sample and its theoretical model. Mater Sci Eng B 260:114638. https://doi.org/10.1016/j.mseb.2020.114638

[289] Sharma SK, Chauhan VS, Yadav C (2018) A theoretical model for the electromagnetic radiation emission from ferroelectric ceramics. Mater Today Commun. https://doi. org/10.1016/j.mtcomm.2018.01.002

[290] Kumar A, Sharma SK, Chauhan VS, Kumar R (2018) Electromagnetic radiation response from cement paste: a 
tool to monitor hydration and extent of deformation. J Sustain Cem Based Mater 8:20-38. https://doi.org/10.10 80/21650373.2018.1506369

[291] Dickinson J, Jensen L, McKay M, Freund F (1986) The emission of atoms and molecules accompanying fracture of single-crystal MgO. J Vac Sci Technol A Vac Surf Films 4(3):1648-1652. https://doi.org/10.1116/1.573985

[292] Shibkov A, Zheltov M, Skvortsov V, Koltsov RY, Shuklinov A (2005) Electromagnetic emission under uniaxial compression of ice: I Identification of nonstationary processes of structural relaxation by electromagnetic signals. Crystallogr Rep 50(6):994-1004

[293] Mizuno Y, Mizuno T (2002) Photon emission from ice during fracture. Jpn J Appl Phys 41(2B):L209. https://doi. org/10.1143/JJAP.41.L209

[294] Dickinson J, Langford S, Jensen L, McVay G, Kelso J, Pantano CG (1988) Fractoemission from fused silica and sodium silicate glasses. J Vac Sci Technol A Vac Surf Films 6(3):1084-1089. https://doi.org/10.1116/1.575646

[295] Lacidogna G, Manuello A, Carpinteri A, Niccolini G, Agosto A, Durin G (2011) Acoustic and electromagnetic emissions in rocks under compression experimental mechanics on emerging energy systems and materials, vol 5. Springer, New York, pp 57-64

[296] Bespalko A, Yavorovich L, Eremenko A, Shtirts V (2018) Electromagnetic emission of rocks after large-scale blasts.
J Min Sci 54(2):187-193. https://doi.org/10.1134/ S1062739118023533

[297] Carpinteri A, Cardone F, Lacidogna G (2009) Piezonuclear neutrons from brittle fracture: early results of mechanical compression tests 1. Strain 45(4):332-339. https://doi.org/ 10.1111/j.1475-1305.2008.00615.x

[298] Enomoto Y, Hashimoto H (1989) Fractoemission during indentation fracture of brittle solids. J Mater Sci Lett 8(9):1107-1109. https://doi.org/10.1007/BF01730503

[299] Lacidogna G, Carpinteri A, Manuello A et al (2011b) Acoustic and electromagnetic emissions as precursor phenomena in failure processes. Strain 47:144-152. https://doi. org/10.1111/j.1475-1305.2010.00750.x

[300] Misra A, Kumar A (2004) Some basic aspects of electromagnetic radiation during crack propagation in metals. Int $\mathrm{J}$ Fract 127(4):387-401. https://doi.org/10.1023/B:FRAC.00 00037676.32062.cb

[301] Kyriazopoulos A, Stavrakas I, Anastasiadis C, Triantis D (2011) Study of weak electric current emissions on cement mortar under uniaxial compressional mechanical stress up to the vicinity of fracture. Strojniski Vestnik/J Mech Eng 57(3):237-244. https://doi.org/10.5545/sv-jme.2010.174

Publisher's Note Springer Nature remains neutral with regard to jurisdictional claims in published maps and institutional affiliations. 